\title{
WestVirginiaUniversity
}

THE RESEARCH REPOSITORY @ WVU

Graduate Theses, Dissertations, and Problem Reports

1999

\section{Decision support tool for costing of the pultrusion process}

Taher Badrudin Patrawala

West Virginia University

Follow this and additional works at: https://researchrepository.wvu.edu/etd

\section{Recommended Citation}

Patrawala, Taher Badrudin, "Decision support tool for costing of the pultrusion process" (1999). Graduate Theses, Dissertations, and Problem Reports. 1044.

https://researchrepository.wvu.edu/etd/1044

This Thesis is protected by copyright and/or related rights. It has been brought to you by the The Research Repository @ WVU with permission from the rights-holder(s). You are free to use this Thesis in any way that is permitted by the copyright and related rights legislation that applies to your use. For other uses you must obtain permission from the rights-holder(s) directly, unless additional rights are indicated by a Creative Commons license in the record and/ or on the work itself. This Thesis has been accepted for inclusion in WVU Graduate Theses, Dissertations, and Problem Reports collection by an authorized administrator of The Research Repository @ WVU. For more information, please contact researchrepository@mail.wvu.edu. 


\title{
DECISION SUPPORT TOOL FOR COSTING OF THE PULTRUSION PROCESS
}

\author{
Taher B. Patrawala
}

\author{
Thesis Submitted to the \\ College of Engineering and Mineral Resources \\ at West Virginia University \\ in partial fulfillment of the requirements for \\ the degree of
}

Master of Science

in

Industrial \& Management Systems Engineering

\author{
Robert C. Creese, Ph.D., PE, CCE, Chair \\ Majid Jaraiedi, Ph.D. \\ Rakesh Gupta, Ph.D.
}

Morgantown, West Virginia

1999

Keywords: Pultrusion Costing, Composite Costing, Cost Model for Pultrusion Process 


\section{ABSTRACT \\ DECISION SUPPORT TOOL FOR COSTING OF THE PULTRUSION PROCESS}

Taher B. Patrawala

The use of advanced composites has grown over the last two decades. These high strength, low weight materials can now be found in many structural applications, including bridges. However, the substitution of plastics for conventional materials, such as steel, is governed by engineering constraints and cost competitiveness. A brief discussion of the process variables and engineering constraints is presented in the first chapter. To analyze the latter and to identify cost centers in production more readily, a computerized cost model was developed. This model estimates the cost of producing components by the pultrusion process.

The technical cost modeling methodology employed involves dividing the total cost of the process into the individual cost elements that contribute to the total cost. Based upon theoretical considerations, engineering judgements, and statistically derived relationships, equations are developed to estimate the individual cost elements. Cost elements were divided into two categories: variable and fixed costs. The variable cost elements were raw materials, direct labor and utilities. The fixed cost elements were main machine, auxiliary equipment, tooling, tool setting operator, building, installation, maintenance, overhead and the capital recovery cost of invested capital.

The technical cost model developed can be used to estimate the cost of fabricating different components by pultrusion process. It can also be used for performing sensitivity and comparative cost analysis. An example of sensitivity analyses is presented for a sample bridge deck product which is a new application in the structural area and results in lighter decks (about 75\% lighter) and longer service because of lower corrosion rates. 


\section{Dedication}

This thesis is dedicated to my Mother, Father and Sisters 


\section{ACKNOWLEDGEMENT}

I wish to express my profound gratitude to all faculty members, friends and everybody who helped to make this thesis a reality. Much of whatever merit my work may have is due to this. However, they are in no way responsible for its deficiencies. Especially, I would like to thank the following persons:

To Dr. Robert C. Creese for providing an opportunity to work under his guidance. I am indebted to him for his valuable suggestion and support throughout the course of this study. Also special thanks goes to Dr. Majid Jaraiedi, Dr. Rakesh Gupta and Dr. Gangarao Hota for their valuable comments and for helping me in my problems.

I would like to express my sincere appreciation to my mother, father and sisters for their help and for inspiring me to pursue higher education. It was only their moral support that helped me to stand through the difficult times of this project. Also, I appreciated the cooperation extended by "Riechhold Chemicals" and "Creative Pultrusions" members, especially Mr. Nelson Douglas and Mr. Dustin Troutman, during the course of this research.

The U.S. Federal Highway Administration and West Virginia Department of Transportation provided financial support for this research and their assistance was appreciated. 


\section{DECISION SUPPORT TOOL FOR COSTING OF PULTRUSION PROCESS \\ TABLE OF CONTENTS}

Page

Acknowledgements iv

List of Tables $\quad$ xii

List of Figures $\quad$ xiv

Glossary of Terms $\quad$ xvii

$\begin{array}{lll}\text { CHAPTER } 1 . \quad \text { INTRODUCTION } & 1\end{array}$

1.1 Polymeric Composite Materials 3

1.2 Fiber Materials 3

$\begin{array}{lll}1.3 & \text { Matrix Materials } & 4\end{array}$

1.4 Manufacturing Processes for Polymer Composites 6

1.4.1 Hand Lay-Up $\quad 7$

1.4.2 Filament Winding 8

1.4.3 Resin Transfer Molding (RTM) 8

1.4.4 Reaction Injection Molding (RIM) 9

$\begin{array}{ll}\text { 1.4.5 Pultrusion } & 9\end{array}$

1.5 Pultrusion Process Variables 11 


\section{TABLE OF CONTENTS}

(continued)

Page

CHAPTER 2. BACKGROUND

2.1 Need for Costing of Composites

20

2.2 Need for Costing of Pultrusion Process 20

2.3 Cost Analysis Methods 22

2.3.1 Material Times Two 22

2.3.2 Material Cost Plus Shop Time 23

2.3.3 Material Cost Plus Loaded Shop Time 24

$\begin{array}{ll}\text { 2.3.4 Quotes } & 24\end{array}$

2.3.5 Technical Cost Modeling 26

$\begin{array}{lll}\text { CHAPTER } 3 . & \text { COST MODEL } & 28\end{array}$

3.1 Cost Model Description 28

3.2 Inputs to the Model 29

$\begin{array}{lll}\text { 3.2.1 Material Inputs } & 31\end{array}$

3.2.2 Geometry Inputs 31

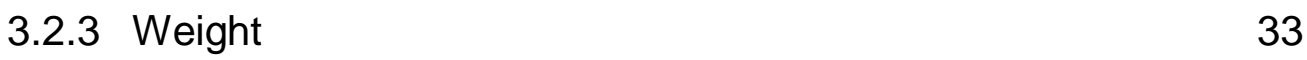

3.2.4 Cross - Sectional Area 33 


\section{TABLE OF CONTENTS}

(continued)

\section{Page}

3.2.5 Annual Production

3.2.6 Number of Runs 34

3.2.7 Line Speed 34

3.2.8 Set - Up \& Tear-Down Time 34

3.2.9 Number of Cavities per Die 34

3.2.10 Tool Provided by Client 35

3.2.11 Start - Up \& Tear-Down Scrap 35

3.2.12 End - Squaring Losses $\quad 35$

3.2.13 Number of Product Manufacturing Lines 36

$\begin{array}{lll}3.3 & \text { Model Data } & 36\end{array}$

$\begin{array}{lll}\text { 3.3.1 Exogeneous Variables } & 37\end{array}$

$\begin{array}{ll}\text { 3.3.2 Process Variables } & 40\end{array}$

3.3.3 Adjustment Factors 43

3.3.3.1 Material Adjustment Factors 43

3.3.3.2 Geometry Adjustment Factors $\quad 45$

3.4 Cost Calculations $(\$ / \mathrm{ft}) \quad 46$

3.4.1 Variable Costs 46

$\begin{array}{lll}\text { 3.4.1.1 Raw Material Cost } & 47\end{array}$

3.4.1.2 Direct Labor Cost 48 


\section{TABLE OF CONTENTS}

(continued)

\section{Page}

3.4.1.3 Indirect Labor Cost

$\begin{array}{lll}\text { 3.4.1.4 Utility Cost } & 50\end{array}$

3.4.2 Fixed Costs 51

3.4.2.1 Main Machine Cost 52

3.4.2.2 Auxiliary Equipment Cost 55

$\begin{array}{lll}\text { 3.4.2.3 Die Cost } & 57\end{array}$

3.4.2.4 Tool Setting Operator Cost 59

3.4.2.5 Building Cost $\quad 60$

3.4.2.6 Installation Cost 62

3.4.2.7 Maintenance Cost 63

3.4.2.8 Overhead Cost 63

3.4.2.9 Capital Recovery Cost 64

3.5 Cost Calculations (\$/hour) 65

3.5.1 Variable Costs 66

3.5.1.1 Raw Material Cost 66

3.5.1.2 Direct Labor Cost $\quad 66$

3.5.1.3 Indirect Labor Cost $\quad 66$

3.5.1.4 Utility Cost 66 


\section{TABLE OF CONTENTS}

(continued)

\section{Page}

3.5.2 Fixed Costs 66

3.5.2.1 Main Machine Cost 66

$\begin{array}{lll}\text { 3.5.2.2 Auxiliary Equipment Cost } & 67\end{array}$

$\begin{array}{lll}\text { 3.5.2.3 Die Cost } & 67\end{array}$

3.5.2.4 Tool Setting Operator Cost 67

3.5.2.5 Building Cost 68

3.5.2.6 Installation Cost 68

3.5.2.7 Maintenance Cost 68

3.5.2.8 Overhead Cost 68

3.5.2.9 Capital Recovery Cost 68

$\begin{array}{lll}\text { CHAPTER } 4 . \quad \text { COSTING OF BRIDGE DECK } & 69\end{array}$

$\begin{array}{lll}\text { 4.1 Why Bridge Deck ? } & 69\end{array}$

4.2 Bridge Deck Cost Elements 72

$\begin{array}{lll}\text { 4.3 Model Validation } & 75\end{array}$ 


\section{TABLE OF CONTENTS}

(continued)

\section{Page}

5.1 Introduction to Sensitivity Analysis

5.2 Sensitivity Analysis on Bridge Deck (\$/ft) 79

5.2.1 Raw Material Cost 79

$\begin{array}{lll}\text { 5.2.2 Mat Cost } & 79\end{array}$

5.2.3 Roving Cost 83

5.2.4 Resin Cost 83

5.2.5 Filler Cost 83

$\begin{array}{ll}\text { 5.2.6 Initiator Cost } & 87\end{array}$

$\begin{array}{lll}\text { 5.2.7 Veils Cost } & 87\end{array}$

5.2.8 Direct Labor Cost 92

$\begin{array}{ll}\text { 5.2.9 Utility Cost } & 92\end{array}$

5.2.10 Tool Set - Up \& Tear-Down Time 96

5.2.11 Overhead Cost 96

$\begin{array}{ll}\text { 5.2.12 Line Speed } & 100\end{array}$

5.2.13 Start-Up \& Tear-Down Losses 100

5.2.14 End-Squaring Losses 104

$\begin{array}{ll}\text { 5.2.15 Annual Production } & 104\end{array}$ 


\section{TABLE OF CONTENTS}

(continued)

Page

$\begin{array}{lll}5.3 & \text { Sensitivity Analysis on BridgeDeck (\$/hour) } & 108\end{array}$

5.4 Summary of Sensitivity Analysis 111

$\begin{array}{lll}\text { CHAPTER } 6 . & \text { CONCLUSIONS }\end{array}$

$\begin{array}{lll}6.1 & \text { Conclusions } & 112\end{array}$

6.2 Major Assumptions in the Model 113

6.3 Scope for Future Work 115

$\begin{array}{ll}\text { REFERENCES } & 116\end{array}$

USER SCREENS OF COST MODEL $\quad 124$

$\begin{array}{ll}\text { VITA } & 143\end{array}$ 


\section{LIST OF TABLES}

$\underline{\text { Table }}$

Page

1.1 Property Comparison of Resins 6

3.1 Part Material Options 32

3.2 Part Geometry Options 32

3.3 Exogeneous Factors 38

3.4 Process Factors 41

3.5 Material Adjustment Factors 44

3.6 Geometry Adjustment Factors 45

4.1 BRIDGEDECK Input Parameters 73

$\begin{array}{lll}\text { 4.2 BRIDGEDECK Material Input } & 73\end{array}$

4.3 Summary of Cost Output $\quad 74$

5.1 Change in Total Cost with \% Change in Raw Material Cost 80

5.2 Change in Total Cost with \% Change in Mat Cost 80

5.3 Change in Total Cost with \% Change in Roving Cost 84

5.4 Change in Total Cost with \% Change in Resin Cost 84

5.5 Change in Total Cost with \% Change in Filler Cost 88

5.6 Change in Total Cost with \% Change in Initiator Cost 88

5.7 Change in Total Cost with \% Change in Veils Cost 88

5.8 Change in Total Cost with \% Change in Direct Labor Cost 93 


\section{LIST OF TABLES}

Table

Page

5.9 Change in Total Cost with \% Change in Utility Cost 93

5.10 Change in Total Cost with \% Change in Tool Set-Up 97

\& Tear-Down Time

5.11 Change in Total Cost with \% Change in Overhead Cost 97

5.12 Change in Total Cost (\$/ft) with \% Change in Line Speed 101

5.13 Change in Total Cost with \% Change in Start-Up 101

\& Tear-Down Losses

5.14 Change in Total Cost with \% Change in End-Squaring Losses 105

5.15 Change in Total Cost with \% Change in Annual Production 105

5.16 Change in Total Cost (\$/hour) with \% Change in Line Speed 109 


\section{LIST OF FIGURES}

Figure

Page

1.1 Picture of Pultrusion Process 12

1.2 Material \& Die Temperature Profiles 16

1.3 Material Temperature \& Die Pressure Profiles 19

3.1 Flow Diagram of Cost Model Methodology 30

3.2 Plot for Machine Cost Regression Parameters 53

3.3 Plot for Die Cost Regression Parameters 58

3.4 Plot for Building Area Regression Parameters 61

4.1 Bridge Deck Product Diagram 70

5.1 Raw Material Cost Sensitivity Graph 81

5.2 Mat Sensitivity Cost Graph 82

5.3 Roving Sensitivity Cost Graph 85

5.4 Resin Sensitivity Cost Graph 86

5.5 Filler Sensitivity Cost Graph 89

$\begin{array}{ll}5.6 & \text { Initiator Sensitivity Cost Graph }\end{array}$

5.7 Veils Sensitivity Cost Graph 91

5.8 Direct Labor Cost Sensitivity Graph $\quad 94$

5.9 Utility Cost Sensitivity Graph 95 


\section{LIST OF FIGURES}

Figure

Page

5.10 Tool Set-Up \& Tear-Down Time Sensitivity Graph 98

5.11 Overhead Cost Sensitivity Graph 99

5.12 Line Speed Sensitivity Graph 102

5.13 Start-Up \& Tear-Down Losses Sensitivity Graph 103

5.14 End-Squaring Losses Sensitivity Graph 106

5.15 Annual Production Sensitivity Graph 107

5.16 Line Speed Sensitivity Graph 110

6.1 Bridge Deck Drawing 115

1 Input Parameters User Screen 124

2 Exogeneous Factors User Screen 125

3 Process Factors User Screen 126

4 Material Adjustment Factors User Screen 127

5 Geometry Adjustment Factors User Screen 128

6 Cost \& Life User Screen 129

7 Raw Material Cost Input User Screen 130

8 Raw Material Cost Output User Screen 131

9 Cost Output User Screen 132

10 Total Raw Material \& Mat Cost Sensitivity Analysis 133

11 Roving Cost Sensitivity Analysis 134 


\section{LIST OF FIGURES}

Figure

Page

12 Resin Cost Sensitivity Analysis 135

13 Filler \& Initiator Cost Sensitivity Analysis 136

14 Veils, Direct labor \& Utility Cost Sensitivity Analysis 137

15 Set-Up Time and Overhead Cost Sensitivity Cost Analysis 138

16 Line Speed Sensitivity Analysis 139

17 Start-Up Losses Sensitivity Analysis 140

18 End-Squaring Losses Sensitivity Analysis 141

19 Annual Production Sensitivity Analysis 142 


\title{
GLOSSARY OF TERMS
}

\section{- EXOGENEOUS FACTORS}

\author{
WDL - Wages of Direct Labor \\ WIDL - Wages of Indirect Labor \\ WSL - Wages of Set-Up Labor \\ WDCY - Working Days per Calendar Year \\ NSPD - Number Shifts per Day \\ NHPS - Number of Hours per Shift \\ PU - Price of Utilities \\ PFFS - Price of Factory Floor Space \\ DLB - Depreciation Life of Buildings \\ R - Rate of Return on Capital \\ PUMS - Percent Utilization of Machine per Shift
}

\section{- PROCESS FACTORS}

CRLM - Capital Recovery Life of Machine

CRLD - Capital Recovery Life of Die

AC - Auxiliary Equipment Cost as Fraction of Machine Cost

IC - Installation Cost as Fraction of Machine Cost

DLPM - Direct Labor Requirement per Machine

IDLPM - Indirect Labor Requirement per Machine

OC - Overhead Cost as Fraction of Machine Cost 
MC - Maintenance Cost as Fraction of Machine Cost

UCP - Utility Consumption Rate of Process

- MATERIAL ADJUSTMENT FACTORS FOR

$\mathrm{ACM}_{\mathrm{O}}$ - Cost of Die

ALMo - Life of Die

ACA - Cost of Auxiliary Equipment

$\mathrm{ACM}_{\mathrm{A}}$ - Cost of Machine

$\mathrm{ALM}_{\mathrm{A}}$ - Life of Machine

AUC - Utilities Consumption

- GEOMETRY ADJUSTMENT FACTORS FOR

$\mathrm{GACM}_{\mathrm{O}}$ - Cost of Die

DALMo - Life of Die

- OTHERS

TNSPR $=$ Total Number of Shifts Required per Run

SS - Time for Set-Up and Tear down of Machine and Die

NPML - Number of Product Manufacturing Lines

PPMPR - Production per Machine per Run

WPF - Weight of the Product in lbs/linear foot

PTFUP - Proportion of Time the Facility is used in a Year for Manufacturing Product under consideration

NTSO - Number of Tool-Setting Operators 
TCCPV - Total Capital Cost Present Value for an Asset

P - Capital Investment for an Asset

A - Equal Installment paid each Year during the Life of an Asset

TNHPY = Total number of working hours per year 


\section{Chapter 1}

\section{INTRODUCTION}

This chapter gives an introduction to polymeric composites and explains the intricacies of the pultrusion process. This introduction is important before proceeding to the costing and cost analysis discussion of the pultrusion process which is the main objective of this thesis. Chapter 2 presents the importance of costing of the pultrusion process and Chapter 3 discusses detail analysis of the cost of the product manufactured by pultrusion process. Chapter 4 demonstrates the use of the model developed in the Chapter 3 on the bridge deck product. The sensitivity analysis performed on different cost components of this product is demonstrated in Chapter 5. Chapter 6 summarizes the conclusion from the costing analysis performed.

Materials have such an influence on our lives that periods of the history of humankind have been dominated, and named, after materials. Over the last thirty years, composite materials and ceramics have been the dominating

engineering materials. A composite material is formed by the combination of two or more distinct materials to form a new material with desired properties e.g. rocks are combined with cement to make concrete, which is as strong as the rocks it contains but can be shaped much easier than carving rock. While the enhanced properties of concrete are strength and ease of fabrication, 
most physical, chemical, and processing-related properties can be enhanced by a suitable combination of materials. While man-made composites date back to the use of straw-reinforced clay for bricks and pottery, modern composites use metal, ceramic, or polymer binders reinforced with a variety of fibers or particles e.g. fiberglass boats are made of a polyester resin reinforced with glass fibers [1].

In response to the requirements of aerospace applications, the development of materials with low density, high performance, and low maintenance costs has brought composite materials to the forefront. The superior performance of composites over conventional materials in some applications has caused composite materials to become a viable alternative to conventional single-phase metallic materials and are termed as "materials of the future". Also, the fatigue endurance limit, corrosion resistance, etc., are significantly higher when compared with conventional materials. Being unusually versatile, composites applications range from critical use in aerospace such as aircraft components (heat shields, cabin interiors) to sports and recreational equipment [2].

Polymeric composites are one of the composite materials formed by combining reinforcing fibers with a resin matrix and are often considered in design when strength and weight are of utmost importance. This composite will be topic of further discussion. 


\section{$1.1 \quad$ Polymeric Composite Materials}

The main components of polymeric composites are fibers and matrix. The fibers provide most of the stiffness and strength, and the matrix binds the fibers together, providing load transfer between them. Other substances are added to improve the specific properties e.g. fillers are used to reduce the cost and impart special properties such as fire retardancy.

\section{$1.2 \quad$ Fiber Materials}

One of the important factors determining manufacturing process variables is the nature of fiber used. The fiber materials determine the mechanical properties of the composite to a great extent. The relative volume of fibers in the total composition has a direct bearing on the properties of the composite. The higher the volume fraction of fibers, the higher is the strength to a point. Also, proper directional orientation of the fiber gives optimum properties for specific profile requirements. Continuous reinforcing fibers are available in the form of monofilaments, multifilament bundles, unidirectional ribbons, single layer fabrics, and multilayer fabric mats [3]. Rovings used in axial orientation give optimum tensile strength, mat for a balanced, isotropic set of properties, woven roving for bi-directional strength and non-woven knitted "fabric" for maximum bi-directional strength. Among the different types of fibers available for pultrusion process, the most significant are E-glass, S-2 glass, silicon carbide, boron, alumina, fused silica, alumina-boria-silica and carbon/graphite [4]. Glass fibers are less expensive, but are lower in strength and modulus when compared with carbon fibers. Glass fibers are mainly 
suitable for non-critical applications such as automobile, marine and other applications. Carbon/graphite fibers have very high specific strength and modulus but are costly and hence its use is limited to aerospace and other critical applications. Depending upon the design, a combination of two or more fibers can be used to manufacture hybrid composites.

\subsection{Matrix Materials}

The matrix material holds the reinforcements together, thus transferring the load between reinforcements and between the composite and the supports. Other functions of the matrix are to protect the reinforcements from the environment and mechanical abrasion, and to carry some of the loads, particularly transverse stress and intralaminar shear stress [1]. Thus the selection of correct resin for a particular reinforcement is very important. Matrix materials can be polymers, metals, ceramics, etc. Polymer matrices are the most common because they add two crucial advantages to composites, which are the ease of fabrication of very complex parts with low tooling cost and low capital investment. In general, the polymer is called resin system during processing and matrix after the polymer has cured (solidified) [1]. There are two different types of resins - the thermoset resins and the thermoplastic resins. The thermosets can not be remelted or reshaped once formed because of the extensive crosslinking produced during polymerization. Thermoplastics can be remelted and remolded. In the past, the thermoset resins were widely used for pultruded composites. However, the higher 
service temperatures, higher toughness, and post-process formability (by applying heat and pressure) have increased the popularity of using thermoplastics in composites $[5,6]$.

The major thermosetting matrices used for pultrusion process are polyesters, vinylesters, and epoxies. Polyester resins have the advantage of high processing speeds and lower cost over epoxies. Epoxies have low shrinkage, more die adherence and longer times to gelation and cure which overall contributes to high pulling forces and poor surface quality. However, with the development of new series of epoxy resins $\left(E P O N^{\circledR}\right.$ Resin 9302/EPON CURING AGENT ${ }^{\circledR}$ CA 9350), the composites will retain properties even at temperatures as high as $120^{\circ} \mathrm{C}$ [7]. In the selection of an epoxy resin for high temperature application, the resin system must have a glass transition temperature $\left(T_{g}\right)$ well above the temperature at which the composite will be used, since the resin properties change drastically above $T_{g}$ [8]. Polyesters have high resistance to water, good resistance to gasoline, oil, weak acids and alkali, but they cannot withstand aromatic hydrocarbons, ketones, or some concentrated acids. During cure, they have very high shrinkage $(7 \%)$. Vinylesters have many of the same handling properties, appearance, and cure as polyester resins and, therefore, are used in similar applications. Epoxy and vinylesters are used when corrosion resistance is needed for higher concentration levels of acids, bases and solvents, especially at elevated service temperatures. Resins provide the durability or toughness, needed to keep composites from crazing or cracking, which can 
cause moisture to penetrate and cause insulation failure. Vinylesters are higher in cost than polyesters [9]. The comparison of different resins with respect to strength, chemical attack resistance, cost and processing speed is summarized in Table 1.1

\subsection{Manufacturing Processes for Polymer Composites}

The choice of manufacturing process is dependent on the type of matrix and fibers, the temperature required to cure the matrix and form the part, and the cost effectiveness of the process. Often, the manufacturing process is the initial consideration in the design of a composite structure. This is because of cost, production volume, production rate, and adequacy of a

\section{Table 1.1 Property Comparison of Resins}

\begin{tabular}{|c|c|c|c|c|}
\hline & \multicolumn{4}{|c|}{ PROPERTY } \\
\hline Resin & $\begin{array}{c}\text { Tensile } \\
\text { Strength }\end{array}$ & $\begin{array}{c}\text { Chemical } \\
\text { Resistance }\end{array}$ & $\begin{array}{c}\text { Material } \\
\text { Cost }\end{array}$ & $\begin{array}{c}\text { Processing } \\
\text { Speed }\end{array}$ \\
\hline Polyesters & Medium & Low & Low & High \\
\hline Vinylester & High & High & Medium & Low \\
\hline Epoxy & High & High & High & High \\
\hline Phenolics & Medium & Low & Low & High \\
\hline
\end{tabular}


manufacturing process to produce the type of structure desired. Each manufacturing process imposes particular limitations on the structural design. Therefore, the designer needs to understand the advantages, limitations, cost, production rate and volume, and typical uses of various manufacturing processes of composites [1].

The five major methods of producing polymer composites are:

- Hand lay-up

- Filament Winding

- Resin Transfer Molding (RTM)

- Reaction Injection Molding (RIM)

- Pultrusion

\subsubsection{Hand Lay-up}

The hand lay-up technique also called wet lay-up, is the simplest and most widely used manufacturing process. Basically, it involves manual placement of the dry reinforcements in the mold and subsequent application of the resin. Then, the wet composite is rolled using hand rollers to facilitate uniform resin distribution and removal of air pockets. This process is repeated until the desired thickness is reached. The layered structure is then cured [1].

Dry lay-up or Prepreg lay-up uses a pre-impregnated fiber reinforced material where the resin is partially cured or thickened prior to molding. The prepregs are usually supplied in rolls, which are then cut to fit in the mold, and laid up layer by layer until the desired thickness is reached. Heat and 
pressure are applied which accelerate the final curing process. Dry lay-up can produce a stronger composite than the wet lay-up due to the higher fiber volume content. The process is widely used for making high performance aerospace parts and complex geometries [1].

\subsubsection{Filament Winding}

Filament winding can be divided into two subcategories, wet winding and dry winding. Wet winding is the most common form of filament winding due to the lower cost involved in coating the fibers and winding them onto the mandrel using one machine. In dry winding, the fibers are coated with resin and in some cases shipped to a manufacturer, which completes the filament winding process. Most shapes generated through this process are surfaces of revolution, such as pipes, cylinders, and spheres [1]. Examples of filament wound products include aboveground and below ground tanks, buried gas and chemical pipes, submarine missiles and rocket launch tubes etc. [10].

\subsubsection{Resin Transfer Molding (RTM)}

The resin transfer molding (RTM) uses a mold, with inlets to introduce the resin and outlets that allow air to escape. The fiber reinforcement is placed dry in the mold, and the mold is closed. Liquid resin is pumped into the mold through the inlet, soaking the fibers and filling the mold cavity. When the mold is full, the resin supply is removed, the mold inlets and outlets are sealed, and heat is applied to cure the resin. After the resin is completely 
cured, the mold is opened and the resulting composite part is removed [1]. Shapes which are difficult or impossible to form using other processes can be made using RTM. Due to the long cure time associated with this process, it is used most often where a high volume is not required, such as in aerospace applications [10].

\subsubsection{Reaction Injection Molding (RIM)}

RIM is used in processes requiring faster production rates. This process typically utilizes a rapid curing epoxy system making curing time a fraction of that for RTM. This rapid curing rate allows RIM to be used in high volume industries such as automobile manufacturing e.g. front and rear fascia, bumpers, fenders, tractor grills, cab roofs, window frames, office furniture, marine boarding ladders etc. [10]

\subsubsection{Pultrusion}

Pultrusion is a primary process for making reinforced polymeric composite profiles [10]. In this, fibers/mats impregnated with resin are pulled through a heated die to produce a cured composite. The fibrous reinforcement raw materials are drawn from a creel system, through a resin impregnation bath. The uncured composite is pulled through the heated steel die, allowing sufficient time to cure the composite by setting the pull speed

and the die temperature at desired operating conditions. The hot pultruded composite exiting the die is allowed to cool under ambient temperature 
conditions before it reaches the puller mechanism and into the saw station which automatically clamps and cuts the part to the desired length [11].

\section{Advantages and limitations of Pultrusion Process}

Pultrusion being an axial process, the finished profile can be achieved in any length that is desirable or manageable. The process has the ability to economically produce large shapes (18" x $36 ")$, the limitation being the pulling force required and the size of the die. It is very efficient for substantial volume runs on a 24-hour/day basis. It is particularly suitable for applications demanding good surface appearance $[12,13]$.

Also, pultrusion process gives consistent controlled fiber tensioning and orientation, lower void content, and uniform fiber fraction retention. The manufacture of composites using pultrusion process has less wastage of material in the form of scrap, and about $95 \%$ of the material is used in the production as compared with lay-up process which uses only $75 \%$ of the material [14].

When compared to the speed of aluminum or thermoplastic extrusion processes, the pultrusion process is slow. The throughput speed is a limiting factor because it can affect the total cost of the product. It is a time/temperature relationship process. The heavier the wall thickness, the longer the time required to cure the material. The cross-section of the product is a limitation since it is not possible to taper the shape or wall thickness. This forces the product to undergo post fabrication processes to achieve any variation in cross-sectional shape [11]. 


\subsection{Pultrusion Process Variables}

It is very important to understand the relationship and role of different processing/manufacturing variables to control the process economics and product quality. The pultrusion process is a very complex process whose intricacies are not yet well understood.

There is only a general qualitative information about what goes on inside the pultrusion die which can be summarized roughly as follows [15]:

1. The heating of a chemically active material (resin) starts the reaction process.

2. The reaction advances while under the influence of pressure within the die.

3. The reaction is exothermic and at some point within the die the direction of heat flow is reversed.

4. At some point within the die the degree of cure reaches the point where shrinkage allows the part to release from the die wall.

In the pultrusion process the interface bonding between the resin and the fiber is very important. This bonding depends upon the chemical nature of the fiber and resin selected and also upon the sizing (a coupling agent to promote bonding between fiber and matrix in the composite) used. Fibers sustain considerable damage during processing by rubbing against each other and

with the equipment. The other important factors affecting the properties of a pultruded composite are resin bath properties such as viscosity and 


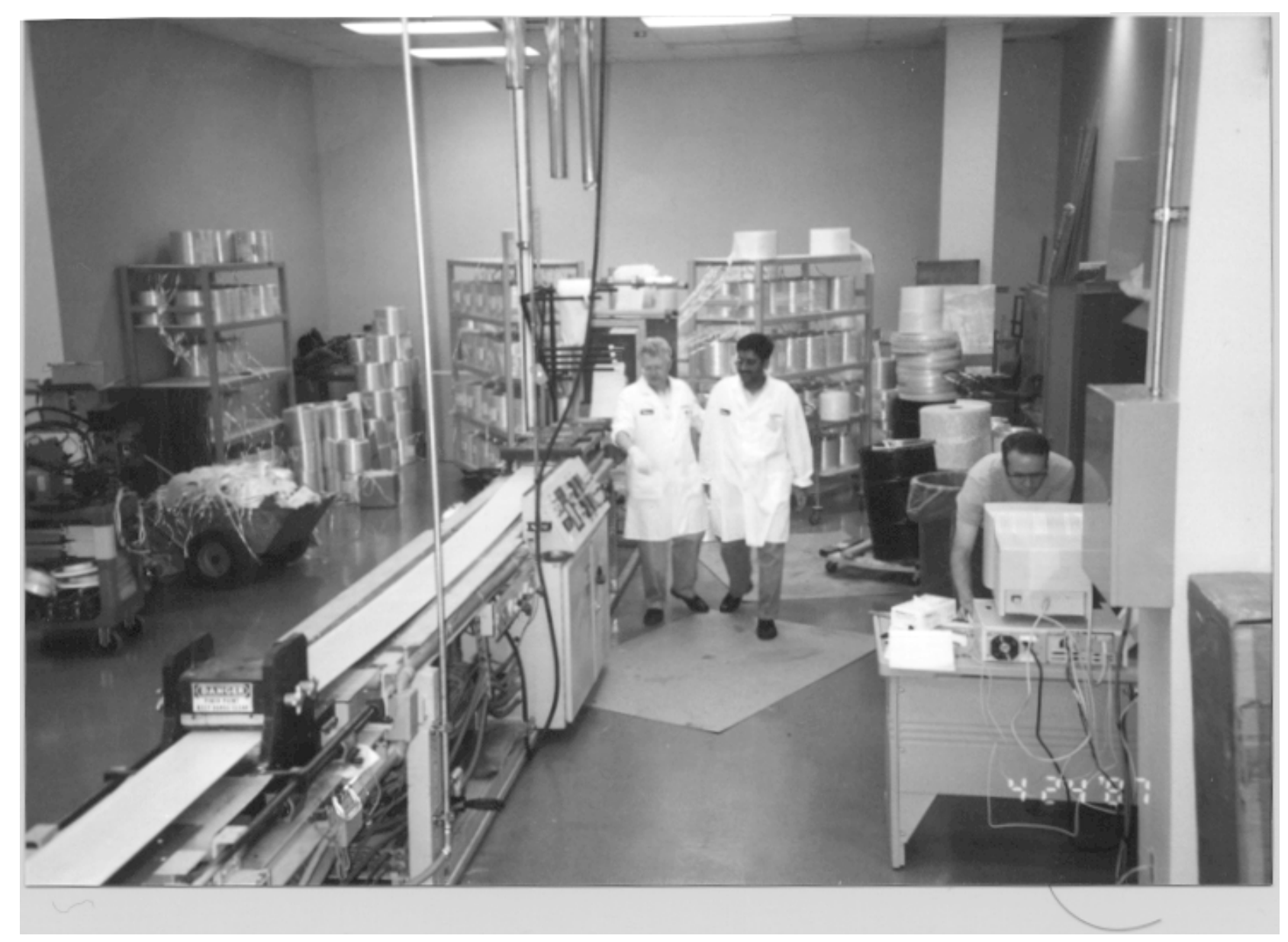

Figure 1.1 PICTURE OF THE PULTRUSION PROCESS [45] 
temperature, temperature profile in the die, initiator used (determines the point of start and rate of curing of the resin), internal die pressure, pulling force and pulling speed.

Fibers from the creel, after passing through guide holes, pass through the resin bath for impregnation of the resin before entering the die. One of the important factors to be considered in the formulation of the resin is the viscosity of the resin. The most obvious effect of viscosity is the ability to wetout reinforcing fibers prior to entering the die. The ability to wet-out fibers depends upon following factors: (1) initial viscosity, (2) time of immersion, (3) temperature of resin when applied to fibers, (4) amount of work applied to fibers in the bath. Generally, the degree of wet-out is improved for a given initial viscosity as the time of immersion increases, the degree of working of fibers increases, and as the resin bath temperature increases. Preheating of the resin in the resin bath reduces the viscosity and allows a greater degree of wet-out. However, if the viscosity is lowered significantly, an increase in fiber volume may be necessary to maintain sufficient pressure at the die entrance to avoid internal and surface porosity in the product [16]. A second way to reduce viscosity is by the addition of reactive diluents which polymerizes during resin cure either as part of the resin or separately to form its own network.

Fibers then enters the thermally heated die, the temperatures within which must be stabilized at the set point (depending upon the initiators used) or problems can occur. Temperatures below the proper set point can cause 
sloughing on the product surface [17]. The magnitude and position of the control temperatures depend on the length of the die, the size and shape of the part, and the inlet temperature [18]. It is recommended that temperatures inside the die increase gradually over the first 12 inches of the die to avoid a large difference in the die wall and the material entering the die. This allows a slow thermal transfer from the outside of the part to the inside. If a constant temperature profile is maintained along the die, it is more likely that the surface of the material in contact with the die consumes most of the heat and cures. The cured composite surface has a low thermal diffusivity compared to the uncured resin, and the necessary amount of heat may not be transferred to the center portion of the composite for proper curing. The thicker the crosssection, the greater the importance of increasing heat gradually along the length of the die. Also, if temperatures do not increase gradually at the front of the die, a build-up of cured resin occurs on the die wall, allowing uncured resin to be pulled past this point producing a poor surface quality on the product [16]. Equally important is to avoid raising the temperature at the entrance of the die above the gel point to prevent progressive build-up of the hardened resin at the entrance which can cause snapping of the fibers. To avoid these, the die needs to be extended beyond the heating platens so that this portion stays below the gel point $[19,13]$. Some pultruders are equipped with cooling water, which keeps the front end of the die cool. If this length is tapered, the backflow of the resin can be expected as the excess is scraped off the wet strand entering the tapered die. 
Ma et al [20] showed that a high die temperature was needed to increase pull speed and thereby increase production. However, if the temperature is too high or the reaction too fast, thermal cracking will take place within the product. To avoid this, a multiple heating die with a preheating zone, gel zone and curing reaction zone is used. Also, preheating the resin before it enters the die can be beneficial by reducing the reaction time.

The gradual transfer of heat from the die to the material in the first half of the die results in significant viscosity drop in resin. Thus, adjustment of the total filler content is necessary to control the decreased viscosity as otherwise too much resin will flow to the stock surface as the fiber distributes the pulling force. A resin rich surface causes effects, which range from excess sloughing to large surface fractures [21]. Heat flow from the die to the material supplies required thermal energy to bring the whole cross-section of the composite close to the required temperature to initiate gelation [19]. The process of gelation initiates curing at the surface of the composite when the temperature reaches the curing temperature and this process is exothermic. The intermediate portion of the composite for curing consumes the heat from this exothermic reaction. Due to multiple exothermic chain reactions, the temperature of the composite material rises above the die temperature at the beginning of last half of the die, and reversal of heat flow takes place [22]. A temperature profile of the die and material along the length of the die is shown in Figure 1.2. 


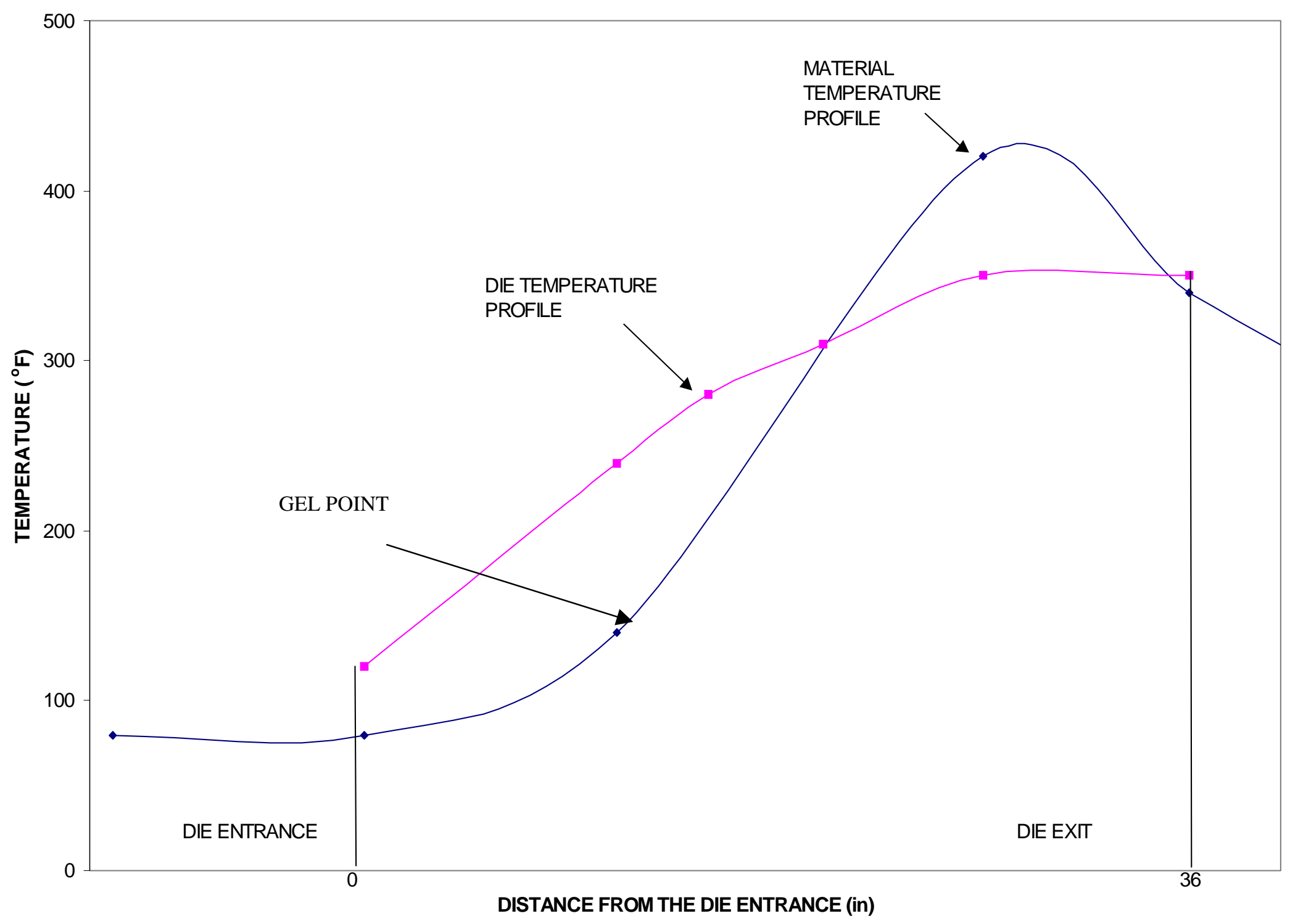

Figure 1.2 MATERIAL \& DIE TEMPERATURE PROFILES [26] 
Outwater [23] noted that the exotherm of resin typically raises the temperature of the product by approximately $4{ }^{\circ} \mathrm{C}$, allowing the composite to cure all the way to the center. Thus, the temperature at the center of the product must be within $4{ }^{\circ} \mathrm{C}$ of the temperature needed for curing these resins beforethe reaction begins at the outside of the product. If the temperature at the center is not high enough, cure will begin to take place at the outside and be quenched before reaching the center. It was also determined that composites with lower fiber volume cure more completely compared to higher fiber volume. This is because a lower fiber volume means a higher resin volume, which provides a higher amount of exothermic heat. It is normally desirable to substantially decrease the product temperature prior to product leaving the die by decreasing the mold exit temperature, so that the rate of heat transfer from the product to the die increases, allowing the composite to cool sufficiently enough so as to avoid exothermic cracking. This technique is more effective for thin products due to poor mass heat transfer properties of the composite. With thick sections it is more effective to restrain the level of peak exotherm through resin catalyzation chemistry, heat sinking fillers, or inhibition [16].

To produce a quality part, application of pressure within the die is required. This pressure ensures that laminates are bonded together and helps to eliminate voids. This pressure, developed at the die entrance depends upon the viscosity of the resin. The higher the initial viscosity of the resin, the higher the initial pressure develops. The volumetric shrinkage has a 
significant role in the sense that for higher shrink materials the internal pressure falls to zero prior to the material achieving peak exotherm which can then cause boiling of resin. If the viscosity is lowered significantly, an increase in fiber volume may be necessary to maintain sufficient pressure.

The shear stress between the die wall and the product increases initially at the die entrance corresponding to viscous drag of the resin on the die wall. As, the resin is heated in the die, its viscosity reduces till the time it reaches gel point, after which the reduction in viscosity is contradicted by increase in molecule size, and thus we see fluctuations in the pulling force. As the reaction reaches completion and the product cools by giving away heat to die, it shrinks and separates away from the die walls, which causes reduction in pull pressure. Figure 1.3 shows pressure and temperature profiles [24].

Pull time influences the dwell time of the composite in the die. For a particular temperature profile, the point of gelation and the variation of pull load and pull pressure is influenced by the pull speed $[16,25]$. If gelation takes at the end of the die, then improper curing takes place in the composite. 


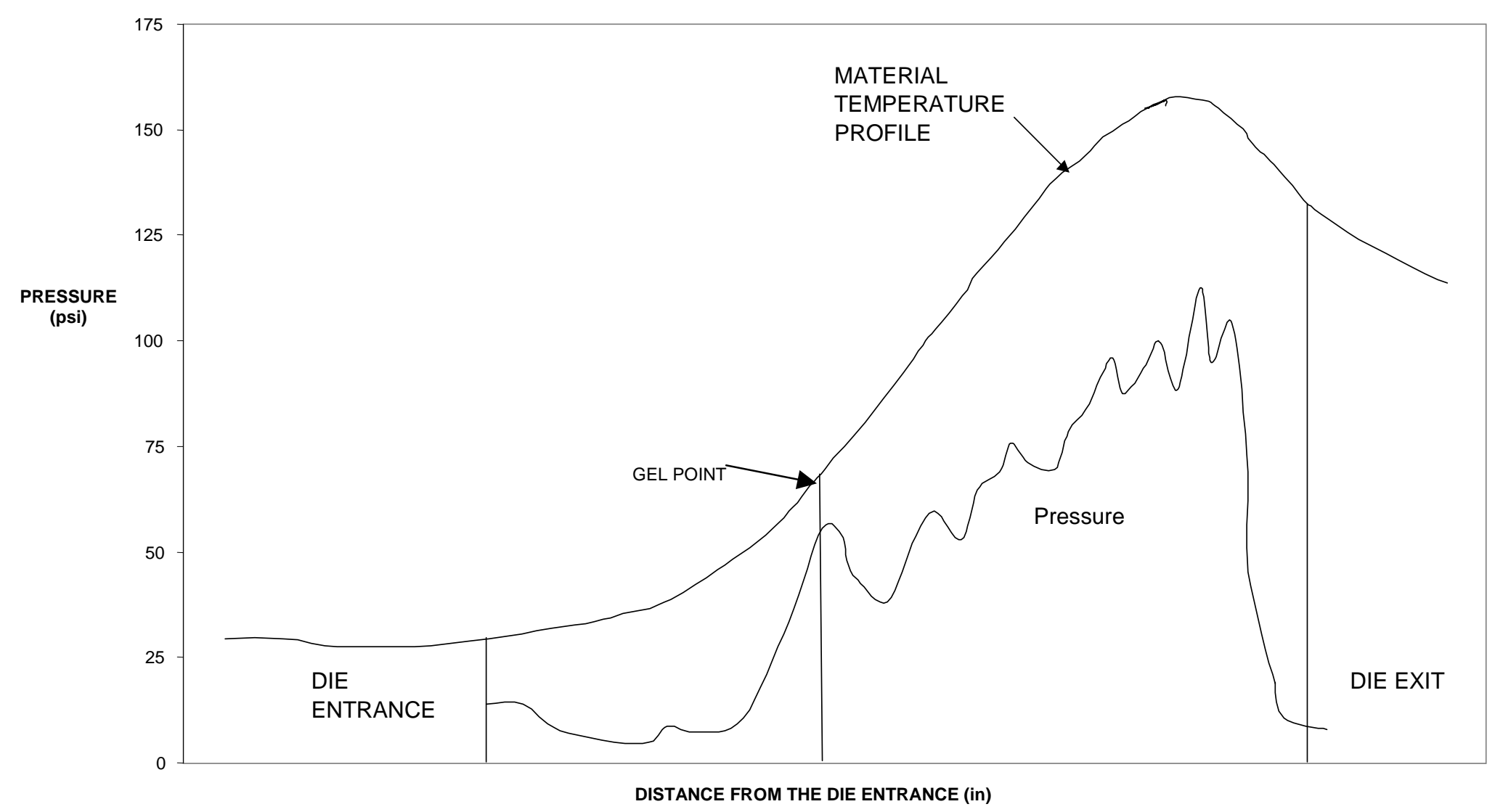

Figure 1.3 MATERIAL TEMPERATURE \& DIE PRESSURE PROFILES [24] 


\section{Chapter 2}

\section{BACKGROUND}

\subsection{Need for Costing of Composites}

In today's world market environment of stiff competition, the cost of improved performance with lightweight and corrosion resistance of composites must be justified economically over that of conventional materials. Also, costing of composites is helpful in the ongoing continuous efforts to reduce the initial cost of composites.

These have given rise to a need for developing of a reliable cost model to predict the different cost components (material, direct labor, overhead, tooling, etc.) at the design stage itself. This enables the designer to explore different geometry and material combinations and quantify their cost, saving time and money, which, otherwise would have been wasted by modifications and alterations at later stages of production.

\subsection{Need for Costing of Pultrusion Process}

Many current methods for cost estimation of composites [Section 2.3] are direct adaptations of the methods used for metallic parts. Cost components are added up based on a known history of making a particular type of part, which uses similar equipment and processes. E.g. the cost of stamping metal parts can be easily predicted based on the practice gained 
through years of experience. On the other hand, advanced polymer composites have had a relatively short history, and it is more difficult to base predictions of cost on past experience. Some fabrication techniques, such as hand lay-up, are already well established and have accumulated a sizeable database upon which cost estimates may be made.

However, other processes, such as pultrusion, resin transfer molding, filament winding etc., which allow high volume productions of composites are still being developed. A strong analysis of costs is needed if the new methods are to be justified in the long run.

Of all these processes, pultruded FRP's have been found to have desirable mechanical, thermal, acoustic, magnetic and electrical properties. There is virtually no limit to size except as it relates to size of equipment available for production. Pultrusion is a continuous molding process with a twenty-four hour output possible.

It is the intent of this thesis to present a systematic and comprehensive method for estimating primary fabrication costs of the pultrusion process. This type of cost modeling is also very useful in giving directional estimates of different alternative designs by identifying cost drivers in production at the design stage itself. 


\subsection{Cost Analysis Methods}

A variety of techniques are used to estimate the cost of a manufactured plastic component. Five of the most commonly used estimating techniques are described here.

\subsubsection{Material Times Two}

As the name suggests, the cost of a manufactured plastic component is estimated as a constant multiple of the cost of the material required to manufacture it. This multiple commonly used is two i.e. twice the material cost [26].

\section{Cost $=2$ * Material Cost}

The cost estimate generated by this technique is often near to the actual cost of manufacturing a component. This heuristic approach has the distinct advantage of simplicity over all other techniques. However, the distinct disadvantage of this technique is that it does not take into consideration the fabrication technology at all. Thus, for a given part, the cost of blow molding, injection molding and pultrusion will be identical if the material costs are same for all the three processes.

The "material times two" technique also fails to consider the effect of two major process parameters: cycle time (line speed for pultrusion process) and annual production volume. Of these, cycle time clearly influences labor 
content per unit of the product manufactured and annual production influences the proportion of equipment cost (in case of non devoted facility) corresponding to the utilization time and the recovery of capital investments.

\subsubsection{Material Cost Plus Shop Time}

The other most commonly employed cost estimating technique in the plastic industry is to add the cost of the material to the cost of the time required to process it. The following equation explains this technique [26]:

\section{Cost $=$ Material Cost + Machine Rate * manufacturing cycle time}

Unlike the preceding technique, this cost estimating method does capture some of the influence of cycle time on manufactured part cost. Also, it separates processing costs from material costs. Given good values for machine cost and cycle time, very accurate estimates can be obtained.

However, this technique still does not consider the effect of annual production volume i.e. it is assumed that cost is not influenced by the level of equipment utilization.

Finally, this technique wrongly incorporates the influence of cycle time on production cost, by assuming that costs are linear with respect to changes in cycle time. This assumption is not generally true over the range of possible cycle times [26]. 


\subsubsection{Material Cost Plus Loaded Shop Time}

A refinement upon the previous technique is to separate the cost of shop time into two components: direct labor and overhead cost as illustrated by the following equation [26]:

\section{Cost $=$ Material Cost + Cycle Time * (Wage Rate + \\ Labor Overhead Rate) $=$ Material Cost + Labor Cost}

This technique introduces the concept of labor overhead, and begins to separate individual elements of part cost and thus enables the assessment of the relative contributions of each element to the total cost.

\subsubsection{Quotes}

An entirely different approach to cost estimation is to obtain production quotes from manufacturers each time a cost estimate is required. In this method, a detailed engineering drawing or part model is submitted to the manufacturer, and the manufacturer returns a contract price for which he is willing to supply the finished product [26].

The obvious advantage of this approach is that there is little uncertainty regarding the cost of acquiring the finished components. However, this method can be used only after product design has been finalized with all the specifications. Also, an estimation time is involved to get 
the quote back from the manufacturers. Other factors, such as pricing policy of vendors and manufacturing process used to fabricate the product also affects the quotes obtained.

In addition to the above four cost estimation methods, numerous other heuristic methods may be employed. The proliferation of these techniques both reflects the importance of estimating manufactured part cost and demonstrates that no one technique is universally appropriate or applicable.

While it is possible to point out deficiencies in each technique, it is important to remember that they are widely used, and yield good results when used by knowledgeable practitioners. The success of plastics molding business is critically dependent upon the skill of its cost estimators.

Nevertheless, there are good reasons to use techniques other than those described above. For one, the above techniques generally rely upon the expertise of individuals, whose insights into cost estimation cannot be easily verified. This again introduces difficulties when it becomes necessary to transfer expertise to others in the organization. Also, these techniques do not indicate how various factors contribute to manufacturing costs, information that is critical for cost control.

The above discussion makes it clear that there should exist an alternative approach which not only reduces the dependency of cost estimation accuracy on an individual expertise, but also which explodes the total cost into its components and calculates this individual components separately to arrive at the total cost. These features are provided by 
'Technical Cost Modeling' approach to cost estimation. Through systematic application of engineering and economic principles, it is possible to reduce cost estimation to a system of elemental equations, relating processing parameters, cost elements, and total cost.

\subsubsection{Technical Cost Modeling}

The technical cost modeling method [26] uses an approach in which each of the elements that contributes to total cost is estimated individually. These individual estimates are derived from basic engineering principles, from the physics of manufacturing process, and from clearly defined and verifiable economic assumptions. The technical cost approach reduces the complex problem of cost analysis to a series of simpler estimating problems, and brings engineering expertise, rather than intuition, to bear on solving these problems. Also, by providing a breakdown of each contributing element, it provides the information that can be used to direct efforts at cost reduction, or it can be used to perform sensitivity analysis.

There are various bases for cost systems, such as "time" and "quantity". A time based system uses time to describe the costs; that is fixed costs are items such as material since the material is fixed and variable costs vary with time such as depreciation, administrative, and property taxes. In a quantity based system, the material cost is a variable as the material varies as the number of components whereas the fixed costs with respect to quantity would be depreciation, administrative, and property taxes. 
Each of these cost systems has its application. Time based system (\$/hour) is particularly used by the company for its internal record keeping cost computations. Quantity based system is used in quoting rates to clients. This model calculates the cost on both, a time basis and a quantity basis.

In dividing cost into its contributing elements, a distinction is made between costs elements that vary with the number of components manufactured annually (variable), and those that do not (fixed). For example, in most instances (without considering quantity discounts), raw materials contribute the same cost per unit regardless of the number of components produced. These types of cost components are called variable costs. On the other hand, per piece cost of tool set-up labor will vary with changes in production volume. These cost components are called fixed costs. 


\section{Chapter 3}

\section{COST MODEL}

\subsection{Cost Model Description}

The computer model was developed to estimate the production costs of making polymer composite products using pultrusion process. The model is an Excel spreadsheet (Microsoft Excel 97) and uses Visual Basic 5 code as needed. It was designed to work on Windows 95 or Windows 98 operating system.

The methodology of the model consists of the following steps $[27,28,29]:$

1. The user inputs values for variables such as material, geometry, weight, cross-sectional area, annual production, number of runs during the year, line speed, set-up \& tear down time, number of cavities per die, start-up and tear down scrap, end-squaring losses and number of product manufacturing lines [Section 3.2].

2. The model selects exogeneous [Section 3.3.1], process [Section 3.3.2], material adjustment [Section 3.3.3.1] and geometric adjustment factors [Section 3.3.3.2] corresponding to values of the input variables and asks the user for confirmation. At this point the user may enter his values for these parameters. 
3. The model then calculates the cost and life of different equipments and again asks the user for confirmation. If desired, user can override these calculated values by entering his own values.

4. The material cost is then calculated, taking material specific input from the user.

5. Finally, the different cost components are tabulated along with their percentage of components in the total cost (\$/ft \& $\$ /$ hour).

6. The user can than perform cost sensitivity analysis for any of the cost components or other important variables such as line speed, start-up and end-squaring losses or annual production, to quantify the effect of these variables on total cost $(\$ / \mathrm{ft})$.

A flow diagram of the cost model methodology is shown in Figure 3.1.

\subsection{Inputs to the Model}

The user provides the inputs to the model as they pertain to the component, which is to be fabricated/cost estimated. The inputs provide the basis for the selection of exogeneous, process, material adjustment and geometric adjustment factors and for estimation of the production costs.

Inputs are to be entered in the specific fields provided for each. The following inputs must be supplied for each component whose cost is estimated $[27,28,29]$ :

1. Material

2. Geometry 


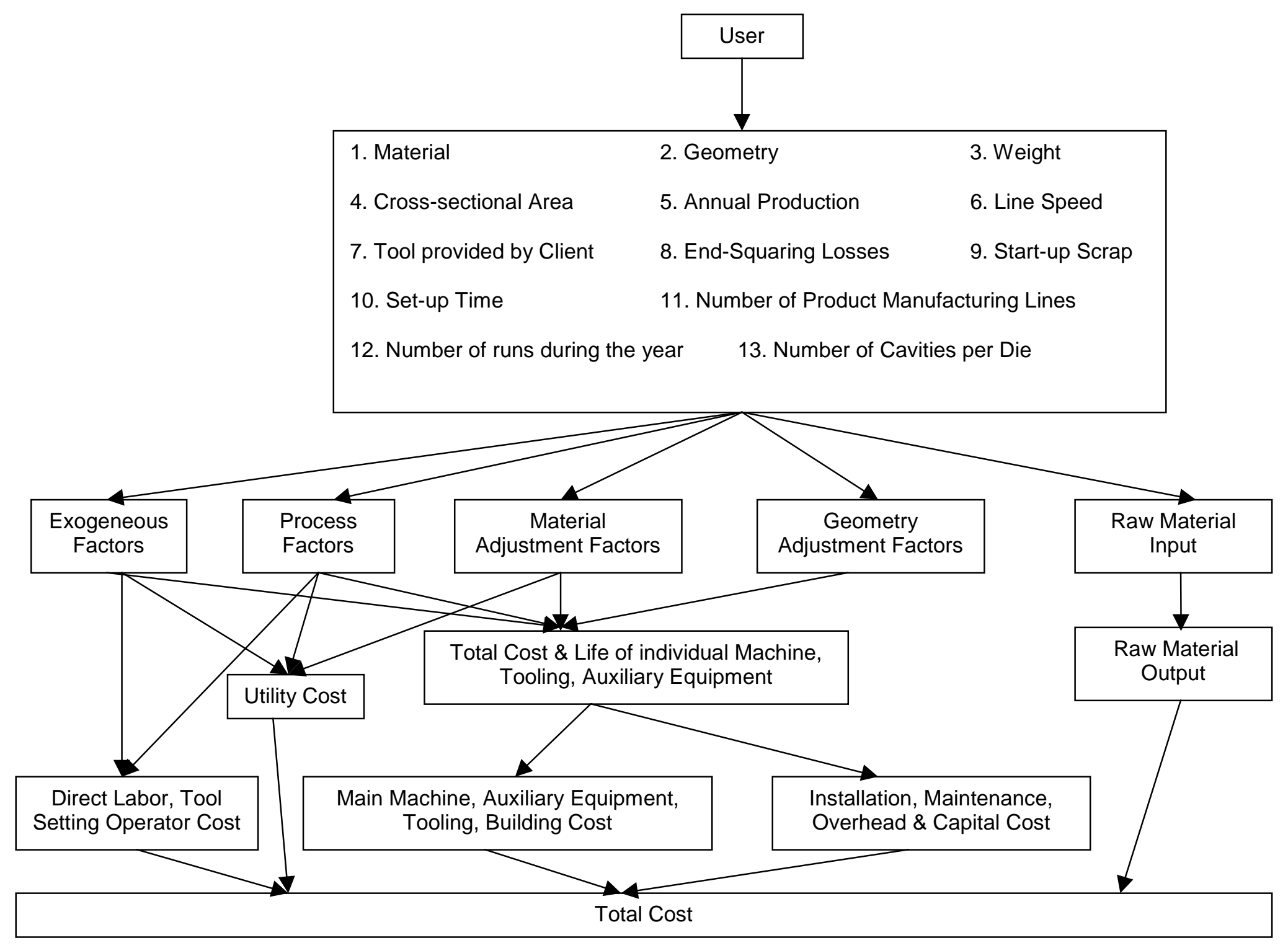

Figure 3.1 FLOW DIAGRAM OF COST MODEL METHODOLOGY 
3. Weight $(\mathrm{lbs} / \mathrm{ft})$

4. Cross-sectional area $\left(\mathrm{in}^{2}\right)$

5. Annual production (ft)

6. Number of runs during the year

7. Line speed (in/min)

8. Set-up and Tear-down time (shifts)

9. Number of cavities per die

10. Tool provided by client (yes or no)

11. Start-up and Tear-down scrap (\%)

12. End-squaring losses (\%)

13. Number of product manufacturing lines

\subsubsection{Material Inputs}

In this, the resin and fiber combination is selected from the drop down provided. The options provided on the basis of the most widely used materials $[30,31]$ are shown in Table 3.1.

Corresponding to the material selected, material adjustment factors are selected. These material adjustment factors are discussed in more detail in Section 3.3.3.1.

\subsubsection{Geometry Inputs}

Component geometry is another model input, which the user must supply. Nine geometries appear on the second drop down menu and the user is expected to select one which best describes the component of 
interest. Categorizing geometries is difficult since real components rarely occur as simple categorical shapes. A listing of these geometries appears in Table $3.2[26]$.

Table 3.1 PART MATERIAL OPTIONS [30,31]

\begin{tabular}{|l|}
\hline Resin/Fiber Options \\
\hline Phenolic/Glass \\
\hline Polyester/Glass \\
\hline Epoxy/Glass \\
\hline Epoxy/Graphite \\
\hline
\end{tabular}

Table 3.2 PART GEOMETRY OPTIONS [26]

\begin{tabular}{|l|}
\hline Geometry Options \\
\hline Simple Curved Panels \\
\hline Complex Curved Panels \\
\hline Open Box Beams \\
\hline Closed Box Beams \\
\hline Hollow Columns \\
\hline Simple Hollow Containers \\
\hline Complex Hollow Containers \\
\hline Complex Solid \\
\hline
\end{tabular}

This geometry selection causes certain geometric adjustment factors to be selected by the model, which is discussed in Section 3.3.3.2. 


\subsubsection{Weight}

The user must input a numerical value for the weight of the component of interest. The component weight refers to the weight in Ibs./linear $\mathrm{ft}$ for the cross-section of as pultruded product. It does not include the weight loss or added by either removal or adding of the material in secondary joining or inserting operations. This weight is used in the calculation of weight percentage of various material components from the volume fractions provided by the user as explained in Section 3.4.1.1.

\subsubsection{Cross-sectional area}

The user must input a numerical value for the cross-sectional area in a plane perpendicular to pultrusion axis of the component of interest. This variable is useful in calculating the material cost component as explained in Section 3.4.1.1.

\subsubsection{Annual Production}

A value for this variable is required to indicate the total number of feet (continuous process) of the component to be produced over the course of production year. When the total annual production involves several short production runs, the annual volume is the sum of these runs. This variable is then used to determine fraction of time the facility is used (assuming nondevoted facility) for manufacturing this product during the year. 


\subsubsection{Number of Runs}

This option is provided assuming that the entire annual production will be divided into lots of equal sizes manufactured at different periods of time. If the entire production is made in one run, then the user can input number of runs equal to one.

\subsubsection{Line Speed}

The line speed is the speed at which the product is to be pultruded, expressed in the units of $\mathrm{ft} / \mathrm{min}$. This is a very important variable and has a considerable effect on the total cost through the fixed cost variables.

\subsubsection{Set-Up and Tear down time}

This is the time needed in terms of shifts, to set-up and tear down the die and the machine for the product under consideration. This includes time to set-up fiber creels, guides, resin bath and die. Similarly, during tear down it consists of time for cleaning the die, cleaning the resin bath etc. This variable affects the tool set-up operator cost in the total cost.

\subsubsection{Number of Cavities per Die}

This variable has been introduced to take care of the situations in which number of same products are pultruded all at the same time from the same die. e.g. broom handles. The user inputs the number of products under consideration pultruded simultaneously. 


\subsubsection{Tool Provided by Client}

This is the boolean expression, for which the user replies 'yes' or 'no'. This field is provided to consider the situation when the client provides the tool and tooling cost is not considered in the total cost calculation. However, if the client does not provide the tool, then the cost is calculated as explained in Section 3.4.2.3.

\subsubsection{Start-up and Tear-down Scrap}

The user inputs the expected value of scrap likely to be produced before the actual production of the desired quality of the product under consideration starts. This affects the fixed cost components, which determines the proportion of time the facility is used by the product under consideration.

The above variable also includes the scrap produced while tearing down the machine.

\subsubsection{End-Squaring Losses}

These losses occur if ends of the product have to be trimmed. This is similar to start-up losses and will affect the proportion of the time the facility is used by the product under consideration. 


\subsubsection{Number of Product Manufacturing Lines}

Here, the user inputs the number of similar lines pultruding the product under consideration, all at the same time. This would require multiple dies and would only be used for extremely high production levels. It is very important to note the difference between this variable and 'number of cavities per die' variable. They are not related to each other.

\subsection{Model Data}

The estimation of different cost components of the product is done using three different types of variables. These variables are:

1. Exogeneous variables

2. Process variables

3. Adjustment factors
a. Material Adjustment Factors
b. Geometric Adjustment Factors

To change the default values of the first two of these variable types, the user must input new values in the fields provided and click the 'save' button. This will modify the database permanently. However, if he/she wants to override the default value only for that particular run, he/she need not click 'save' button. However, for changing the third variable type, the appropriate data files must be edited. Only the appropriate authority having access to password of these files can do this. 


\subsubsection{Exogeneous Variables}

Exogeneous variables are the factors, which are either company dependent (e.g. shifts per day), or determined by the region where the company is located (e.g. wages of direct labor). The value may vary from region to region, however, for a given region the value will be fixed and will be accurately known. Exogeneous variables provide information on the structure of the industry and on the economic environment in which the industry operates. These variables must be reviewed and adjusted regularly. The exogeneous variables used in this model along with their acronyms and default values are shown in Table 3.3 and are described below:

1. Wages of Direct Labor $(W D L)$ : This value is in $\$ /$ hour and includes employee benefits i.e. health insurance, retirement plans, and other employee incentives that directly benefit the laborer. The default value is $20.00 \$ /$ hour [32].

2. Wages of Indirect Labor (WIDL): This value is in $\$ /$ hour and is wages of material handling labor. The default value is $20.00 \$ /$ hour [32].

3. Wages of Set-Up Labor (WSL): This value is in $\$$ /hour and includes employee benefits. The default value is $20.00 \$ /$ hour [32].

4. Working Days per Calendar Year (WDCY): The number of working days per calendar year and default value is 300 days [33].

5. Shifts per Day (NSPD): Number of shifts per day and default value is 3 shifts. 
Table 3.3 EXOGENEOUS FACTORS [26,32,33,34,35,46]

\begin{tabular}{|c|c|l|c|}
\hline S.No & Name & \multicolumn{1}{|c|}{ Description } & Default Values \\
\hline 1 & WDL & Wages of Direct Labor $(\$ /$ Hour) & 20 \\
\hline 2 & WIDL & Wages of Indirect Labor $(\$ /$ Hour) & 20 \\
\hline 3 & WSL & Wages of Set-Up Labor $(\$ /$ Hour) & 20 \\
\hline 4 & WDCY & Working Days per Calendar Year & 300 \\
\hline 5 & NSPD & Shifts per Day & 3 \\
\hline 6 & NHPS & Hours per Shift & 8 \\
\hline 7 & PU & Price of Utilities $(\$ /$ KWh) & 50 \\
\hline 8 & PFFS & Price of Factory Floor Space $\left(\$ / t^{2}\right)$ & 40 \\
\hline 9 & DLB & Depreciation Life of Buildings (years) & $10 \%$ \\
\hline 10 & R & Rate of Return on Capital $(\%)$ & $95 \%$ \\
\hline 11 & PUMS & Percent Utilization of Machine per Shift $(\%)$ & \\
\hline
\end{tabular}


6. Hours per Shift (NHPS): Number of hours per shift. The default value is 8 hours.

7. Price of Utilities (PU): This value is in $\$ / k W h$ and default value is 0.05 $\$ / k W h$. Values for this parameter depend on the region and level of consumption [34].

8. Price of Factory Floor Space (PFFS): This parameter is the average price of factory floor space. Unit is $\left(\$ / \mathrm{ft}^{2}\right)$ and the default value is $50.00 \$ / \mathrm{ft}^{2}$. Actual values can vary considerably from region to region. [34]

9. Depreciation Life of Buildings (DLB): This is the number of years over which the capital investment in factory buildings is recovered. The default value is taken 40 years [46].

10. Rate of Return on Capital $(R)$ : The unit is $\%$ and the default value is taken as $10 \%$. This parameter specifies the interest rate for capital recovery i.e. return on investment for capital investments in machinery, tooling, buildings, etc. The industry average value for this parameter is difficult to establish. However, it is reasonable to assume that the average capital recovery rate is slightly higher than the prime lending rate of major banks [35].

11. Percent Utilization of Machine per Shift (PUMS): The unit is \% and the default value is taken as $95 \%$ [26].

These variables are used in Section 3.4. 


\subsubsection{Process Variables}

These variables are assumed to be pultrusion process specific e.g. auxiliary equipment cost as fraction of main machine cost for the pultrusion process. The process variables with their acronyms and default values are shown in Table 3.4 and are defined as:

1. Capital Recovery Life of the Machine (CRLM): This is the period over which the capital investment made in the machine is scheduled to be recovered by distribution of the recovery burden onto the parts produced during this period. Ideally, it should correspond to the expected physical life of the equipment. The value for this variable is 7 years determined from IRS bulletin [46] and [33].

2. Capital Recovery Life of the Die (CRLD): This is the period over which the capital investment made in the die (tooling) is scheduled to be recovered by distribution of the cost over the parts produced during this period. The value for this variable is taken as 3 years as stated in IRS depreciation publication 946 [46] and [33].

3. Auxiliary Equipment Cost as Fraction of Machine Cost (AC): Auxiliary equipment is termed as any equipment needed for the manufacture of the product in addition to main machine and die. e.g. handling equipment, stands for fibers, resin bath tub, pumps etc. [26] 
Table 3.4 PROCESS FACTORS $[26,36,37,38,46]$

\begin{tabular}{|c|c|l|c|}
\hline S. No. & Name & \multicolumn{1}{|c|}{ Description } & Default Values \\
\hline 1 & CRLM & Capital Recovery Life of the Machine (years) & 7 \\
\hline 2 & CRLD & Capital Recovery Life of the Die (years) & 3 \\
\hline 3 & AC & Auxiliary Equipment Cost as Fraction of Machine Cost & 0.2 \\
\hline 4 & IC & Installation Cost as Fraction of Machine Cost & 0.15 \\
\hline 5 & DLPM & Direct Labor Requirements per Machine & 0.1 \\
\hline 6 & IDLPM & Indirect Labor Requirements per Machine & 0.35 \\
\hline 7 & OC & Overhead Cost as Fraction of Fixed Cost & 0.03 \\
\hline 8 & MC & Maintenance Cost as Fraction of Machine Cost & 0.4 \\
\hline 9 & UCP & Utility Consumption Rate of the Process $(\mathrm{kWh} / \mathrm{lb})$ & 0.1 \\
\hline
\end{tabular}


4. Installation Cost as Fraction of Machine Cost (IC): This includes the cost of preparing the building for installation (foundation) of the main machine and auxiliary equipment (electrical, plumbing etc.) as well as the actual cost of setting up the equipment. Suggestion on averages of this factor is found in [43], however, in this thesis it is assumed that the building (plant) already exists, hence the factors for cost of structural steel, building, insulation etc are not considered. Also, in [43] it has been clearly stated that for expensive equipment (above $\$ 200,000$ ), the relationship between the cost of equipment and its installation cost is not constant. In this thesis value for this variable is taken from $[36,37,38]$.

5. Direct Labor Requirement per Machine (DLPM): This gives the labors needed to operate the main machine. This component does not include labor for janitorial services, quality control, maintenance etc.[36]

6. Indirect Labor Requirement per Machine (IDLPM): This is the number of indirect labor assisting in the production of component of interest e.g. labor needed for putting the sawed part into rack, for sand polishing the ends, material handling etc. [36]

7. Overhead Costs as Fraction of Fixed Cost (OC): This component includes the costs such as wages of managerial staff, quality control, shipping, receiving, janitorial etc. This also includes the overhead items, such as costs of marketing, advertisement \& sales.[26] 
8. Maintenance Cost as Fraction of Machine Cost (MC): This is the cost of maintaining the main machine and auxiliary equipment including labor and capital costs. [26]

9. Utility Consumption Rate of the Process (UCP): The unit is $\mathrm{kWh} / \mathrm{lb}$ and is the measure of the power consumed by the main machine during the processing of parts. It includes the power consumed in heating, cooling and in mechanical transport of the material during processing.

\subsubsection{Adjustment Factors}

\subsubsection{Material Adjustment Factors:}

These are the factors introduced to appropriately accommodate the effect of different materials processed on the following variables:

1. The cost of the die $\left(\mathrm{ACM}_{\mathrm{O}}\right)$ [Section 3.4.2.3]

2. The physical life of the die $\left(A L M_{0}\right)$ [Section 3.4.2.3]

3. The auxiliary equipment requirement and cost ( $\mathrm{ACA})$ [3.4.2.2]

4. The cost of main machine $\left(\mathrm{ACM}_{\mathrm{a}}\right)$ [3.4.2.1]

5. The physical life of main machine $(A L M a)$ [3.4.2.1]

6. Utilities Consumption (AUC) [3.4.1.3]

Table 3.5 shows these adjustment factor values. These values were obtained from [26]. 
Table 3.5 MATERIAL ADJUSTMENT FACTORS [26]

\begin{tabular}{|c|c|l|c|c|c|c|c|}
\hline S.No. & Name & \multicolumn{1}{|c|}{ Description } & $\begin{array}{c}\text { Phenolic } \\
\text { /Glass }\end{array}$ & $\begin{array}{c}\text { Polyester } \\
\text { /Glass }\end{array}$ & $\begin{array}{c}\text { Epoxy } \\
\text { /Glass }\end{array}$ & $\begin{array}{c}\text { Vinylester } \\
\text { /Glass }\end{array}$ & $\begin{array}{c}\text { Epoxy } \\
\text { /Graphite }\end{array}$ \\
\hline 1 & $\mathrm{ACM}_{\mathrm{O}}$ & Adjustment to Cost of Mold & 1.00 & 1.15 & 1.15 & 1.15 & 1.15 \\
\hline 2 & $\mathrm{ALM}_{\mathrm{o}}$ & Adjustment to Life of Mold & 1.00 & 0.80 & 0.80 & 1.00 & 1.00 \\
\hline 3 & $\mathrm{ACA}$ & Adjustment to Cost of Auxiliary Equipment & 1.00 & 1.00 & 1.00 & 1.00 & 1.00 \\
\hline 4 & $\mathrm{ACM}_{\mathrm{a}}$ & Adjustment to Cost of Main Machine & 1.00 & 1.08 & 1.08 & 1.08 & 1.08 \\
\hline 5 & $\mathrm{ALM}$ & Adjustment to Life of Main Machine & 1.00 & 0.70 & 0.70 & 1.00 & 1.00 \\
\hline 6 & $\mathrm{AUC}$ & Adjustment to Utility Cost & 1.00 & 1.12 & 0.96 & 1.12 & 0.75 \\
\hline
\end{tabular}




\subsubsection{Geometry Adjustment Factors:}

The different geometry of a component effects two aspects of the cost of pultruding that component, namely:

1. The cost of the die $\left(\mathrm{GACM}_{0}\right)$ [3.4.2.3]

2. The physical life of the die $\left(G_{A L M}\right)$ [3.4.2.3]

Table 3.6 shows these adjustment factor values. These values were obtained from [26].

Table 3.6 GEOMETRY ADJUSTMENT FACTORS [26]

\begin{tabular}{|c|l|c|c|}
\hline S. No. & \multicolumn{1}{|c|}{ Geometry } & GACM $^{*}$ & GALM $^{*}{ }^{* *}$ \\
\hline 1 & Simple Curved Panels & 1.00 & 1.00 \\
\hline 2 & Complex Curved Panels & 1.10 & 1.00 \\
\hline 3 & Open Box Beams & 1.10 & 1.00 \\
\hline 4 & Closed Box Beams & 1.00 & 1.00 \\
\hline 5 & Hollow Columns & 1.00 & 1.00 \\
\hline 6 & Simple Hollow Containers & 1.00 & 1.00 \\
\hline 7 & Complex Hollow Containers & 1.00 & 1.00 \\
\hline 8 & Complex Solid & 1.15 & 1.10 \\
\hline
\end{tabular}

- * - Geometry Adjustment factor for the Cost of the Mold

- ** - Geometry Adjustment factor for the Life of the Mold 


\subsection{Cost Calculations $(\$ / \mathrm{ft})$}

Data from the inputs, materials, and geometries sections of the model are combined by a series of equations to produce a cost estimate, and these equations are described in detail in this section.

The overall cost components are estimated using:

1. Total Cost $=$ Variable Costs + Fixed Costs

2. Variable Costs $=$ Raw Material + Direct Labor + Indirect Labor + Utilities

3. Fixed Costs $=$ Main Machine + Auxiliary Equipment + Tooling + Tool Setting Operator + Building + Installation + Maintenance + Overhead + Capital Recovery.

This broad categorization of the cost components into fixed and variable possess difficulties in certain cases e.g. direct labor cannot be classified purely as a variable cost because a minimum number of labor employee are required. Similarly, tooling costs can be considered as variable when the production volume is sufficiently large to cause more than one set of tools to be consumed.

\subsubsection{Variable Costs}

These cost elements are cost components whose per unit cost is fixed and is independent of the number of pieces produced. There are four "Variable Cost Elements" accounted for within the model. These are raw material cost, direct labor cost, indirect labor cost and utility cost. 


\subsubsection{Raw Material Cost}

The material cost is calculated using the following seven inputs from the user in "Raw Material Cost Input " form:

1. Cost of each of the component material $(\$ / \mathrm{lb}$.)

2. Density of each of the component material $\left(\mathrm{lb} / \mathrm{in}^{3}\right)$

3. Mix Ratio (Volume \%)

4. Total part weight (lb./ft)

5. Part cross-sectional area $\left(\mathrm{in}^{2}\right)$

6. Start-up and end-squaring losses

7. Any other user specified costs e.g. gluing, surface preparation, secondary operation cost etc.

The volume fraction is converted into weight fraction using the following formula [29]:

$$
W t_{i}=\frac{\rho_{i} V_{i}}{\rho_{1} V_{1}+\rho_{2} V_{2}+\rho_{i} V_{i}----+\rho_{i} V_{i}}
$$

$\rho_{\mathrm{i}}=$ density of $\mathrm{i}^{\text {th }}$ constituent material, where $\mathrm{I}=1$ to $\mathrm{n}$

$V_{i}=$ volume of $i^{\text {th }}$ constituent material, where $\mathrm{I}=1$ to $\mathrm{n}$

The weight fraction of each constituent is then multiplied by the weight of the part to get each constituent weight. This parameter is then multiplied by their respective cost $(\$ / \mathrm{lb}$.$) . These costs are added to get net raw material cost.$ This is then adjusted for start-up and end-squaring scrap losses to get gross 
material costs. Any other user specified costs are then added to this cost to get the total material cost $(\$ / \mathrm{ft})[36]$.

\subsubsection{Direct Labor Cost}

The cost of direct labor is a function of the wages paid, the amount of time required to produce a piece, the number of laborers directly associated with the process, and the productivity of this labor. These wages should not include the cost of supervisory or other overhead labor.

The direct labor cost per foot of the product produced is estimated using the following formula:

\section{Direct Labor $=($ TNSPR - SS $)$ * WDL * NPML * DLPM * NHPS Cost (\$/ft) PPMPR * NPML}

where

TNSPR $=$ total number of shifts required per run

SS = time for set-up and tear down per run (in shifts)

WDL $=$ Wages of Direct Labor $(\$ /$ hour) (Table 3.3)

NPML = number of product manufacturing lines (user input)

DLPM = direct labor requirements per machine (Table 3.4)

NHPS = number of hours/shift (Table 3.3)

PPMPR $=$ production per machine per run (ft) 
TNSPR $=$ SS + PPMPR

$\frac{(60 * \text { line speed }}{12}$ *NHPS )

PPMPR $=\frac{\text { Annual Production }}{\text { Number of runs in a year }{ }^{*} \text { NPML }}$

"WDL" and "NHPS" are exogeneous factors. "DLPM" is process factor.

\subsubsection{Indirect Labor Cost}

This cost component is very similar to direct labor cost component, except that it represents the indirect labor used in manufacturing such as material handling labor.

Indirect labor cost in $\$ / \mathrm{ft}$ is calculated as follows:

Indirect Labor $=($ TNSPR - SS $){ }^{*}$ WIDL * NPML * IDLPM * NHPS Cost (\$/ft)

\section{PPMPR * NPML}

where

TNSPR $=$ total number of shifts required per run

SS $=$ time for set-up and tear down (in shifts)

WIDL = Wages of Indirect Labor (\$/hour) (Table 3.3)

$\mathrm{NPML}=$ number of product manufacturing lines (user input)

IDLPM = Indirect labor requirements per machine (Table 3.4)

NHPS = number of hours/shift (Table 3.3) 
PPMPR = production per machine per run $(\mathrm{ft})$

\subsubsection{Utility Cost}

Ideally, the cost of the consumed energy is estimated by performing an energy balance and by knowing the price of energy. While this sounds simple, performing a detailed energy balance is highly complex. To be accurate the energy balance must include heat losses, mechanical efficiencies, consideration of heat, mass and chemical reaction kinematics.

As a good approximation, it is often possible to estimate energy consumption by relating it to other production variables. e.g. relating energy consumption to pounds of material processed and type of material processed. This approach is acceptable especially when the cost of energy is small compared to the total cost. The following equation is used for calculation of energy in the model in terms of $\$ / \mathrm{ft}$ :

\section{Utility Cost $(\$ / f t)=W P F * A U C * U C P * P U$}

where

WPF = weight (lb.) of the product in pounds per linear foot (user input)

AUC $=$ material adjustment to utility cost (Table 3.5)

$\mathrm{UCP}=$ utility consumption rate of the process $(\mathrm{kWh} / \mathrm{lb}$.) (Table 3.4)

$\mathrm{PU}=$ price of utility $(\$ / \mathrm{kWh})($ Table 3.3$)$ 
"AUC" is a material adjustment factor dependent on the material being processed. "UCP" is a process factor, which specifies the average amount of energy, consumed per pound of material that is processed and it includes energy consumed for heating, cooling and mechanical transport of the material. "PU" is an exogeneous factor and specifies the cost of energy in dollars per kilowatt-hour. It is assumed that all of the energy consumed is electrical.

\subsubsection{Fixed Costs}

Fixed cost are those cost components, whose total over a given period of time is fixed. They are typically one-time capital investments (e.g. building, machinery or tools) or annual expenses, which are incurred independent of the products manufactured (e.g. building rents, engineering and supervisory overhead, administrative salaries). These costs are distributed over the total number of components manufactured during that period. Hence, the higher the volume of production in the period, lower the fixed cost per unit. The model considers and calculates following "Fixed Cost Elements" [38]:

1. Main Machine Cost

2. Auxiliary Equipment Cost

3. Die Cost

4. Tool Setting Operator Cost

5. Building Cost

6. Installation Cost 
7. Maintenance Cost

8. Overhead Cost

9. Cost of Capital

The two basic problems to be resolved in calculating fixed cost components (e.g. main machine, die and building cost) is first, establishing the amount of capital investment and second, determining the most reasonable basis for distributing this investment over the products manufactured. The main machine, die and building costs are distributed over the products manufactured during their calculated lifetimes.

\subsubsection{Main Machine Cost}

The total cost of the main machine is usually a direct function of its size. Equipment size, in turn, is related to its capacity on terms of output in feet per hour.

Once the size of the machine has been established, the investment cost is established using statistical analysis to correlate equipment cost data to the capacity parameter. These regression parameters were obtained from [26] and required corrections were made after discussion with Mr. Dustin Troutman [12]. The regression plot and the equation are shown in Figure 3.2.

The following equation has been used to estimate the total machine cost:

\section{Total Machine Cost (\$)}

$=\mathrm{NPML} *{ }^{*} \mathrm{ACM}_{\mathrm{a}}{ }^{*} 10^{((0.78 * \text { LOG (gross output (ft/hour) }))+4.65)}$ 


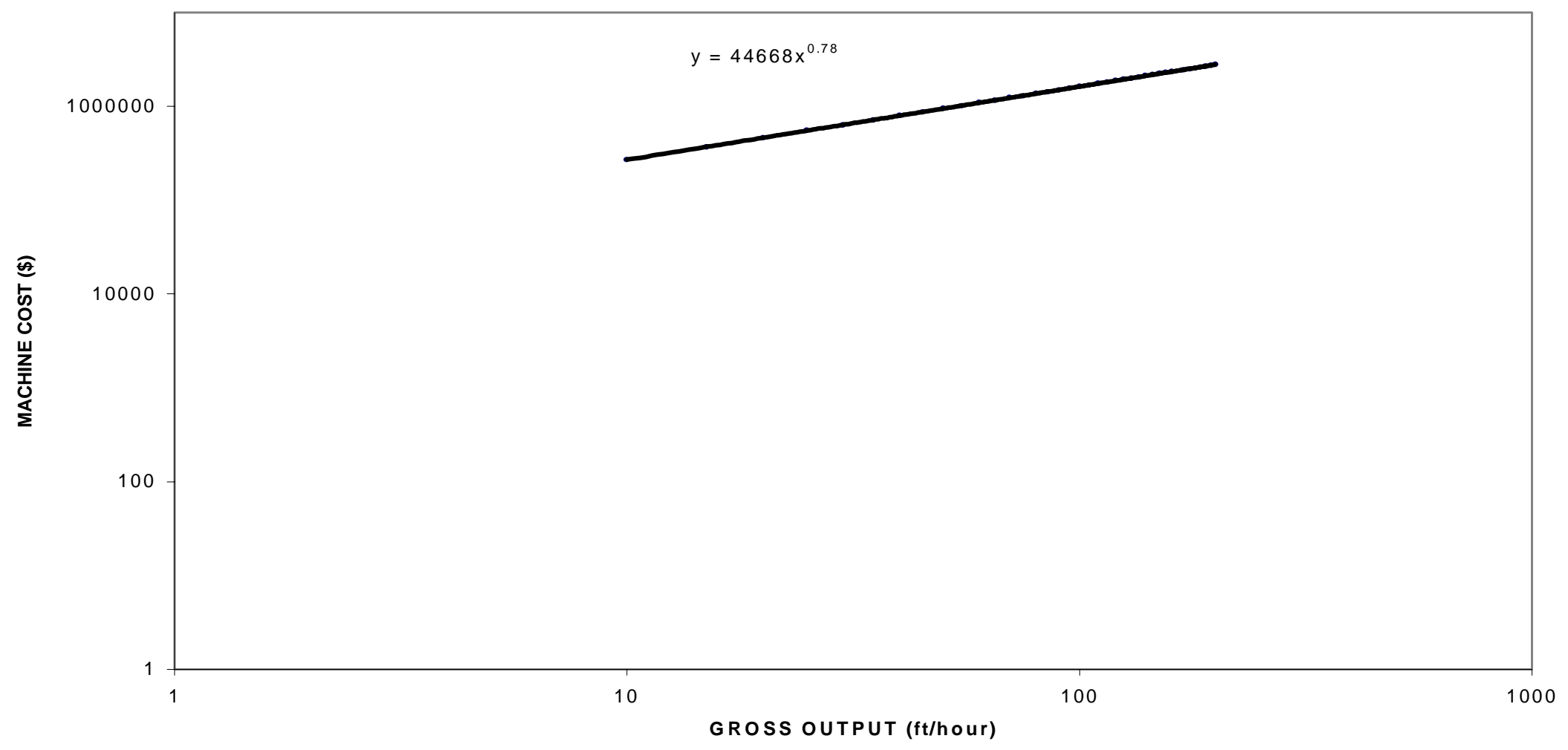

Figure 3.2 PLOT FOR MACHINE COST REGRESSION PARAMETERS [26] 
$=\mathrm{NPML} * A C M_{\mathrm{a}}$ * 44668 * gross output (ft/hour) ${ }^{0.78}$

where

$\mathrm{NPML}=$ number of product manufacturing lines (user input)

$\mathrm{ACM}_{\mathrm{a}}=$ material adjustment to cost of machine (Table 6)

Gross output $=$

PPMPR

(ft/hour)

60* line speed * NHPS * PUMS * (1- start-up \& tear down scrap $){ }^{*}(1$ - end scrap)

" $A C \mathrm{a}_{\mathrm{a}}$ " is material adjustment factor for the cost of main machine and is selected corresponding to the user-selected material. Gross output is calculated considering the annual production and losses.

The following equation is used to calculate the main machine cost in $\$ / \mathrm{ft}$ :

\section{Main machine cost $(\$ / \mathrm{ft})=\underline{\text { Total machine cost }}$ * PTFUP CRLM * annual production}

where

PTFUP $=$ proportion of time the facility is used in a year for manufacturing product under consideration 


$$
\text { PTFUP }=\frac{\text { TNSPR }^{*} \text { number of runs in a year }}{\text { WDCY }{ }^{*} \text { NSPD }}
$$

where

$$
\begin{aligned}
& \text { WDCY = working days per calendar year (Table 3.3) } \\
& \text { NSPD = number of shifts per day (Table 3.3) }
\end{aligned}
$$

The above equation is most applicable considering that we are assuming that many different parts are produced with the same machine i.e. non-dedicated facility. Thus, here we multiply the total annualized investment by a fraction, the ratio of the time required to complete the production run to the total available time. If only half a year is required for the production run, only half of the annual investment cost will be distributed onto those components.

\subsubsection{Auxiliary Equipment Cost}

It is possible to identify auxiliary equipment requirements from the product information such as its size, material used etc. and investment requirements for these equipments can be determined from vendor literature, regression analysis, and/or handbooks.

This whole procedure can be simplified to get estimates by assuming the ratio of the cost of the auxiliary equipment to the cost of the main machine is constant [26]. Then adjustment to this estimated cost is done for the 
material being processed. The following equation is used to calculate total auxiliary equipment cost:

\section{Total Auxiliary Equipment Cost (\$)}

$=A C * A C A$ * total machine cost

where

$\mathrm{AC}=$ Auxiliary equipment cost as fraction of machine cost (Table 3.4)

$\mathrm{ACA}=$ material adjustment to cost of auxiliary equipment (Table 3.5)

Here, "AC" is the process factor, which defines the percent of the main machine cost, which must be added to account for expenditures on auxiliary equipment. "ACA" is material adjustment factor for the cost of the auxiliary equipment.

The life over which this cost is to be recovered is assumed to be same as that of the main machine. If required, user can input his own value to override this default value. As, these auxiliary equipments are also assumed to be used for different products, the logic of cost calculation $(\$ / \mathrm{ft})$ remains same as that used for the main machine cost. The following equation is used:

\section{Auxiliary Equipment $=$ total auxiliary equipment cost * PTFUP Cost (\$/ft)}




\subsubsection{Die Cost}

It is difficult to accurately estimate the investment cost of a die set for pultrusion process. There are many variables such as die material, design and size of the part, the level of process automation etc which contribute to the investment cost of the die. Because dies are often procured from outside, some other variables such as pricing policy of vendors, the manufacturing process used to fabricate the die etc. This model uses regression analysis to correlate the investment cost with the output in feet per hour. These regression parameters were obtained from [26] and modified after discussion with Mr. Troutman [12]. Figure 3.3 shows this regression line and equation. Following equation is used to estimate the total cost of the die (\$):

\section{Total Die Cost(\$)}

$=\mathrm{NPML} * \mathrm{ACM}_{\mathrm{O}}{ }^{*} \mathrm{GACM}_{\mathrm{O}}{ }^{*} 10^{(0.74 * \mathrm{LOG} \text { (gross output (ft/hour)) + 3.75) }}$

$=\mathrm{NPML}$ * $\mathrm{ACM}_{\mathrm{o}}$ * $\mathrm{GACM}_{0}$ * 5623 * gross output (ft/hour) 0.74

where

$$
\begin{aligned}
& \mathrm{ACM}_{\mathrm{o}}=\text { material adjustment to cost of mold } \\
& \mathrm{GACM}_{\mathrm{o}}=\text { geometry adjustment to cost of mold }
\end{aligned}
$$

Here, "ACMo" is the material adjustment factor introduced because different product materials pultruded effects the cost of the die. "GACM ${ }_{0}$ " is the 


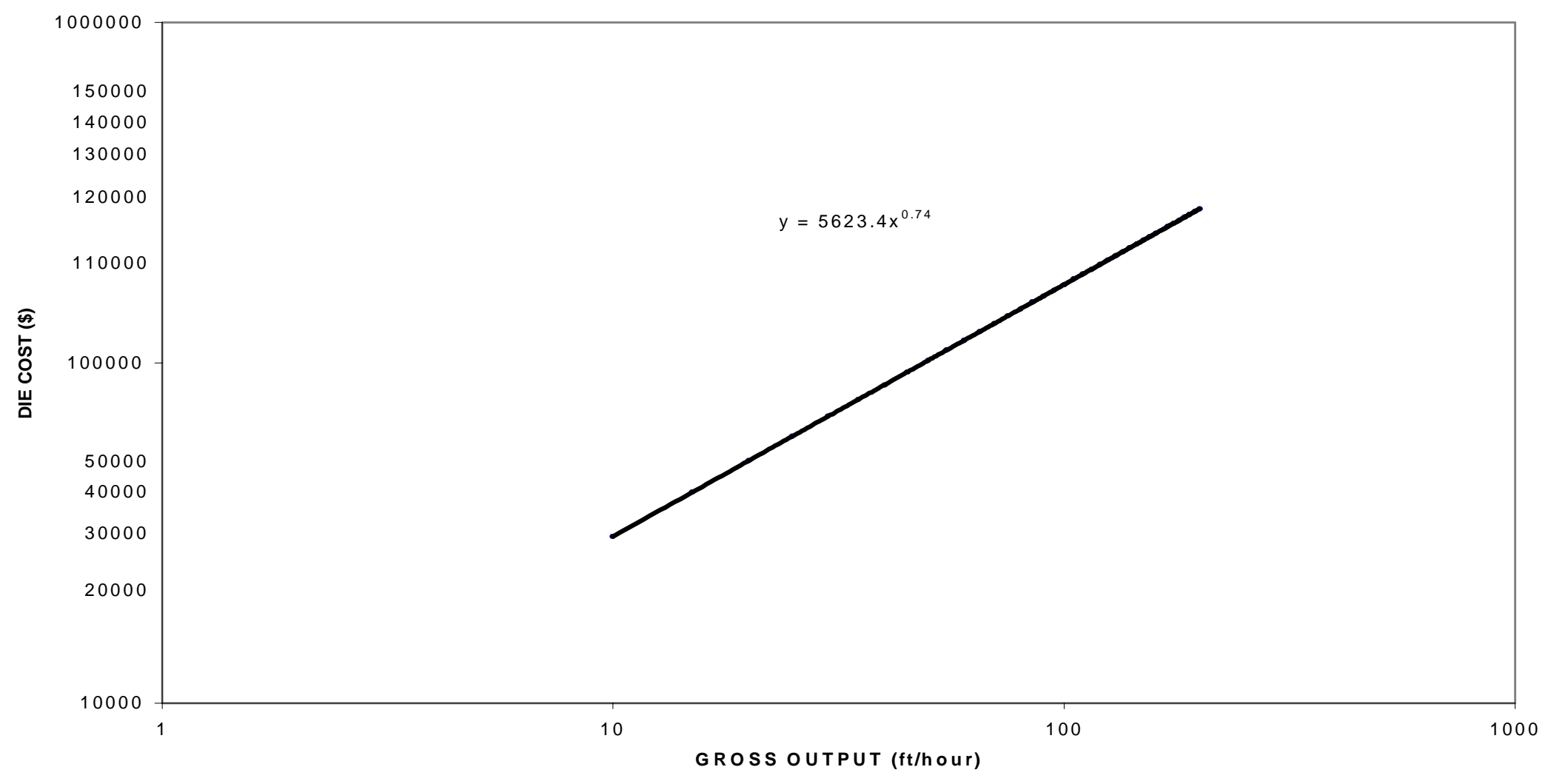

Figure 3.3 PLOT FOR DIE COST REGRESSION PARAMETERS [26] 
geometry adjustment factor to account for cost differences, which arise from the various possible shapes of components considered in this model.

The investment calculated is than allocated to the products manufactured over the predicted life of the die by the following equation:

Cost of tool $(\$ / f t)=$ total die cost

\section{annual production * CRLD}

where

$$
\text { CRLD = capital recovery life of the die (Table 3.4) }
$$

\subsubsection{Tool Setting Operators Cost}

The next cost component calculated is the tool setting operators cost. Here it is assumed that tool-setting operators are different from direct labor. This is a unique feature, which has been provided in this model. The following equation is used for calculating this cost component $(\$ / \mathrm{ft})$ :

\section{Tool Setting Operator $=$ WSL * NTSO * SS * NHPS Cost (\$/ft) PPMPR}

where

$$
\begin{aligned}
& \text { WSL = wages of set-up labor ( } \$ / f t) \text { (Table 3.3) } \\
& \text { NTSO = number of tool setting operators (user input) } \\
& \text { SS = set-up \& tear down time (shifts) (user input) }
\end{aligned}
$$




\subsubsection{Building Cost}

The building investment cost can be readily estimated if we can estimate the amount of space required and the price per square foot of factory floor space. The first of these parameters can be obtained from equipment vendors, or estimated using regression coefficients as shown below [26]:

\section{Building area $\left(\mathrm{ft}^{2}\right)$}

$$
\begin{aligned}
& =10^{((0.5 * \text { LOG (gross output (ft/hour) })+3.47)) *(1+0.3 *(\text { NPML }-1))} \\
& =2951{ }^{*} \text { gross output }(\text { ft/hour }){ }^{0.5 *}(1+0.3 *(\text { NPML - 1)) }
\end{aligned}
$$

The second term estimates the additional floor space needed for more than one parallel manufacturing line. Figure 3.4 shows the regression line and equation for the above used coefficients.

This calculated floor space is then used to calculate the total building cost (\$) as follows:

\section{Total Building Cost $(\$)=$ building area * PFFS}

where

PFFS $=$ price of floor space per square foot and is exogeneous factor. (Table3.3) 


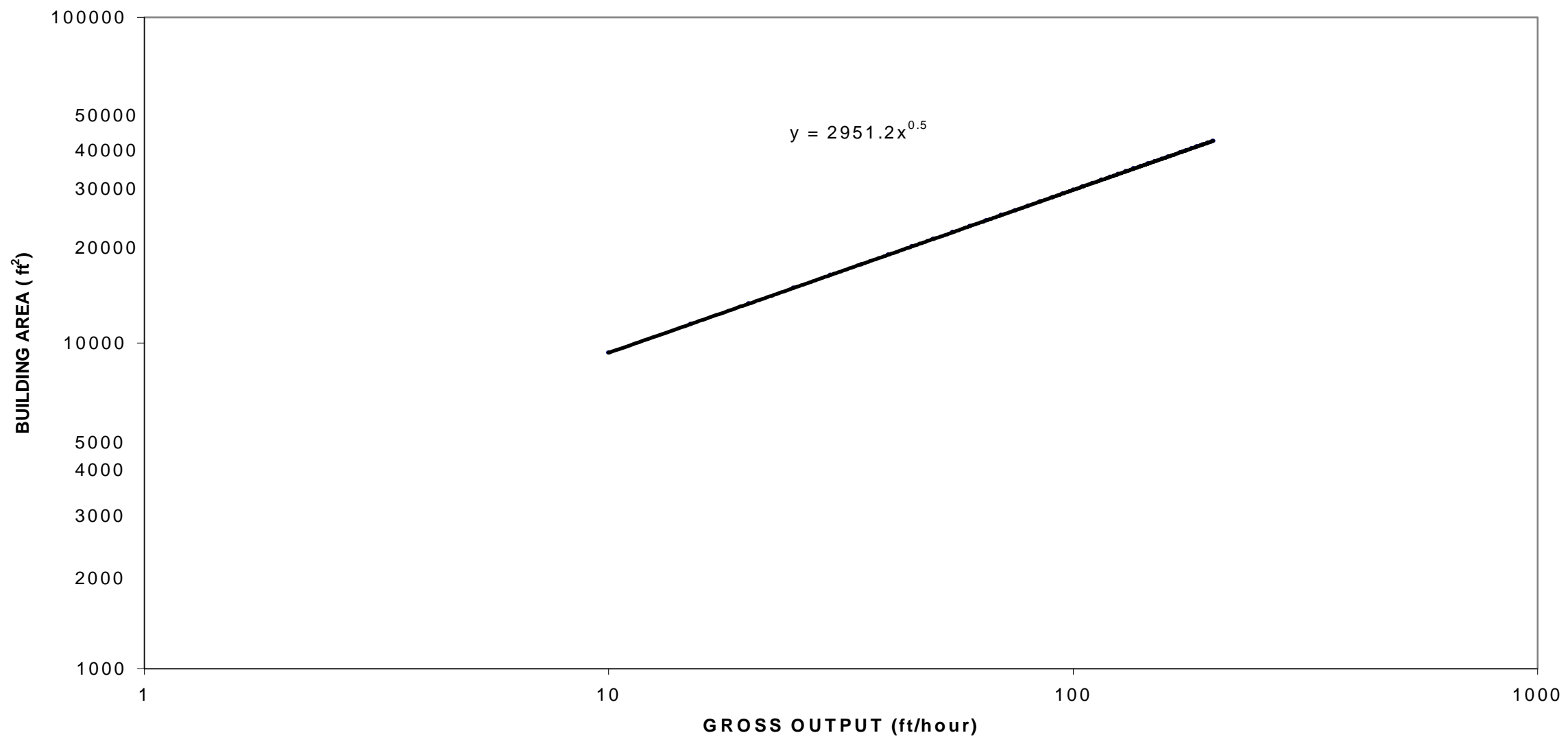

Figure 3.4 PLOT FOR BUILDING AREA REGRESSION PARAMETERS [26] 
This total building cost is distributed over the parts produced using the following equation:

Building Cost $(\$ / \mathrm{ft})=\frac{\text { total building cost * PTFUP }}{\text { DLB * annual production }}$

where

DLB $=$ depreciation life of the buildings, an exogeneous factor (Table 3.3)

As before, non-dedicated facility is considered.

\subsubsection{Installation Cost}

Installation cost is estimated as a fraction of the main machine cost as follows:

Installation Cost $(\$ / \mathrm{ft})=$ main machine cost ${ }^{*} \mathrm{IC}$

where

$$
\begin{aligned}
I C= & \text { fraction of main machine cost as the installation cost component, } \\
& \text { a process variable (Table } 3.4)
\end{aligned}
$$

Installation costs are distributed over the life of the main machine. 


\subsubsection{Maintenance Cost}

It is reasonable to assume this cost as a fraction of the machine cost and is computed as follows:

\section{Maintenance Cost $(\$ / \mathrm{ft})=$ main machine cost ${ }^{*} \mathrm{MC}$}

where

$$
\begin{aligned}
M C= & \text { fraction of main machine cost as the maintenance cost and is a } \\
& \text { process variable (Table } 3.4)
\end{aligned}
$$

This cost is distributed uniformly over the life of the equipment.

\subsubsection{Overhead Cost}

In this model, the overhead cost is estimated as a fraction of other fixed costs. Also, the model assumes that overhead is independent of production volume, which may not be entirely true, because as production volume increases, the overhead requirements will also generally increase.

Overhead cost component is estimated as:

Overhead Cost $(\$ / f t)=$ fixed costs ${ }^{*} O C$ 
where

$$
\begin{aligned}
\mathrm{OC}= & \text { fraction of total fixed costs as the overhead cost and is a process } \\
& \text { variable (Table 3.4) }
\end{aligned}
$$

\subsubsection{Capital Recovery Cost}

The cost of capital is a fixed cost component introduced to account for the time value of money. It is equivalent to the interest portion of a loan payment brought to the present value. This cost component is considered fixed because its total value is independent of the production volume. However, on a piece cost basis, the cost of capital varies inversely with production volume. This component is calculated individually for each of the capital investments i.e. main machine, die, auxiliary equipment and building. The following formula is used for each of this individual capital cost calculation [35]:

Capital Cost $(\$ / f t)=\frac{\sum(\operatorname{TCCPV}(\mathbf{i}) / \mathbf{n}(\mathbf{i}))}{\text { annual production }}$

where

$\mathrm{n}=$ life of the particular asset whose capital cost is calculated (years)

TCCPV $=$ total capital cost present value for a particular asset

$\operatorname{TCCPV}(\$)=n *\left[\frac{\left(R^{*} P\right)-A}{1+R}\right]+A *\left[\frac{(1+R)^{n}-1}{R(1+R)^{n}}\right]$ 
where

$\mathrm{R}=$ rate of return on capital, an exogeneous factor (Table 3.3)

$\mathrm{P}=$ capital investment for the particular asset whose capital cost is calculated

$A=$ equal installment paid each year during the life of the asset.

$A(\$)=P *\left[\frac{R^{*}(1+R)^{n}}{(1+R)^{n}-1}\right]$

The term within the parenthesis is the capital recovery factor.

Once, this capital cost $(\$ / \mathrm{ft})$ is calculated using Equation 25 for each capital investment, they are added up to get total capital cost.

\subsection{Cost Calculations (\$/hour)}

The previous section calculated different cost components on quantity basis, which is helpful in quoting rates to clients. This section calculates cost on time basis ( $\$ /$ hour) which is particularly used by companies for purpose of cost control. The equations used for calculation of different cost elements on time basis are shown below. 
3.5.1 Variable Costs

3.5.1.1 Raw Material Cost

$$
\begin{aligned}
& \text { Raw Material Cost }=\frac{\text { Raw Material Cost }(\$ / \mathrm{ft}){ }^{*} \text { PPMPR }}{(\$ / \text { hour })} \\
& \text { TNSPR }{ }^{*} \text { NHPS }
\end{aligned}
$$

\subsubsection{Direct Labor Cost}

$$
\begin{aligned}
& \text { Direct Labor Cost }=(\text { TNSPR-SS }) \text { * WDL * DLPM } \\
& \text { (\$/hour) } \\
& \text { TNSPR }
\end{aligned}
$$

3.5.1.3 Indirect Labor Cost

$$
\begin{aligned}
& \text { Indirect Labor Cost }=\frac{(\text { TNSPR-SS }) * \text { WIDL * IDLPM }}{\text { (\$/hour })} \\
& \frac{\text { TNSPR }}{}
\end{aligned}
$$

\subsubsection{Utility Cost}

$$
\begin{array}{ll}
\text { Utility Cost }= & \text { Utility Cost }(\$ / \mathrm{ft}){ }^{*} \mathrm{PPMPR} \\
{)} } & \text { TNSPR * NHPS }
\end{array}
$$

\subsubsection{Fixed Costs}

\subsubsection{Main Machine Cost}

$\begin{array}{ll}\text { Main Machine Cost }= & \text { Total Machine Cost } \\ {)} } & \text { Machine Life * TNHPY * NPML }\end{array}$


where

TNHPY $=$ total number of hours per year

TNHPY (hours) $=$ WDCY * NSPD * NHPS * PUMS

\subsubsection{Auxiliary Equipment Cost}

Auxiliary Equipment Cost $=$ total auxiliary equipment cost

(\$/hour)

AEL * TNHPY * NPML

where

$A E L=$ auxiliary equipment life

AEL is assumed to be same as main machine life. However, the user has an option to enter different auxiliary equipment life and then this new life will be considered in calculations.

\subsubsection{Die Cost}

Cost of tool $=$

total die cost

(35)

(\$/hour)

die life * NPML * NHPS * no. of runs * TNSPR

\subsubsection{Tool Setting Operator Cost}

Tool Setting Operator $=\frac{\text { WSL * NTSO * SS }}{\text { Cost }(\$ / \text { hour })}$


3.5.2.5 Building Cost

Building Cost $=\frac{\text { total building cost }}{(\$ / \text { hour })}$
DLB ${ }^{*}$ TNHPY

3.5.2.6 Installation Cost

Installation Cost $=$ main machine cost ${ }^{*} I C$

(\$/hour)

3.5.2.7 Maintenance Cost

Maintenance Cost $=$ main machine cost ${ }^{*}$ MC

(39)

(\$/hour)

3.5.2.8 Overhead Cost

Overhead Cost $=$ fixed costs ${ }^{*} \mathrm{OC}$

(\$/hour)

\subsubsection{Capital Recovery Cost}

Capital Cost $=$ TCCPV

(\$/hour)

TNHPY 


\section{Chapter 4}

\section{COSTING OF BRIDGE DECK}

\subsection{Why Bridge Deck?}

The transportation infrastructure of the United States was worth more than $\$ 2.5$ trillion dollars in 1996 , and the transportation related activities account for about $20 \%$ of the U.S. gross domestic products. Approximately $\$ 120$ billion is spent annually towards construction, operation and maintenance of transportation network, which includes nearly $\$ 100$ billion for maintenance itself [41]. Even marginal investments in research of new materials and technologies can lead to enormous saving by developing new low maintenance, easy to fabricate materials and technologies.

Recent applications of polymer composites are in the construction and maintenance of civil structures. However, the major obstacle in the widespread of polymer composites is the high initial construction cost compared to traditional concrete bridge decks. This is because of the large cost differential in the raw material costs and the high manufacturing costs of the polymer composites. Considering this problem and realizing the potential of enormous saving that can be obtained, Bridge Deck has been selected for analysis in this thesis (Figure 4.1). 


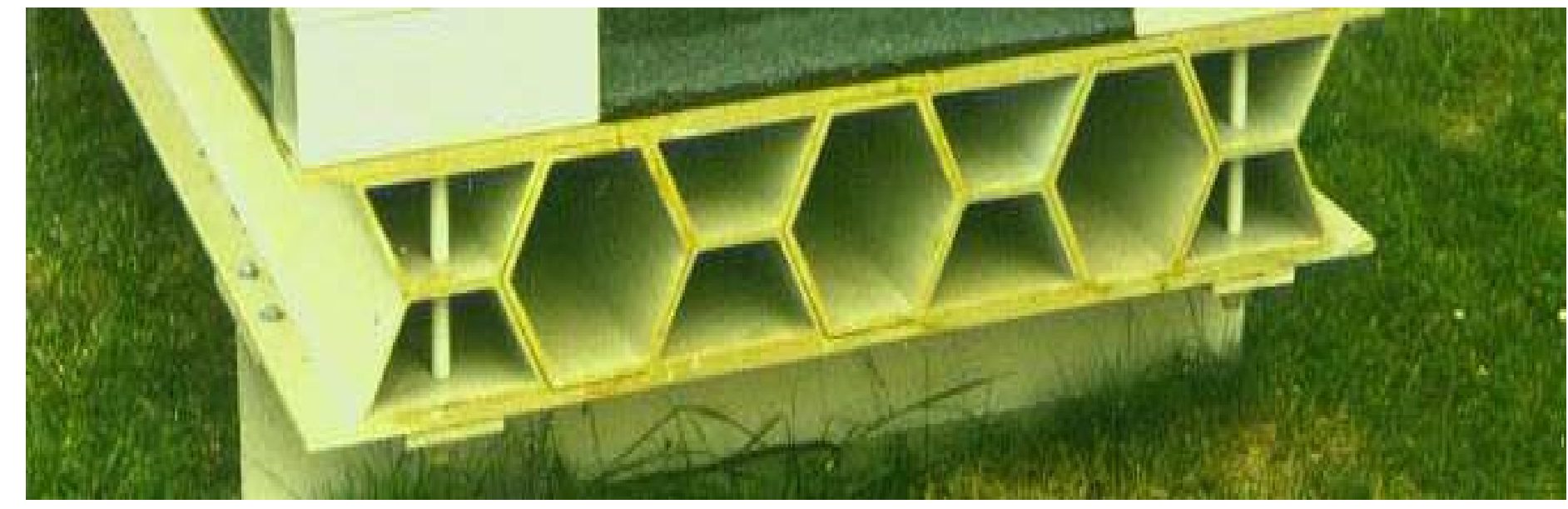

Figure 4.1 BRIDGE DECK PRODUCT DIAGRAM 


\subsection{Bridge Deck Cost Elements}

The following cost components constitute the total cost for Bridge Deck:

\section{VARIABLE COSTS:}

1. Total Raw Material Cost

2. Direct Labor Cost

3. Indirect Labor Cost

4. Utility Cost

\section{FIXED COSTS}

5. Main Machine Cost

6. Auxiliary Equipment Cost

7. Tooling Cost

8. Tool Setting Operator Cost

9. Building Cost

10. Installation Cost

11. Maintenance Cost

12. Overhead Cost

13. Cost of Capital

All the above cost elements are calculated on quantity ( $\$ / \mathrm{ft})$ as well as time (\$/hour) basis as discussed in Sections 3.4 and 3.5. The specifics of the Bridge Deck needed for calculating different cost components are given in Table 4.1 and Table 4.2. The results are summarized in Table 4.3. 
Table 4.1 BRIDGE DECK INPUT PARAMETERS [36,37]

\begin{tabular}{|l|c|}
\hline \multicolumn{1}{|c|}{ Parameter Name } & Value \\
\hline Selected Material & Vinylester/Glass \\
\hline Selected Geometry & Closed Box Beams \\
\hline Weight (Ibs/ft) & 22.00 \\
\hline Cross-Sectional Area (in ${ }^{2}$ ) & 29.00 \\
\hline Annual Production (ft) & 10,000 \\
\hline Number of Runs & 4 \\
\hline Line Speed (in/min) & 5 \\
\hline Set-Up \& Tear-Down Time (shifts) & 3 \\
\hline Number of Cavities/Die & 1 \\
\hline Tool Provided by Client & No \\
\hline Start-Up \& Tear-Down Scrap (\%) & $5.00 \%$ \\
\hline End-Squaring Losses (\%) & $1.00 \%$ \\
\hline Number of Product Manufacturing Lines & 1 \\
\hline
\end{tabular}

Table 4.2 BRIDGE DECK MATERIAL INPUT [36,37]

\begin{tabular}{|l|c|c|c|}
\hline Raw Material & Cost (\$/lb) & Density $\left(\mathbf{I b} / \mathbf{i n}^{\mathbf{3}}\right)$ & Mix Ratio (Vol\%) \\
\hline Mat & $\$ 0.80$ & 0.094 & $42.00 \%$ \\
\hline Roving & $\$ 0.60$ & 0.094 & $13.00 \%$ \\
\hline Resin & $\$ 0.59$ & 0.041 & $12.00 \%$ \\
\hline Filler & $\$ 0.29$ & 0.050 & $26.50 \%$ \\
\hline Initiator & $\$ 12.00$ & 0.050 & $0.50 \%$ \\
\hline Veils & $\$ 2.00$ & 0.008 & $6.00 \%$ \\
\hline Other Costs $(\$ / f t)$ & $\$ 8.00$ & & \\
\hline
\end{tabular}


Table 4.3 SUMMARY OF COST OUTPUT

\begin{tabular}{|c|c|c|c|c|}
\hline & $\begin{array}{c}\text { Total Cost } \\
(\$)^{*}\end{array}$ & $\$ / f t$ & \$/hour & $\%$ of total cost \\
\hline Total Material Cost & & $\$ 24.44$ & $\$ 468.86$ & $58.25 \%$ \\
\hline Direct Labor Cost & & $\$ 1.28$ & $\$ 24.48$ & $3.04 \%$ \\
\hline Indirect Labor Cost & & $\$ 0.64$ & $\$ 12.24$ & $1.52 \%$ \\
\hline Utility Cost & & $\$ 0.49$ & $\$ 9.45$ & $1.17 \%$ \\
\hline Total Variable Cost & & $\$ 26.83$ & $\$ 515.03$ & $63.98 \%$ \\
\hline Main Machine Cost & 72406 & $\$ 1.50$ & $\$ 28.73$ & $3.57 \%$ \\
\hline Auxiliary Equipment Cost & 21722 & $\$ 0.45$ & $\$ 8.62$ & $1.07 \%$ \\
\hline Tooling Cost & 17206 & $\$ 1.72$ & $\$ 33.01$ & $4.10 \%$ \\
\hline Tool Setting Operator Cost & 15360 & $\$ 1.54$ & $\$ 29.46$ & $3.66 \%$ \\
\hline Building Cost & 23324 & $\$ 0.48$ & $\$ 9.26$ & $1.15 \%$ \\
\hline Installation Cost & 14481 & $\$ 0.30$ & $\$ 5.75$ & $0.71 \%$ \\
\hline Maintenance Cost & 7241 & $\$ 0.15$ & $\$ 2.87$ & $0.36 \%$ \\
\hline Overhead Cost & 227519 & $\$ 7.56$ & $\$ 144.98$ & $18.01 \%$ \\
\hline Cost of Capital & 55779 & $\$ 1.42$ & $\$ 27.28$ & $3.39 \%$ \\
\hline Total Fixed Cost & 455038 & $\$ 15.12$ & $\$ 289.95$ & $36.02 \%$ \\
\hline Total Cost & & $\$ 41.96$ & $\$ 805.00$ & \\
\hline Sales Price (\$) & & $\$ 50.36$ & $\$ 966$ & \\
\hline Total Annual Sales & & $\$ 503,569$ & $\$ 503,569$ & \\
\hline
\end{tabular}

* Total cost (\$) is applicable only for fixed costs. These total costs are on annual basis and are then appropriated for the Bridge Deck product by the proportion of time the facility is used for this product. 
The results from the model showed that material cost is the largest percentage of the total cost. The other major cost components were overhead and labor cost. The result summary provides the direction for sensitivity analysis in the next chapter.

Detailed sensitivity analysis of material cost is done to find the effect of different percentage changes in the cost of material constituents on the total cost. The $\$$ /hour calculation of cost components in the result sheet is very useful to the management in identifying the major manufacturing cost drivers for this product.

The result sheet gives the sale price, which is calculated by adding the profit to the total costs. The user provides this profit percentage. Also, the total annual sales figure is calculated for the product. It is important to note that the sales figure provided by the two completely different methods of calculation (time and quantity) are same which justifies the equivalency of the two methods despite of their different purposes.

\subsection{Model Validation}

The model developed for costing of products manufactured using pultrusion process, was validated obtaining major cost components from pultrusion manufacturer. The manufacturer did not reveal their cost estimating process, but did give some general estimate values, which were used to calibrate the model. The comparison of estimates given by the manufacturer 
with those of values calculated by the model for Bridge Deck product is discussed below:

1. The total cost as provided by the manufacturer were $45.00 \$ / \mathrm{ft}$ and $350.00 \$ /$ hour excluding material costs. Against these, the model estimated the total cost to be $41.96 \$ / \mathrm{ft}$ and $336.14 \$ /$ hour respectively, giving a very small deviation of approximately $7 \%$ on cost in $\$ / f t$ and $4 \%$ on $\$$ hour.

2. Approximate material cost provided was $25.00 \$ / \mathrm{ft}$ and the cost estimated by the model was $24.44 \$ / \mathrm{ft}$, again deviating by a very small amount of approximately $2 \%$. The model estimated the material cost to be $58.25 \%$ of the total cost against the benchmark data of $50-60 \%$

3. Main machine cost and tooling cost provided was approximately $\$ 500,000$ and $\$ 60,000$ approximately and that calculated by the model is $\$ 499,006$ and $\$ 60,508$.

Other than these cost comparisons, confirmation on many of the factors used in the calculations such as WDL, WSL, WDCY, PU, PUMS, IC, AC, DLPM, MC etc were obtained from this and other manufacturer sources. 


\section{Chapter 5}

\section{SENSITIVITY ANALYSIS OF BRIDGE DECK}

\subsection{Introduction to Sensitivity Analysis}

Sensitivity analysis is the technique of systematically varying one or more input parameters and examining the effect of these variations on the output of interest which is total cost $(\$ / \mathrm{ft})$ in this study e.g. sensitivity analysis can be used to quantify the effect of changes in line speed over the total cost. It can be seen as a tool for trying different combinations of production parameters to arrive at a combination which will give acceptable total cost $(\$ / f t)$.

Sensitivity analysis is important because of the fact that uncertainty surrounds all variables in a cost estimate. Given uncertainty, sensitivity analysis can be used to quantify the effect of change in one variable on the total cost. By knowing the extent to which changes in input parameters changes total cost, it is possible to identify the most important cost drivers, and focus attention on ascertaining their actual values. This tool is applied to case examples since the impact of a given parameter will vary depending on the specifics of the example. Sensitivity analysis is illustrated on the Bridge Deck product. 
Provision for performing sensitivity analysis on any product by changing the following parameters has been made in the model:

1. Total Raw Material Cost

2. Mat1 Cost, Mat2 Cost, Mat3 Cost

3. Roving1 Cost, Roving2 Cost, Roving3 Cost

4. Resin1 Cost, Resin2 Cost

5. Filler1 Cost, Filler2 Cost

6. Initiator1 Cost, Initiator2 Cost

7. Veils Cost

8. Direct Labor Cost

9. Utility Cost

10. Set-Up \& Tear-Down Time

11. Overhead Cost

12. Line Speed

13. Start-Up \& Tear-Down Scrap

14. End-Squaring Losses

15. Annual Production 


\subsection{Sensitivity Analysis on BridgeDeck (\$/ft)}

The sensitivity analysis was performed on BridgeDeck product and the results are discussed below:

\subsubsection{Raw Material Cost:}

The change in this parameter will uniformly change the cost $(\$ / \mathrm{lb})$ of all raw materials and recalculate the total cost. This is particularly useful to determine the effect of uniform quantity discount obtained because of bulk purchases of raw materials. Raw material cost component was varied from $60 \%$ to $+20 \%$ and the results are shown in Table 5.1 and Figure 5.1. The total cost ranges from $32.10 \$ / \mathrm{ft}$ to $45.25 \$ / \mathrm{ft}$. The results indicate that, $10 \%$ change in raw material cost gives approximate $4 \%$ reduction in total cost. Hence, it can be concluded that the total cost can be appreciably reduced if the raw material quantity discounts are availed by increasing the volume of production.

\subsubsection{Mat Cost:}

This is the major material constituent, contributing approximately $56 \%$ by weight and $60 \%$ by value. The sensitivity of change in price of this raw material constituent on the total cost was tested by varying the price from $60 \%$ to $+20 \%$. This gave the total cost in the range of $35.69 \$ / \mathrm{ft}$ to $44.06 \$ / \mathrm{ft}$. The results are summarized in Table 5.2 and graph in Figure 5.2. The total cost is reduced by approximately $2.5 \%$ with $10 \%$ reduction in mat cost. 
Table 5.1 CHANGE IN TOTAL COST WITH \% CHANGE IN RAW MATERIAL COST

\begin{tabular}{|l|c|c|c|c|c|}
\hline$\%$ Change in Raw Material Costs & $-60 \%$ & $-40 \%$ & $0 \%$ & $10 \%$ & $20 \%$ \\
\hline Total Cost (\$/ft) & $\$ 32.10$ & $\$ 35.39$ & $\$ 41.96$ & $\$ 43.61$ & $\$ 45.25$ \\
\hline
\end{tabular}

Table 5.2 CHANGE IN TOTAL COST WITH \% CHANGE IN MAT COSTS

\begin{tabular}{|l|c|c|c|c|c|}
\hline$\%$ Change in Mat Costs & $-60 \%$ & $-40 \%$ & $0 \%$ & $10 \%$ & $20 \%$ \\
\hline Total Cost (\$/ft) & $\$ 35.69$ & $\$ 37.78$ & $\$ 41.96$ & $\$ 43.01$ & $\$ 44.06$ \\
\hline
\end{tabular}




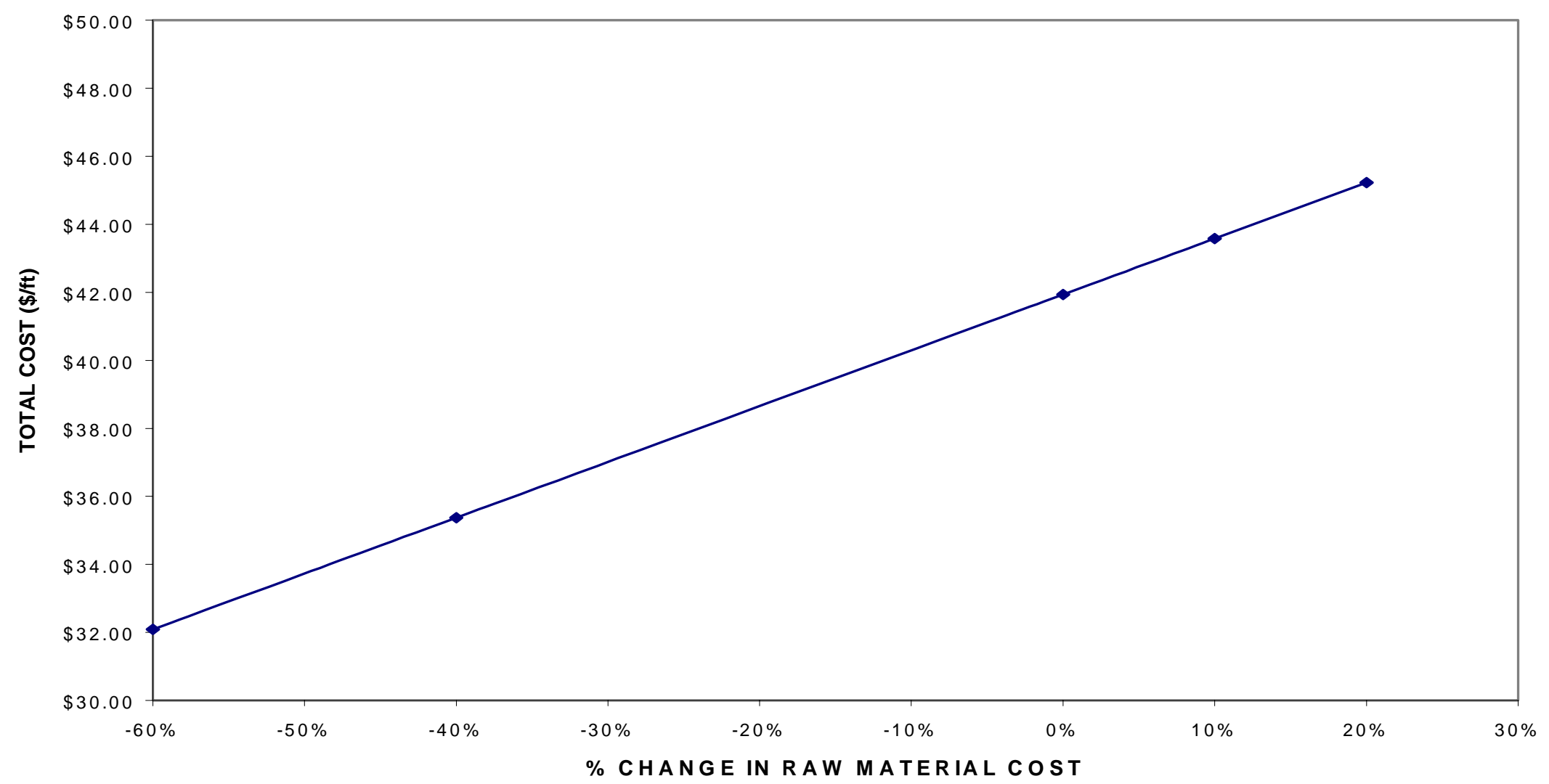

Figure 5.1 RAW MATERIAL COST SENSITIVITY GRAPH 


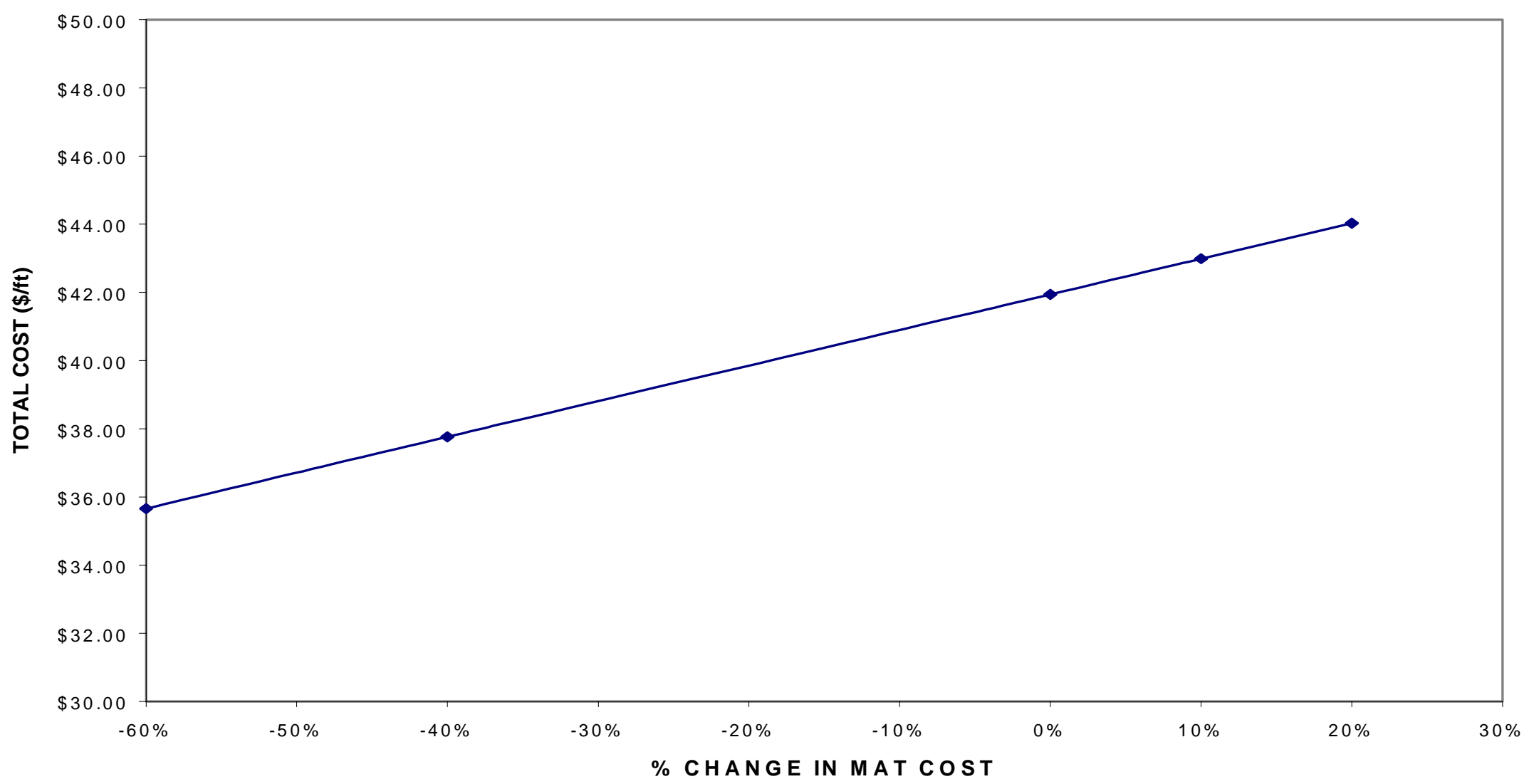

Figure 5.2 MAT COST SENSITIVITY GRAPH 


\subsubsection{Roving Cost:}

This material constituent is approximately $17 \%$ by weight and $14 \%$ by value in the product. The sensitivity analysis performed varied the price from $60 \%$ to $+20 \%$ and the total cost obtained was from $40.51 \$ / \mathrm{ft}$ to $42.45 \$ / \mathrm{ft}$ respectively. The results are presented in Table 5.3 and in Figure 5.3. Approximately $1 \%$ reduction in total cost is observed for every $10 \%$ reduction in roving cost.

\subsubsection{Resin Cost:}

This liquid component is approximately $7 \%$ by weight in the product. The price was varied in the range $-60 \%$ to $+20 \%$ for sensitivity analysis purposes. The total cost calculated by the model was $41.39 \$ / \mathrm{ft}$ to $42.16 \$ / \mathrm{ft}$ respectively. The results are summarized in Table 5.4 and Figure 5.4. A 10\% change in resin cost results in approximately $0.25 \%$ change in total cost.

\subsubsection{Filler Cost:}

Filler is mainly added as a cheap substitute to make volume fraction total $100 \%$, reducing the added proportion of other costly constituents. It also imparts desired special properties such as fire retardancy to the product. This material is approximately $19 \%$ by weight. Its price was varied from $-60 \%$ to $+20 \%$ like other raw material constituents for sensitivity analysis and the total cost obtained was $41.2 \$ / f t$ to $42.22 \$ / f t$ respectively. The filler being low cost 
Table 5.3 CHANGE IN TOTAL COST WITH \% CHANGE IN ROVING COSTS

\begin{tabular}{|l|c|c|c|c|c|}
\hline$\%$ Change in Roving Costs & $-60 \%$ & $-40 \%$ & $0 \%$ & $10 \%$ & $20 \%$ \\
\hline Total Cost (\$/ft) & $\$ 40.51$ & $\$ 40.99$ & $\$ 41.96$ & $\$ 42.21$ & $\$ 42.45$ \\
\hline
\end{tabular}

Table 5.4 CHANGE IN TOTAL COST WITH \% CHANGE IN RESIN COSTS

\begin{tabular}{|l|c|c|c|c|c|}
\hline$\%$ Change in Resin Costs & $-60 \%$ & $-40 \%$ & $0 \%$ & $10 \%$ & $20 \%$ \\
\hline Total Cost (\$/ft) & $\$ 41.39$ & $\$ 41.58$ & $\$ 41.96$ & $\$ 42.06$ & $\$ 42.16$ \\
\hline
\end{tabular}




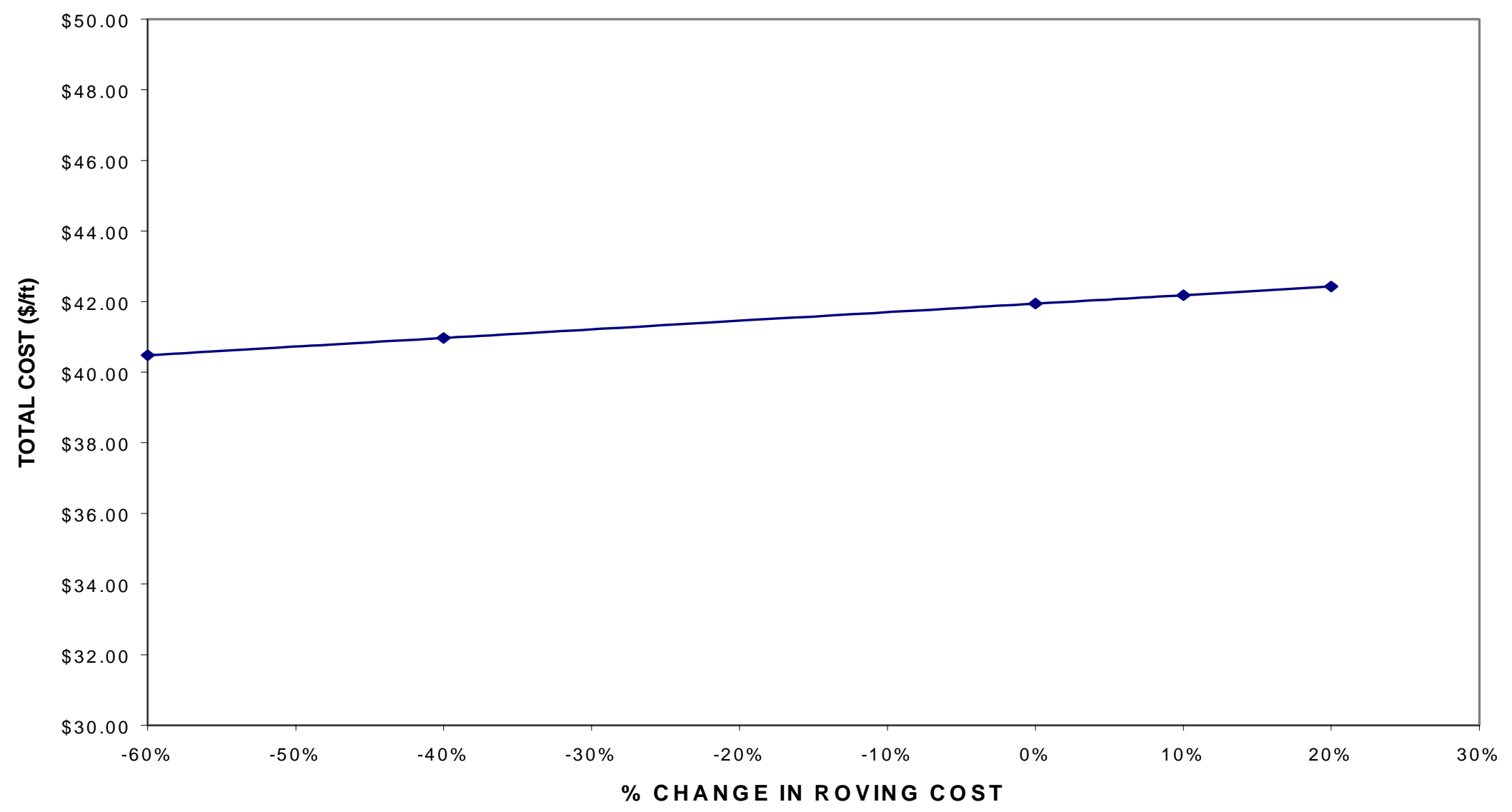

Figure 5.3 ROVING COST SENSITIVITY GRAPH 


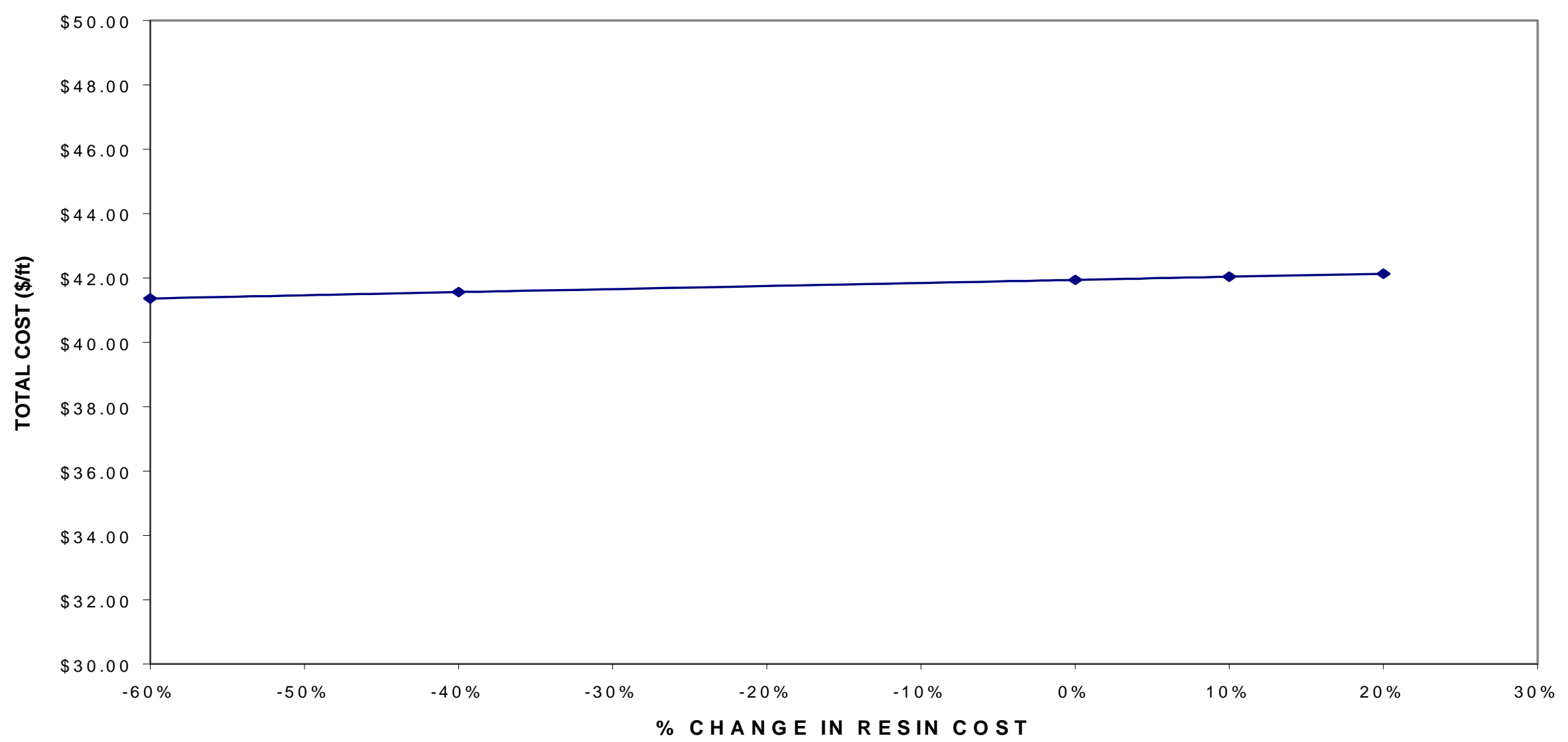

Figure 5.4 RESIN COST SENSITIVITY GRAPH 
constituent, the effect of change in its cost is minimal. Change of $10 \%$ in cost of filler causes approximately $0.5 \%$ change in total cost. These results are summarized in Table 5.5 and Figure 5.5.

\subsubsection{Initiator Cost:}

Although this being costly constituent, the weight percent being very low (approximately $0.5 \%$ ), the variation in the price of this constituent will have negligible effect on the total cost. The same is demonstrated in Table 5.6 and Figure 5.6 by the total cost changing from $41.37 \$ / \mathrm{ft}$ to $42.16 \$ / \mathrm{ft}$ when price varied from $-60 \%$ to $+20 \%$.

\subsubsection{Veils Cost:}

The weight percent of this constituent present in the product is approximately $0.7 \%$ and hence very small change observed in the total cost by changing price from $-60 \%$ to $+20 \%$. The results are summarized in Table 5.7 and Figure 5.7. The total cost corresponding to $-60 \%$ was $41.77 \$ / \mathrm{ft}$ and that for $+20 \%$ was $42.03 \$ / f t$. 
Table 5.5 CHANGE IN TOTAL COST WITH \% CHANGE IN FILLER COSTS

\begin{tabular}{|l|c|c|c|c|c|}
\hline$\%$ Change in Filler Costs & $-60 \%$ & $-40 \%$ & $0 \%$ & $10 \%$ & $20 \%$ \\
\hline Total Cost (\$/ft) & $\$ 41.20$ & $\$ 41.45$ & $\$ 41.96$ & $\$ 42.09$ & $\$ 42.22$ \\
\hline
\end{tabular}

Table 5.6 CHANGE IN TOTAL COST WITH \% CHANGE IN INITIATOR COSTS

\begin{tabular}{|l|c|c|c|c|c|}
\hline$\%$ Change in Initiator Costs & $-60 \%$ & $-40 \%$ & $0 \%$ & $10 \%$ & $20 \%$ \\
\hline Total Cost (\$/ft) & $\$ 41.37$ & $\$ 41.57$ & $\$ 41.96$ & $\$ 42.06$ & $\$ 42.16$ \\
\hline
\end{tabular}

Table 5.7 CHANGE IN TOTAL COST WITH \% CHANGE IN VEILS COSTS

\begin{tabular}{|l|c|c|c|c|c|}
\hline$\%$ Change in Veils Costs & $-60 \%$ & $-40 \%$ & $0 \%$ & $10 \%$ & $20 \%$ \\
\hline Total Cost (\$/ft) & $\$ 41.77$ & $\$ 41.84$ & $\$ 41.96$ & $\$ 42.00$ & $\$ 42.03$ \\
\hline
\end{tabular}




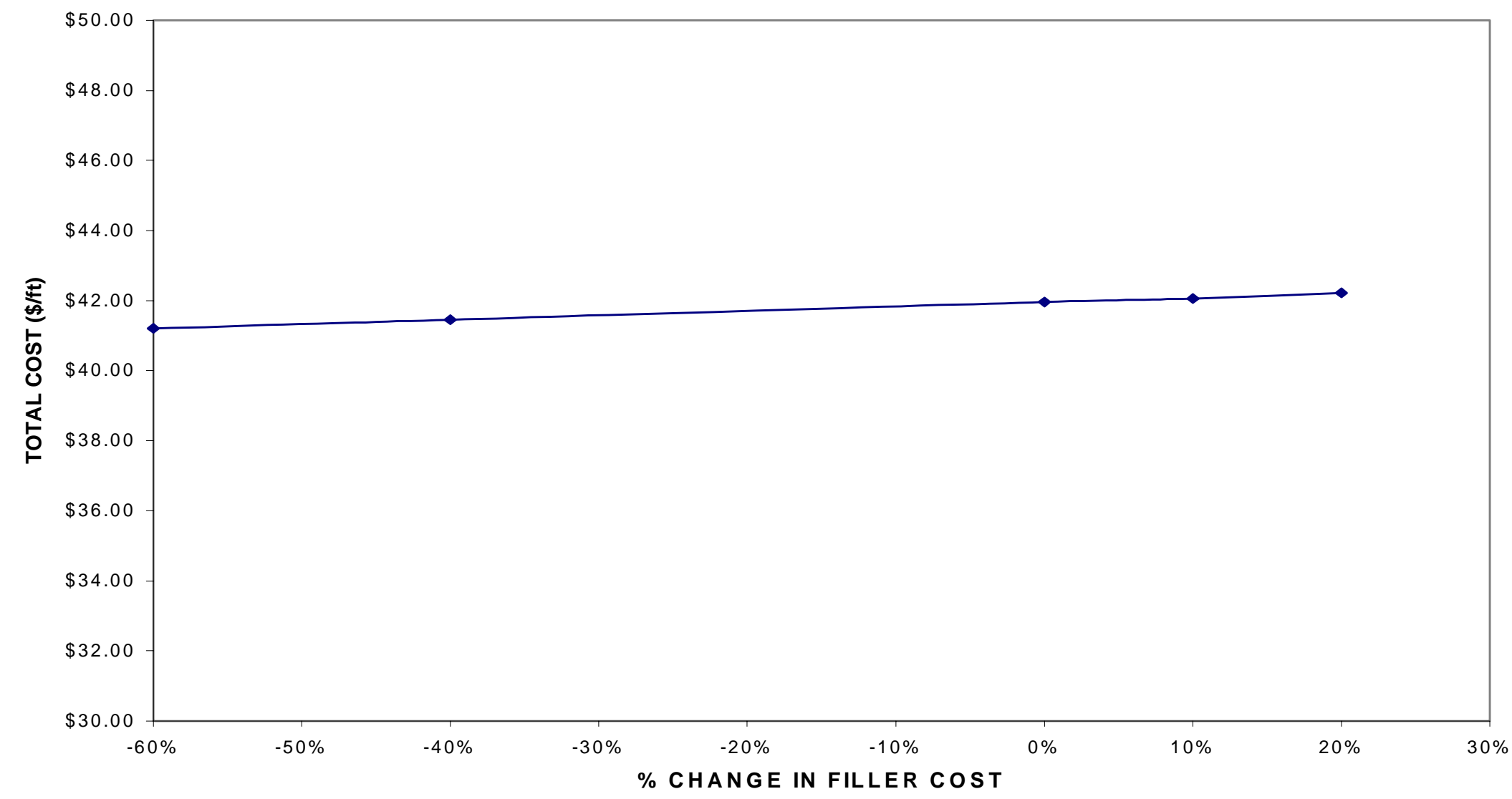

Figure 5.5 FILLER COST SENSITIVITY GRAPH 


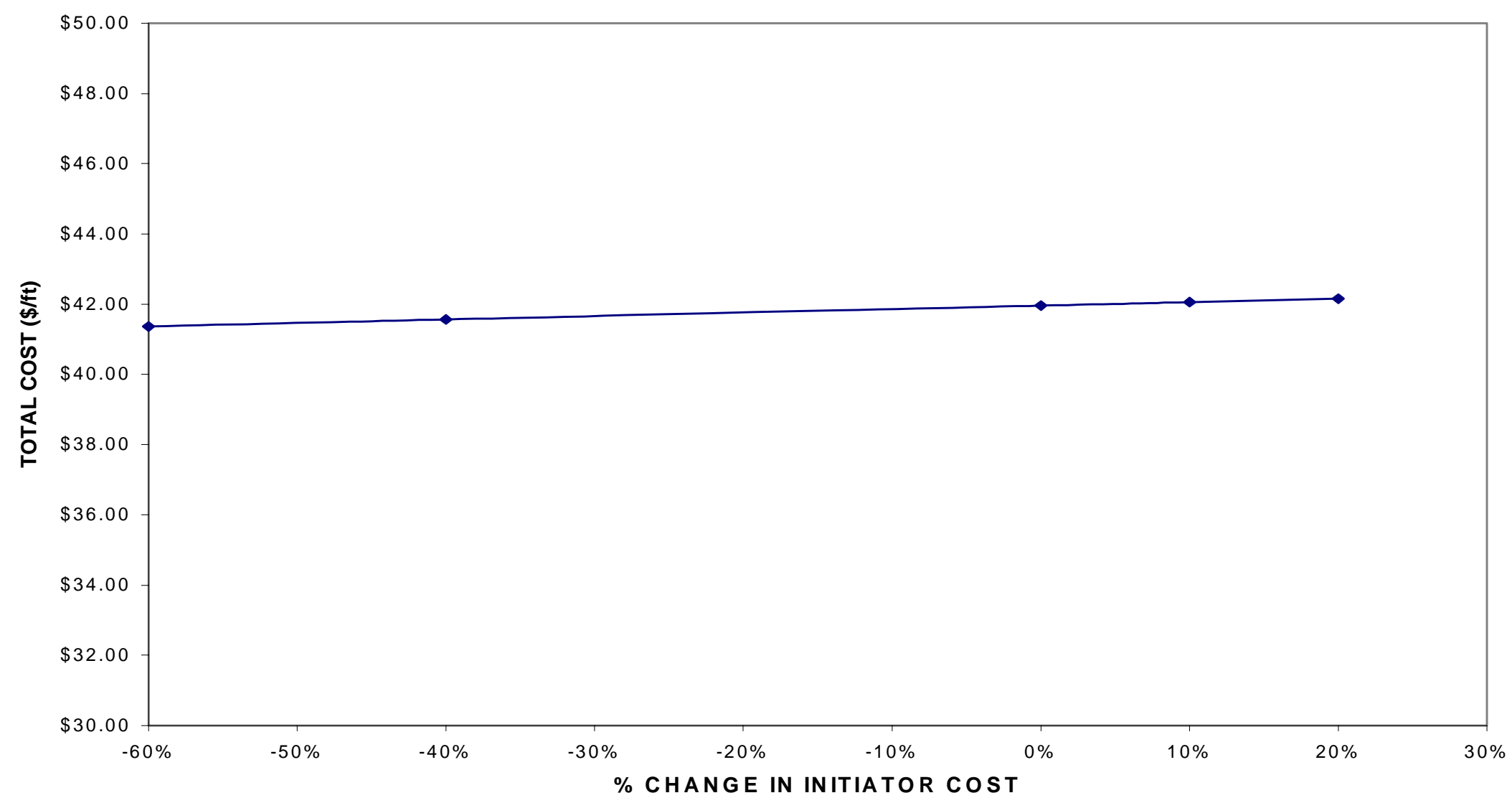

Figure 5.6 INITIATOR COST SENSITIVITY GRAPH 


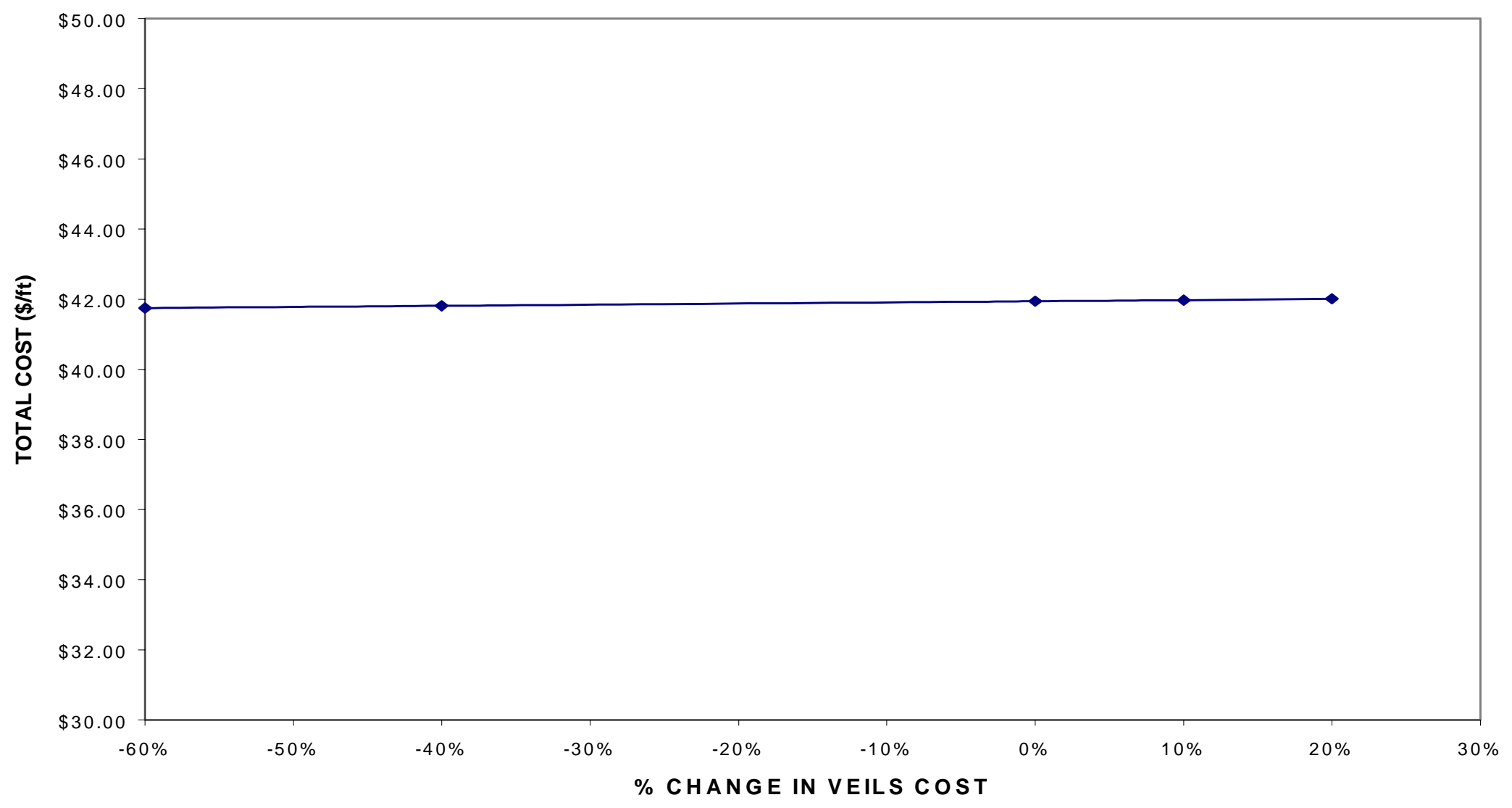

Figure 5.7 VEILS COST SENSITIVITY GRAPH 


\subsubsection{Direct Labor Cost:}

This cost component contributes approximately $3 \%$ to the total cost. The possibility of reducing direct labor cost is by reduction hourly labor rate, increase in line speed or by reducing the number of labors needed per machine i.e. reducing process factor DLPM. Direct labor component is varied from $-40 \%$ to $+40 \%$ and the corresponding total cost calculated was $41.43 \$ / \mathrm{ft}$ to $42.45 \$ / f t$ respectively. The results are summarized in Table 5.8 and Figure 5.8. The $10 \%$ reduction in labor cost reduces total cost by approximately $0.3 \%$

\subsubsection{Utility Cost:}

The effect of this cost component on the total cost will mainly depend on its unit rate $(\$ / k W h)$ which will vary from region to region. In this case study this cost component is approximately $1.5 \%$ and hence the effect on the total cost by varying this from $-40 \%$ to $+40 \%$ is small from $41.74 \$ /$ ft to 42.14\$/ft. The results are summarized in Table 5.9 and Figure 5.9. 
Table 5.8 CHANGE IN TOTAL COST WITH \% CHANGE IN DIRECT LABOR COSTS

\begin{tabular}{|l|c|c|c|c|c|}
\hline$\%$ Change in Direct Labor Costs & $-40 \%$ & $-20 \%$ & $0 \%$ & $20 \%$ & $40 \%$ \\
\hline Direct Labor Cost (\$/ft) & $\$ 0.77$ & $\$ 1.02$ & $\$ 1.28$ & $\$ 1.53$ & $\$ 1.79$ \\
\hline Total Cost (\$/ft) & $\$ 41.43$ & $\$ 41.69$ & $\$ 41.94$ & $\$ 42.20$ & $\$ 42.45$ \\
\hline
\end{tabular}

Table 5.9 CHANGE IN TOTAL COST WITH \% CHANGE IN UTILITY COSTS

\begin{tabular}{|l|c|c|c|c|c|}
\hline$\%$ Change in Utility Costs & $-40 \%$ & $-20 \%$ & $0 \%$ & $20 \%$ & $40 \%$ \\
\hline Utility Cost (\$/ft) & $\$ 0.30$ & $\$ 0.39$ & $\$ 0.49$ & $\$ 0.59$ & $\$ 0.69$ \\
\hline Total Cost (\$/ft) & $\$ 41.74$ & $\$ 41.84$ & $\$ 41.94$ & $\$ 42.04$ & $\$ 42.14$ \\
\hline
\end{tabular}




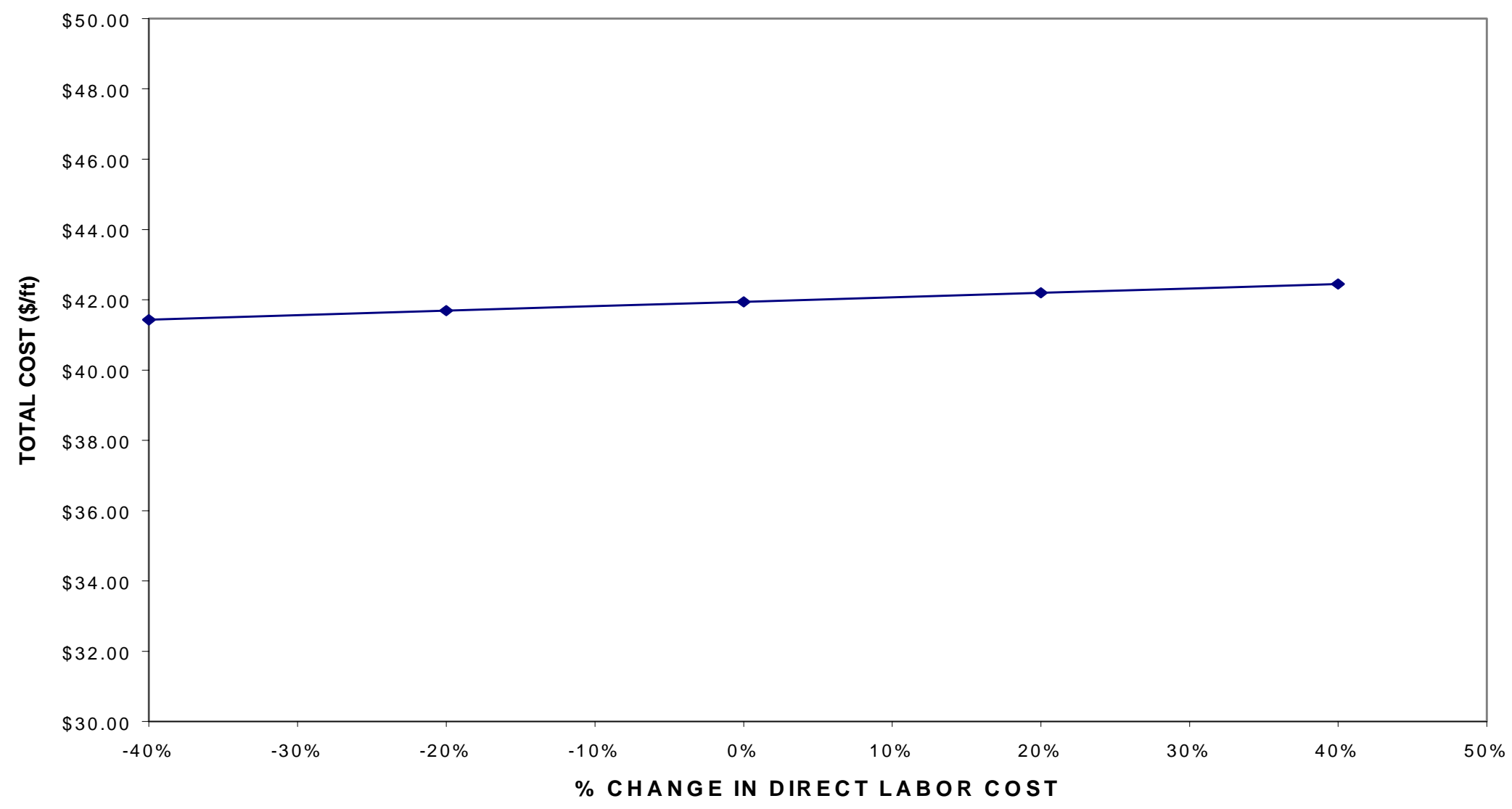

Figure 5.8 DIRECT LABOR COST SENSITIVITY GRAPH 


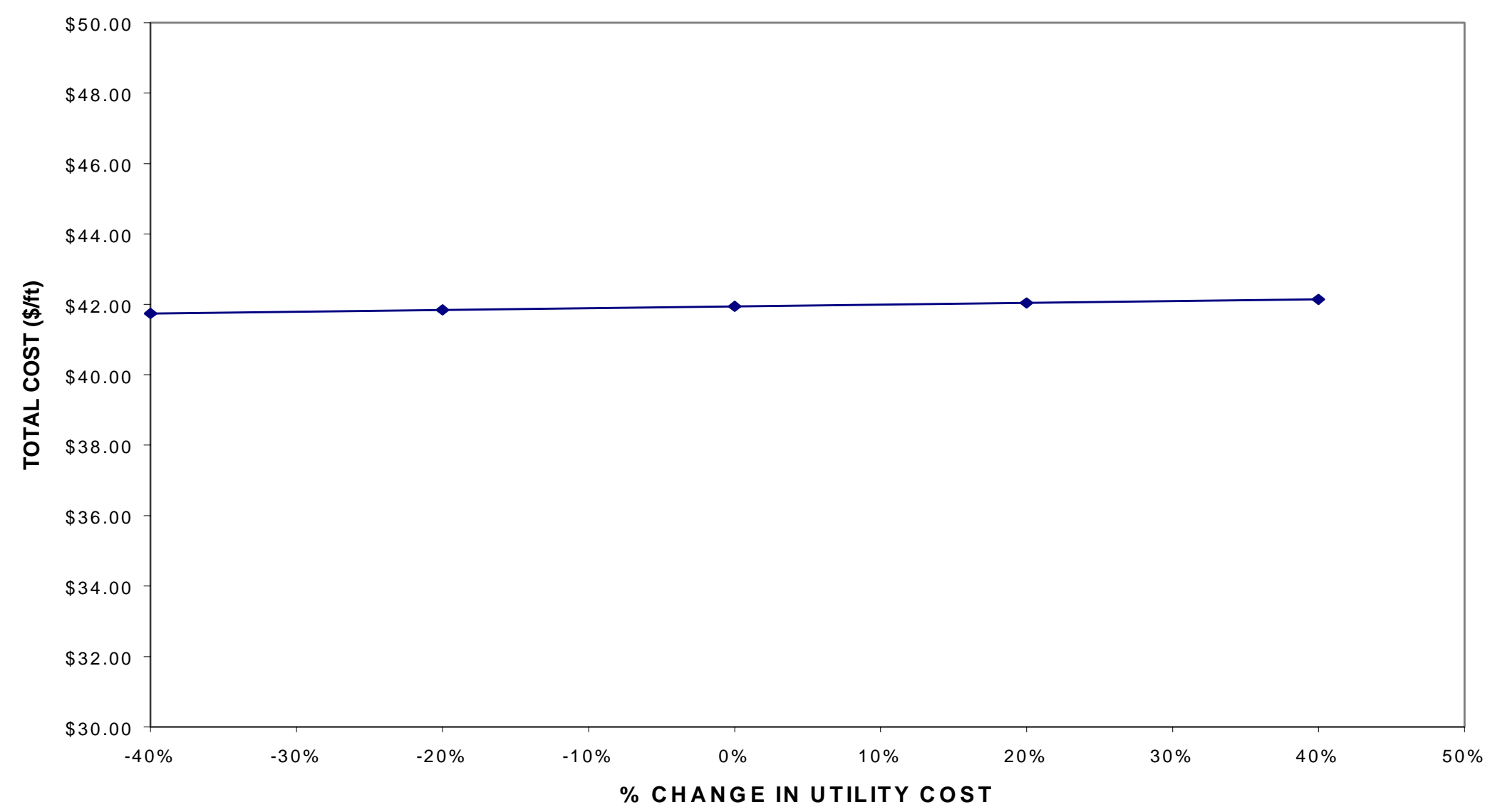

Figure 5.9 UTILITY COST SENSITIVITY GRAPH 


\subsubsection{Tool Set-Up \& Tear-down time:}

This analysis is to quantify the effect of reduction in tool set-up time on the total cost. The set-up time was varied by $-40 \%$ to $+40 \%$ and the total cost changed in the range of $41.33 \$ / \mathrm{ft}$ to $42.56 \$ / \mathrm{ft}$. These results are summarized in Table 5.10 and Figure 5.10 . Approximately $0.5 \%$ reduction in total cost is observed by $10 \%$ reduction in this cost component.

\subsubsection{Overhead Cost:}

As this being one of the major cost component (approximately 18\%) in total cost, the efforts should be directed in reducing this component to reduce the total cost. This component was varied from $-40 \%$ to $+40 \%$ in sensitivity analysis and the corresponding total cost calculated was $38.92 \$ / \mathrm{ft}$ and $44.96 \$ / \mathrm{ft}$ respectively. These results are summarized in Table 5.11 and Figure 5.11 . Change in this cost component by $10 \%$ produces approximately $2 \%$ change in total cost. 
Table 5.10 CHANGE IN TOTAL COST WITH \% CHANGE IN SET-UP \& TEAR-DOWN TIME

\begin{tabular}{|l|c|c|c|c|c|}
\hline$\%$ Change in Set-Up Time (shifts) & $-40 \%$ & $-20 \%$ & $0 \%$ & $20 \%$ & $40 \%$ \\
\hline Tool Setting Operator Cost (\$/ft) & $\$ 0.92$ & $\$ 1.23$ & $\$ 1.54$ & $\$ 1.84$ & $\$ 2.15$ \\
\hline Total Cost (\$/ft) & $\$ 41.33$ & $\$ 41.63$ & $\$ 41.94$ & $\$ 42.25$ & $\$ 42.56$ \\
\hline
\end{tabular}

Table 5.11 CHANGE IN TOTAL COST WITH \% CHANGE IN OVERHEAD COSTS

\begin{tabular}{|l|c|c|c|c|c|}
\hline$\%$ Change in Overhead Costs & $-40 \%$ & $-20 \%$ & $0 \%$ & $20 \%$ & $40 \%$ \\
\hline Overhead Cost (\$/ft) & $\$ 4.53$ & $\$ 6.05$ & $\$ 7.56$ & $\$ 9.07$ & $\$ 10.58$ \\
\hline Total Cost (\$/ft) & $\$ 38.92$ & $\$ 40.43$ & $\$ 41.94$ & $\$ 43.45$ & $\$ 44.96$ \\
\hline
\end{tabular}




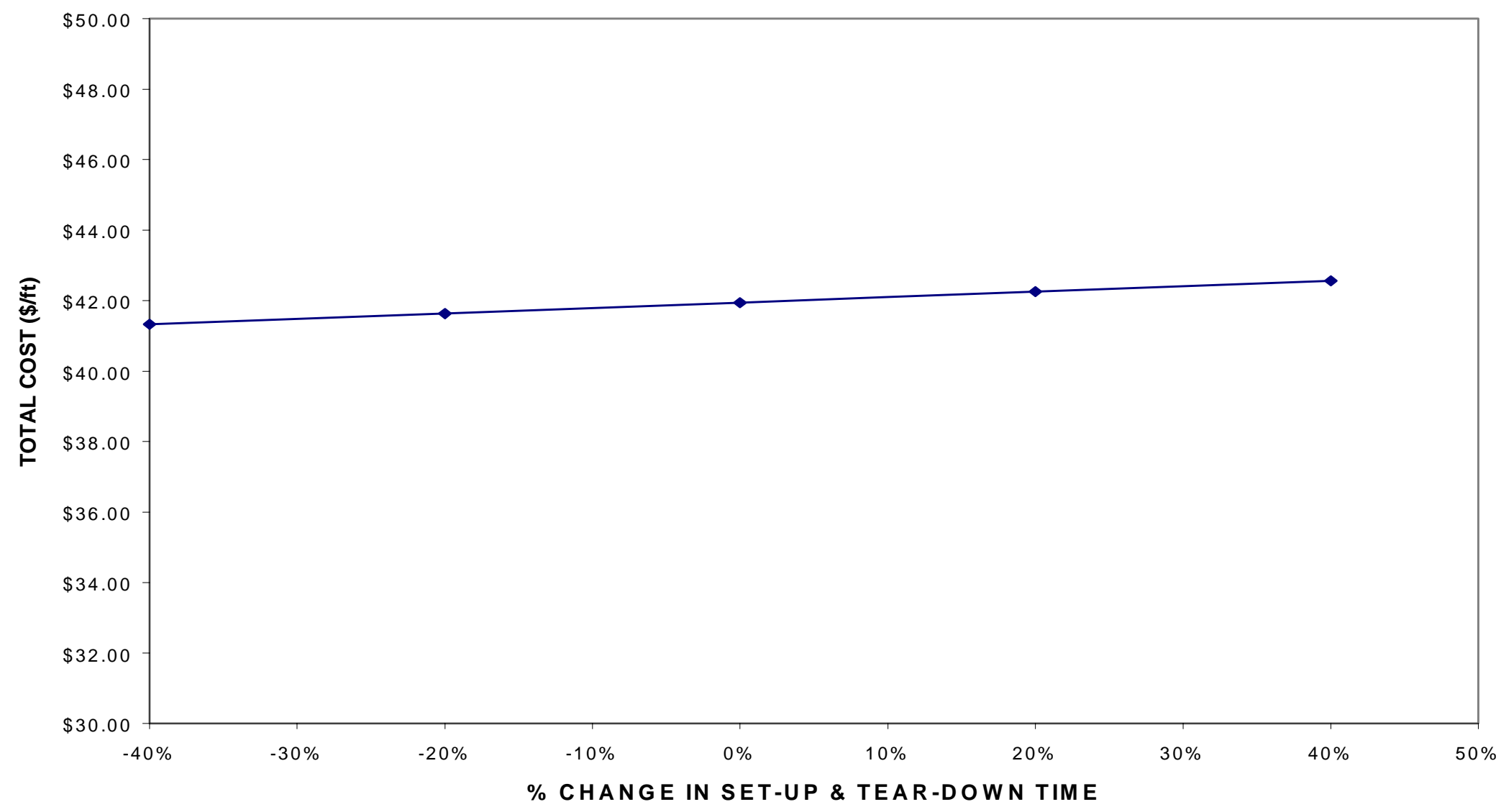

Figure 5.10 TOOL SET-UP \& TEAR-DOWN TIME SENSITIVITY GRAPH 


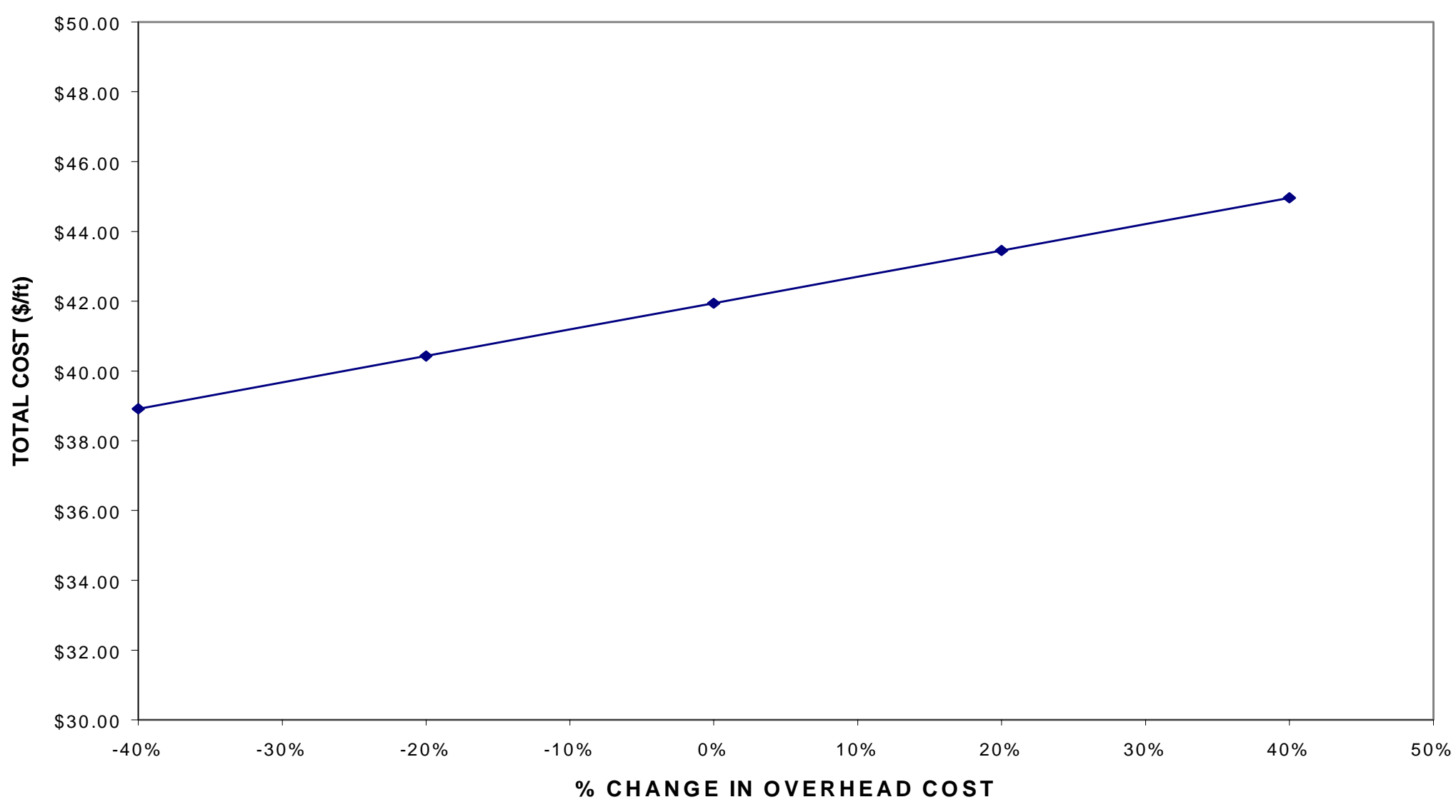

FIGURE 5.11 OVERHEAD COST SENSITIVITY GRAPH 


\subsubsection{Line Speed:}

Analysis shows that this is the most important factor to which the efforts should be directed to reduce the total cost. This is because, the increase in line speed appreciably reduces direct labor and overhead cost components in the total cost. However, the care should be shown as this can increase the scrap and hence have the negative effect. Much of research goes in this field to be able to get satisfactory product with the increase in line speed. Major concern here is to achieve proper heat transfer through the entire thickness of the product during the time while it is in the die. The speed is varied from $-20 \%$ to $40 \%$ in sensitivity analysis and the model calculates the effect on total cost which changes from $44.04 \$ / \mathrm{ft}$ to $39.55 \$ / \mathrm{ft}$ for this change. These results are demonstrated in Table 5.12 and Figure 5.12. A $10 \%$ change in line speed changes the total cost by approximately $2 \%$.

\subsubsection{Start-up \& Tear-down Losses:}

This is also very important factor to be controlled and reduced. High production runs will have low percentage losses and low production runs would have high start-up and teardown percentage losses. For sensitivity analysis, start-up scrap was varied from $1 \%$ to $10 \%$ and the change in total cost was observed from $40.94 \$ / \mathrm{ft}$ to $43.32 \$ / \mathrm{ft}$. The results are presented in Table 5.13 and Figure 5.13. 
Table 5.12 CHANGE IN TOTAL COST WITH \% CHANGE IN LINE SPEED

\begin{tabular}{|l|c|c|c|c|c|}
\hline$\%$ Change in Line Speed & $-20 \%$ & $-10 \%$ & $0 \%$ & $20 \%$ & $40 \%$ \\
\hline Line Speed(in/min) & 4.0 & 4.5 & 5.0 & 6.0 & 7.0 \\
\hline Total Cost (\$/ft) & $\$ 44.04$ & $\$ 42.87$ & $\$ 41.94$ & $\$ 40.55$ & $\$ 39.55$ \\
\hline
\end{tabular}

Table 5.13 CHANGE IN TOTAL COST WITH CHANGE IN START- UP \& TEAR-DOWN LOSSES

\begin{tabular}{|l|c|c|c|c|c|}
\hline Change in Start - Up Losses & $1.00 \%$ & $3.00 \%$ & $5.00 \%$ & $7.00 \%$ & $10.00 \%$ \\
\hline Total Cost (\$/ft) & $\$ 40.94$ & $\$ 41.43$ & $\$ 41.94$ & $\$ 42.48$ & $\$ 43.32$ \\
\hline
\end{tabular}




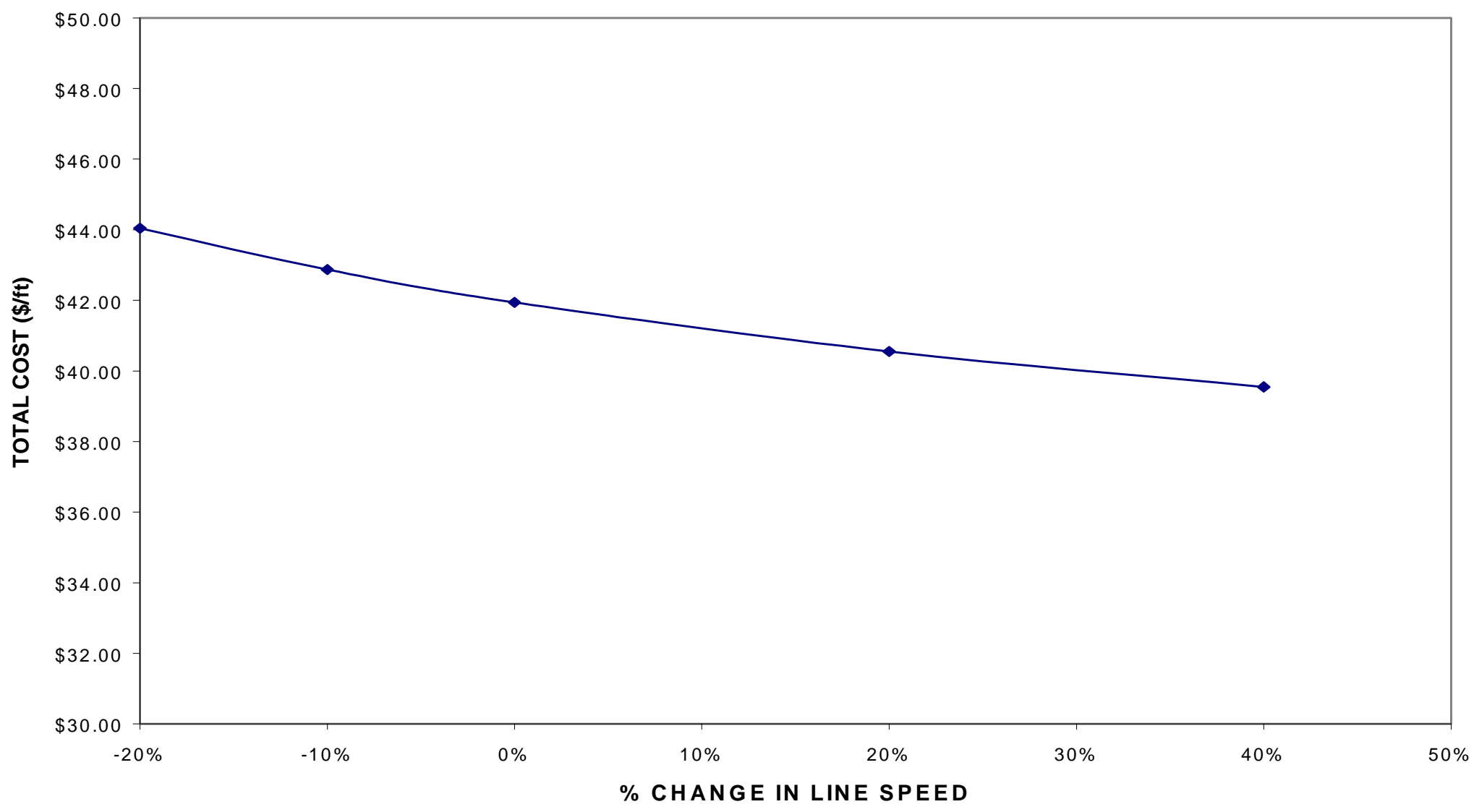

Figure 5.12 LINE SPEED SENSITIVITY GRAPH 


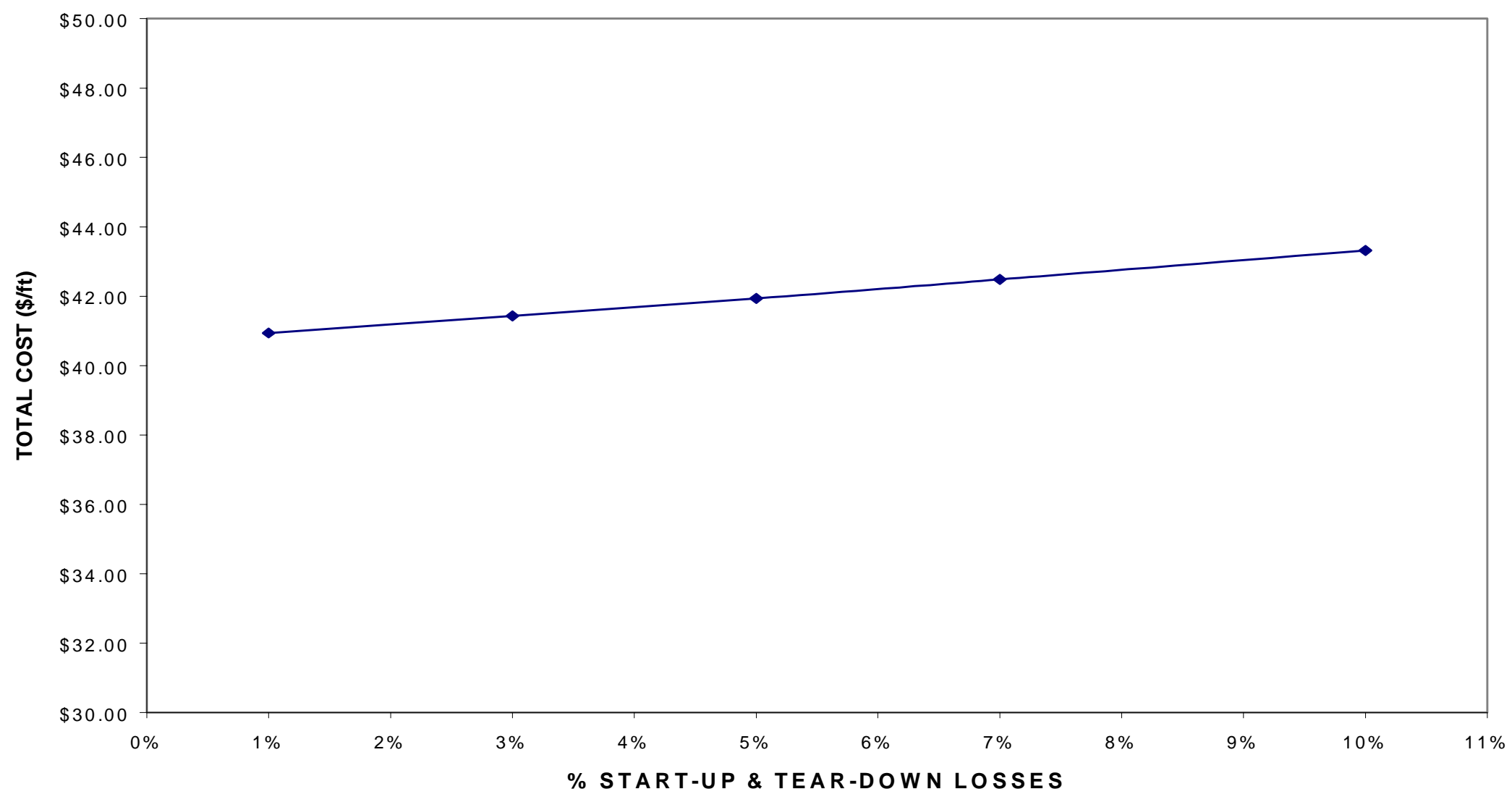

Figure 5.13 START-UP \& TEAR-DOWN LOSSES SENSITIVITY GRAPH 


\subsubsection{End-Squaring Losses}

Similar to start-up scrap, end squaring losses also should be possibly kept as small as possible. For, sensitivity analysis purpose, end squaring losses are varied from $1 \%$ to $5 \%$ and for this change total cost changes from $41.94 \$ / \mathrm{ft}$ to $42.99 \$ / \mathrm{ft}$. These results are summarized in Table 5.14 and Figure 5.14 . For every $1 \%$ change in this losses, the total cost changes by approximately $1 \%$.

\subsubsection{Annual Production}

Because, the model assumes non-dedicated facility, hence this factor does not have appreciable effect on the total cost, as it would have effected in case of dedicated facility, because then the entire capital investment is distributed onto the parts produced, and thus more the parts produced, the cost per part will be reduced. For sensitivity purpose, the factor is changed from $-90 \%$ to $900 \%$ and the change in total cost observed is from $119.78 \$ / \mathrm{ft}$ to $34.16 \$ / f t$. These results are indicated in Table 5.15 and Figure 5.15.

Also, the increasing application of advanced composite materials will have major effect on the raw material cost, which will be drastically reduced. As, raw material being the largest cost component in total cost, this will drastically bring down the total cost. 
Table 5.14 CHANGE IN TOTAL COST WITH CHANGE IN END-SQUARING LOSSES

\begin{tabular}{|l|c|c|c|c|c|}
\hline Change in End - Squaring Losses & $1.00 \%$ & $2.00 \%$ & $3.00 \%$ & $4.00 \%$ & $5.00 \%$ \\
\hline Total Cost (\$/ft) & $\$ 41.94$ & $\$ 42.19$ & $\$ 42.45$ & $\$ 42.72$ & $\$ 42.99$ \\
\hline
\end{tabular}

Table 5.15 CHANGE IN TOTAL COST WITH \% CHANGE IN ANNUAL PRODUCTION

\begin{tabular}{|l|c|c|c|c|c|}
\hline \% Change in Annual Production & $-90 \%$ & $-50 \%$ & $0 \%$ & $400 \%$ & $900 \%$ \\
\hline Annual Production (ft) & 1,000 & 5,000 & 10,000 & 50,000 & 100,000 \\
\hline Total Cost (\$/ft) & $\$ 119.78$ & $\$ 50.59$ & $\$ 41.94$ & $\$ 35.02$ & $\$ 34.16$ \\
\hline
\end{tabular}




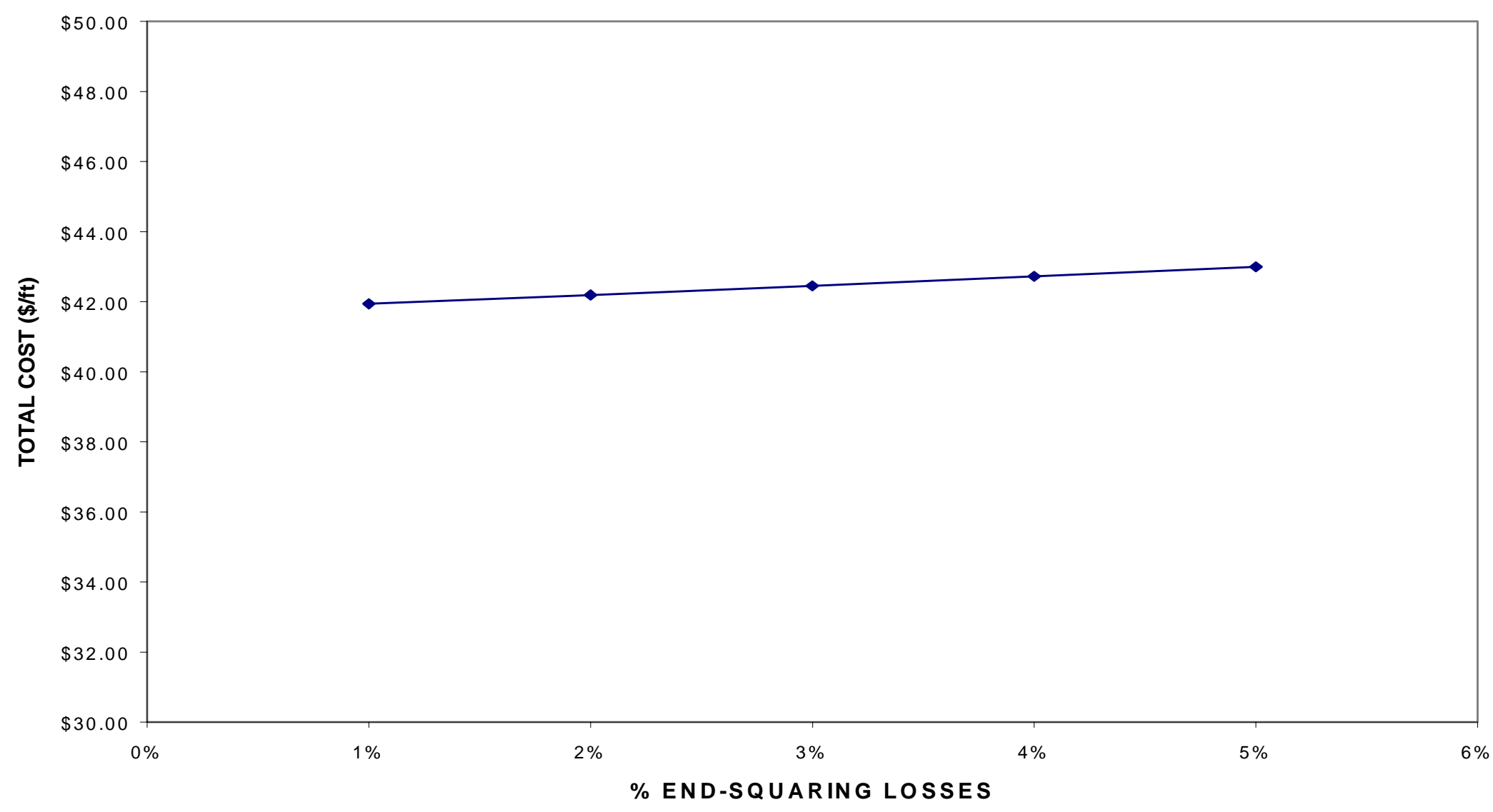

Figure 5.14 END-SQUARING LOSSES SENSITIVITY GRAPH 


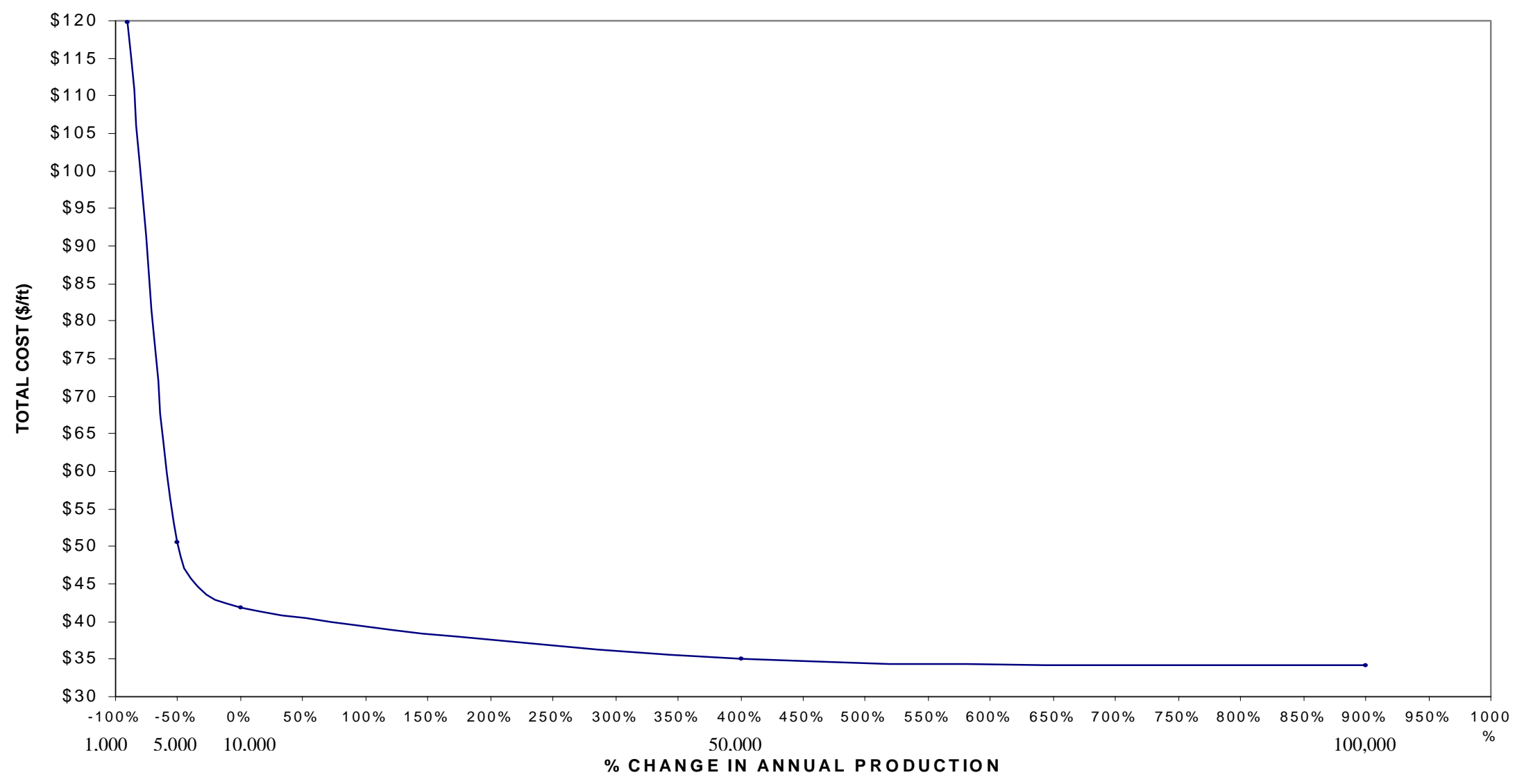

Figure 5.15 ANNUAL PRODUCTION SENSITIVITY GRAPH ( $0 \%$ is base case of $10,000 \mathrm{ft}$ ) 


\subsection{Sensitivity Analysis on BridgeDeck (\$/hour)}

In the previous section we discussed sensitivity analysis with reference to total cost on $\$ / f t$ basis (i.e. unit basis). Now, we will consider time basis analysis for change in total cost calculated on time basis with change in line speed.

The change in total cost (\$/hour) with change in line speed has been summarized in Table 5.16 and graph is shown in Figure 5.16.

It is observed that as speed increases, the total cost also increases which is implicit because the major fixed cost component constituting the total cost in $\$$ hour such as tooling cost and overhead cost are increasing whereas only direct labor cost is decreasing. The following are the percentage changes in the cost components ( $\$ /$ hour) due to increase in line speed by $10 \%$ :

1. The total cost per hour increases by approximately $3.5 \%$ as the amount of material has increased by $10 \%$. However the unit cost would decrease by $6.5 \%$ as the production is increased by $10 \%$.

2. Direct labor cost reduces by approximately $2 \%$, which can be explained by the reduction in time needed to produce the targeted production.

3. Utility cost component increases by approximately $8 \%$, because of the increase in production per hour.

4. Tooling cost component increases by $8 \%$, which can be explained that increase in production rate needs less number of shifts. 
Table 5.16 CHANGE IN TOTAL COST WITH \% CHANGE IN LINE SPEED

\begin{tabular}{|l|c|c|c|c|c|}
\hline \% Change in Line Speed & $-20 \%$ & $-10 \%$ & $0 \%$ & $20 \%$ & $40 \%$ \\
\hline Line Speed(in/min) & 4.0 & 4.5 & 5.0 & 6.0 & 7.0 \\
\hline Total Cost (\$/hour) & $\$ 312.55$ & $\$ 324.56$ & $\$ 336.12$ & $\$ 358.01$ & $\$ 378.39$ \\
\hline
\end{tabular}




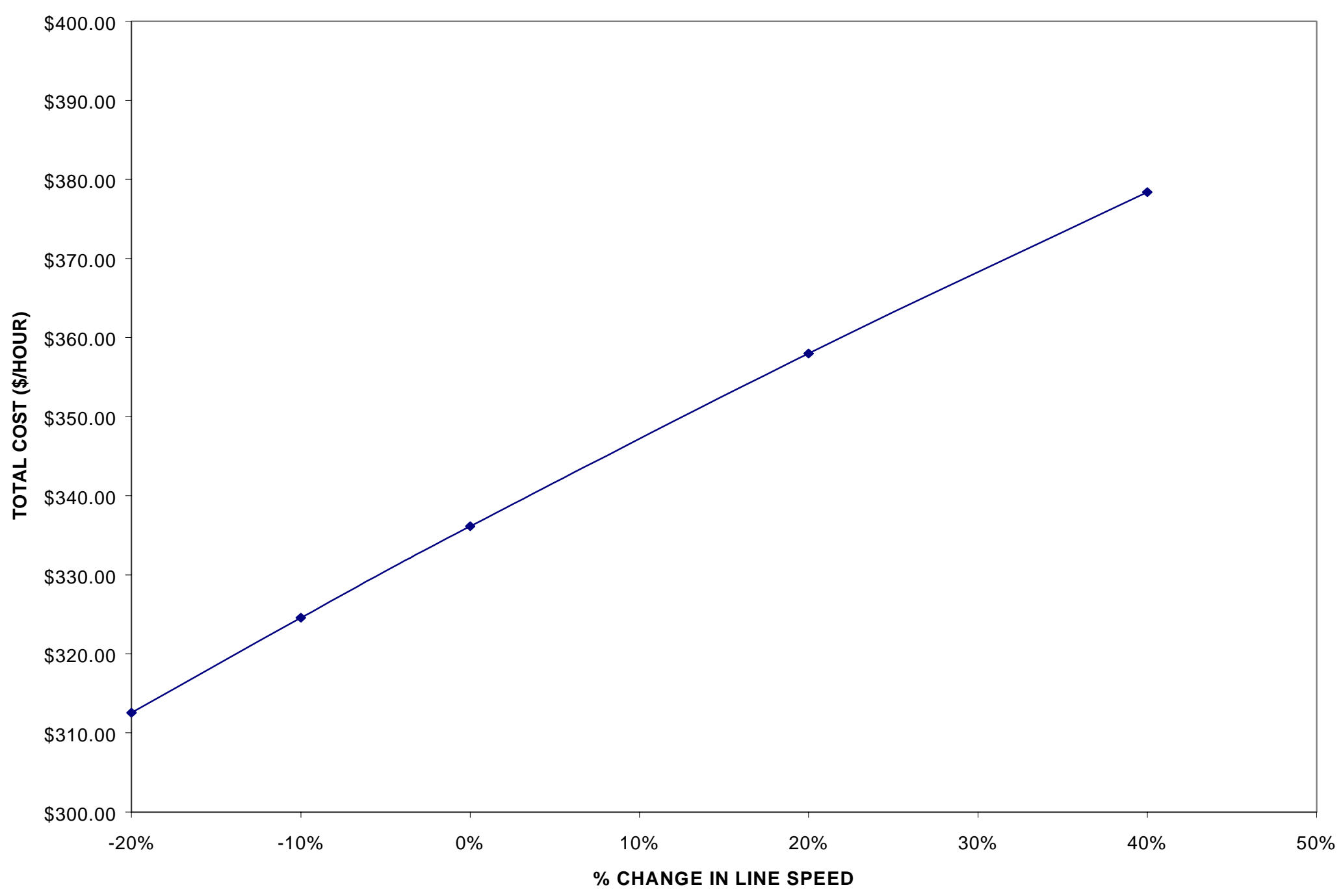

Figure 5.16 LINE SPEED SENSITIVITY GRAPH 
5. The increase in overhead cost by approximately $4 \%$ is due to the increase in total fixed cost.

6. Tool setting operator cost increases by approximately $8 \%$, which is due to reduction in time needed to manufacture the targeted production.

\subsection{Summary of Sensitivity Analysis}

Here, it is important to mention that majority of the conclusions made are product dependent, because their effect to a large extent is determined by the contribution of a particular cost component in the total cost. But again, the conclusions such as effect of annual production can be generalized for all composites manufacturing processes cost. However, it is always recommended to draw conclusions for cost of any process, using a model or tool specific to that process.

The value of sensitivity analysis is that it is a method for dealing with the uncertainty inherent in cost estimation. Sensitivity analysis provides a basis for taking into account a range of possible values for the inputs or assumptions. In many instances, this information is more valuable than a single point cost estimate obtained from cost analysis. 


\section{Chapter 6}

\section{CONCLUSIONS}

\subsection{Conclusions}

1. The model developed can serve as a ready tool for determining approximate costs of the composite products manufactured by pultrusion process. It is specifically designed for costing of pultrusion process.

2. The technical cost modeling approach adopted provides a systematic way of estimating the elements, which contribute to the total cost. When using a systematic approach and because of the need for extensive data management, elemental cost estimation is best accomplished with the use of a digital computer. This approach was successfully employed within this study.

3. The task of performing sensitivity analysis and summarizing the results in graphical form is appreciably eased by use of digital computer and technical cost modeling approach. It is possible to draw directional conclusions to determine on to which cost components and process factors should be controlled to get the desired cost.

4. Sensitivity analysis can help determine the levels of process parameters so that substitution of conventional materials with composite materials becomes economically convincing apart from their superior performance characteristics. 
5. The model has a provision to analyze the effect of change in each process parameter on any desired cost component rather than only total cost. This much-needed feature was missing in previous models $[26,39,40]$.

6. The user friendliness of the model is appreciable, especially the ease with which it allows the user to try different exogenous and process factors without modifying the database permanently and only after he is confident of the applicability of the new value can modify the database permanently simply on the click of a button.

7. Model calculates and suggests capital investment for different equipments, which can be easily overridden by entering new value in the adjacent cell if wanted by the user.

8. Also, the validation features of the model are appreciable which prevents the user from committing errors, knowingly or unknowingly.

\subsection{Major Assumptions in the Model}

Several major assumptions were made in designing the model as explained below:

1. Non-dedicated Facility:

It is assumed that many different products use the same manufacturing facility. Hence the fixed costs has been proportionately allocated to the product under consideration by using a fraction which is a ratio of time needed to manufacture the product to the total time the facility is available. 
2. Variable Labor:

It is assumed that the availability of direct labor is infinitely flexible. i.e. laborers can be switched from the production of one component to the production of another without penalty.

3. Tool-Setting Operator:

There is a separate tool setting operator team for setting up and tearing down machines for different components and no direct labor is involved in this activity.

4. Engineering Feasibility

The decision regarding the engineering feasibility of manufacturing the considered component by pultrusion process is left to the user. To assure meaningful results, engineering analysis should precede the use of this model.

5. Economic Feasibility

The model estimates the production costs. Decision regarding the economic attractiveness of various alternatives are is by the user.

6. The Bridge Deck as one product.

The present design of the Bridge Deck consists of two parts as shown in Figure 6.1, which are then glued together. The next generation Bridge Deck currently in design and development stage will be pultruded as one product. 


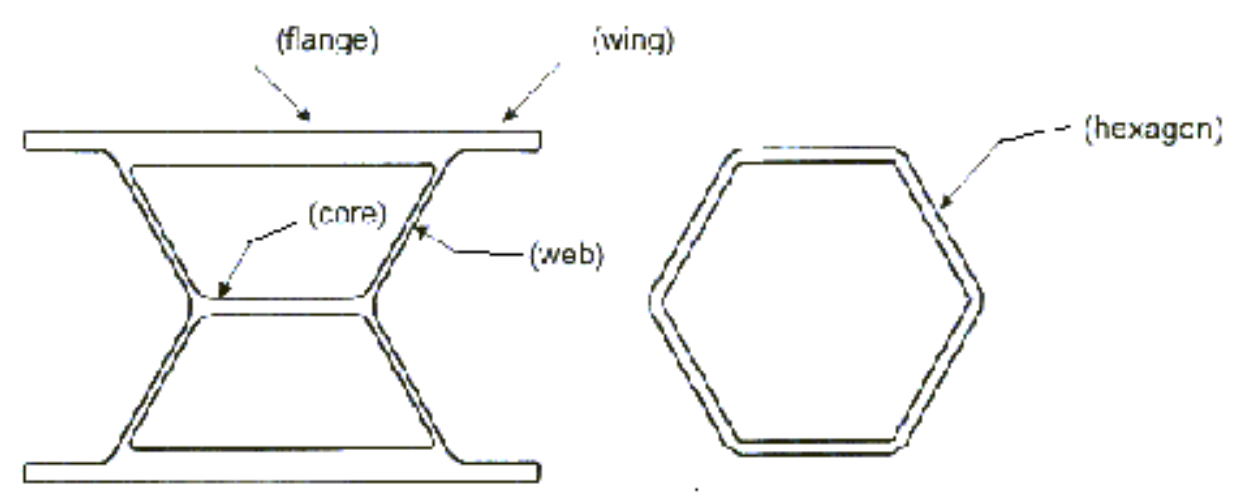

Figure 6.1 BRIDGE DECK DRAWING

\subsection{Scope for Future Work}

The current model has been designed for the costing of products manufactured using pultrusion product. However, it can be extended for costing of other composite manufacturing processes like resin injection molding (RIM), filament winding by changing the process factors and modifying the user input sheet for parameters specific to the RIM process. 


\section{REFERENCES}

1. E.J. Barbero, Introduction to Composite Materials Design, 1998.

2. Engineered Materials Handbook, Volume I, Metals Park: ASM International, 1987, pp. 27-32.

3. Engineered Materials Handbook, Volume I, Metals Park: ASM International, 1987, pp. 33.

4. Engineered Materials Handbook, Volume I, Metals Park: ASM International, 1987, pp. 24.

5. Vaughman, James G., et al, "A Characterization of the Important Parameters for Graphite/PEEK Pultrusion," Journal of Thermoplastic Composite Materials, Vol. 3, April 1990, pp. 131-149.

6. "Researchers Develop Processes for Pultruded PPS Composites," Research and Development, pp. 53-54, August 1987.

7. J. A. Kershaw, "High Performance Pultruded Composites," $15^{\text {th }}$ National SAMPE Technical Conference, October 4-6, 1983. 
8. Continuous Manufacturing Processes, Handbook of Composites, Society of Plastics Engineers, 1982.

9. Engineered Materials Handbook, Volume I, Metals Park: ASM International, 1987, pp. 90-96.

10. Modern Plastics Encyclopedia, Volume 59, Number 10A, Mc.Graw Hill, 1982-83.

11. Jeff Martin, "Designing Pultruded Composite Profiles-Critical Process and Performance Considerations." $15^{\text {th }}$ National SAMPE Technical Conference, October 4-6, 1983.

12. Conversation with Mr. Dustin L. Troutman, Creative Pultrusions Inc., April $23^{\text {rd }} 1999$.

13. Stanley, Jim M. and Matto, Milt W., "A Case History Approach to Demonstrating Pultrusion Design Versatility." $\underline{41^{\text {st }} \text { Annual Conference, }}$ reinforced Plastics/Composites Institute, The Society of Plastics Industry, Inc., January 27-31, 1986. 
14. Strong, Brent A., Fundamentals of Composites Manufacturing: Materials, Methods, and Applications, Society of Manufacturing Engineers, 1989, pp. 127.

15. Sumerak, Joseph E., "Understanding Pultrusion Process Variables for the First Time." $40^{\text {th }}$ Annual Conference, Reinforced Plastics/Composite Institute, The Society of the Plastics Industry, Inc., January 28 - February 1, 1985.

16. Sumerak, Joseph E. and Martin, Jeffrey D., "Pultrusion Process Variables and their Effect upon Manufacturing Capability," $\underline{39^{\text {th }} \text { Annual }}$ Conference, Reinforced Plastics/Composites Institute, The Society of the Plastics Industry, Inc., January 16-19, 1984, 1-B.

17. Hunter, G. A., "Pultruding Epoxy Resins," $43^{\text {rd }}$ Annual Conference, Reinforced Plastics/Composite Institute, The Society of Plastics Industry, Inc., February 1-5, 1988.

18. "Pultrusion with EPON Epoxy Resins," Shell Chemical Company Technical Bulletin SC: 808-86.

19. Outwater, John O., "The Role of the Interface in the Pultrusion Process," $\underline{42^{\text {nd }} \text { Annual Conference, Reinforced Plastics/Composite }}$ 
Institute, The Society of the Plastics Industry, Inc., February 2-6, 1987, 12-D.

20. Ma, Chen-Chi M., et al, "The Correlations of Processing Variables for Optimizing the Pultrusion Process," SAMPE Journal, September/October, 1986, pp. 42-48.

21. J. A. Brydson, Plastics Materials, $4^{\text {th }}$ Edition, 116-117, 1982.

22. Chachad, Y.R., "Prediction of Thermal Curing Characteristics for the Manufacture of Composite Materials by Pultrusion," M.S. Thesis, University of Mississippi, December 1991.

23. Outwater, John O., "On the Mechanics of Pultrusion," $\underline{41^{\text {st }} \text { Annual }}$ Conference, Reinforced Plastics/Composites Institute, The Society of the Plastics Industry, Inc., January 27-31, 1986.

24. Lamb, D. W., et al, "Pultrusion Process Characterization in Terms of thermal parameters and Product/Die Interfacial Shear Stress," $\underline{44^{\text {th }}}$ Annual Conference, Reinforced Plastics/Composite Institute, The Society of the Plastics Industry, Inc., February 6-9, 1989, 4-D. 
25. Sumerak, Joseph E. and Martin, Jeffrey D., "The Pulse of Pultrusion: Pull Force Trending for Quality and productivity Management," $\underline{46^{\text {th }}}$ Annual Conference, Reinforced Plastics/Composites Institute, The Society of the Plastics Industry, Inc., February 1-8, 1991, 4-B.

26. Busch, John V., "Primary Fabrication Methods and Costs in Polymer Processing for Automotive Applications," M.S. Thesis, Massachusetts Institute of Technology, June 1983.

27. Workshop on Fiber Reinforced Polymer (FRP) Composites in Construction, September 14-15, 1998.

28. Conversation with Dr. Gangarao Hota, Dr. Rakesh Gupta, Dr. Robert Creese, West Virginia University, October $17^{\text {th }} 1998$.

29. Conversation with Dr. Robert Creese, West Virginia University, March $12^{\text {th }} 1999$.

30. Conversations with Mr. Nelson H. Douglass, REICHOLD CHEMICALS, SC, March $25^{\text {th }} 1999$.

31. Conversations with Dr. Rakesh Gupta, West Virginia University, March $27^{\text {th }} 1999$. 
32. "1994 Labor Survey - Plastics Processing Companies," The Society of Plastics Industry, Survey no. 56 - 1994.

33. Conversation with Dr. Robert Creese, West Virginia University, April $15^{\text {th }} 1999$.

34. Industrial Assessment Center, West Virginia University, Report No.106.

35. Chan S. Park. and Gunter P. Sharp-Bette., Advanced Engineering Economics, John Wiley \& Sons, 1990.

36. Conversation with Mr. Dustin L. Troutman, Creative Pultrusions Inc. and Mr. Mike Andrews, Brunswick Technologies Inc., December $10^{\text {th }}$ 1997.

37. Conversation with Mr. Dustin L. Troutman, Creative Pultrusions Inc., May $4^{\text {th }} 1998$.

38. Telephonic conversation with Mr. Dustin L. Troutman, Creative Pultrusions Inc., July $8^{\text {th }} 1998$. 
39. Isabelle Goss, "Production Functions and Cost Models for Fibers in Advanced Composite Materials," M.S. Thesis, Massachusetts Institute of Technology, February 1986.

40. Mawuli Tse, "Design Cost Model for Advanced Composite Structures," M.S. Thesis, Massachusetts Institute of Technology, September 1992.

41. GangaRao, H.V.S and Thippeswamy, H.K., "Advanced Polymer Composites for Transportation Infrastructure," A Conference on Polymer Composites, Constructed Facilities Center, Parkesburg, West Virginia, April19-21, 1999.

42. Creese, R.C., "Overcoming Composite Cost Differentials by Life-Cycle Costing," A Conference on Polymer Composites, April19-21, 1999, Technomic Publishing Company Inc., Pennsylvania 17604.

43. Lopez-Anido, R., "Life-Cycle Cost Evaluation of FRP Composite Bridge Decks," 1998.

44. Creese, R.C., Adithan, M., and Pabla, B.S., "Estimating and Costing for the Metal Manufacturing Industries," Marcel Dekker Inc., 1992. 
45. Photograph at Reichold Chemicals Facility, Research Triangle Park, NC.

46. Depreciation Publication 946(1998), Department of Treasury, IRS. 


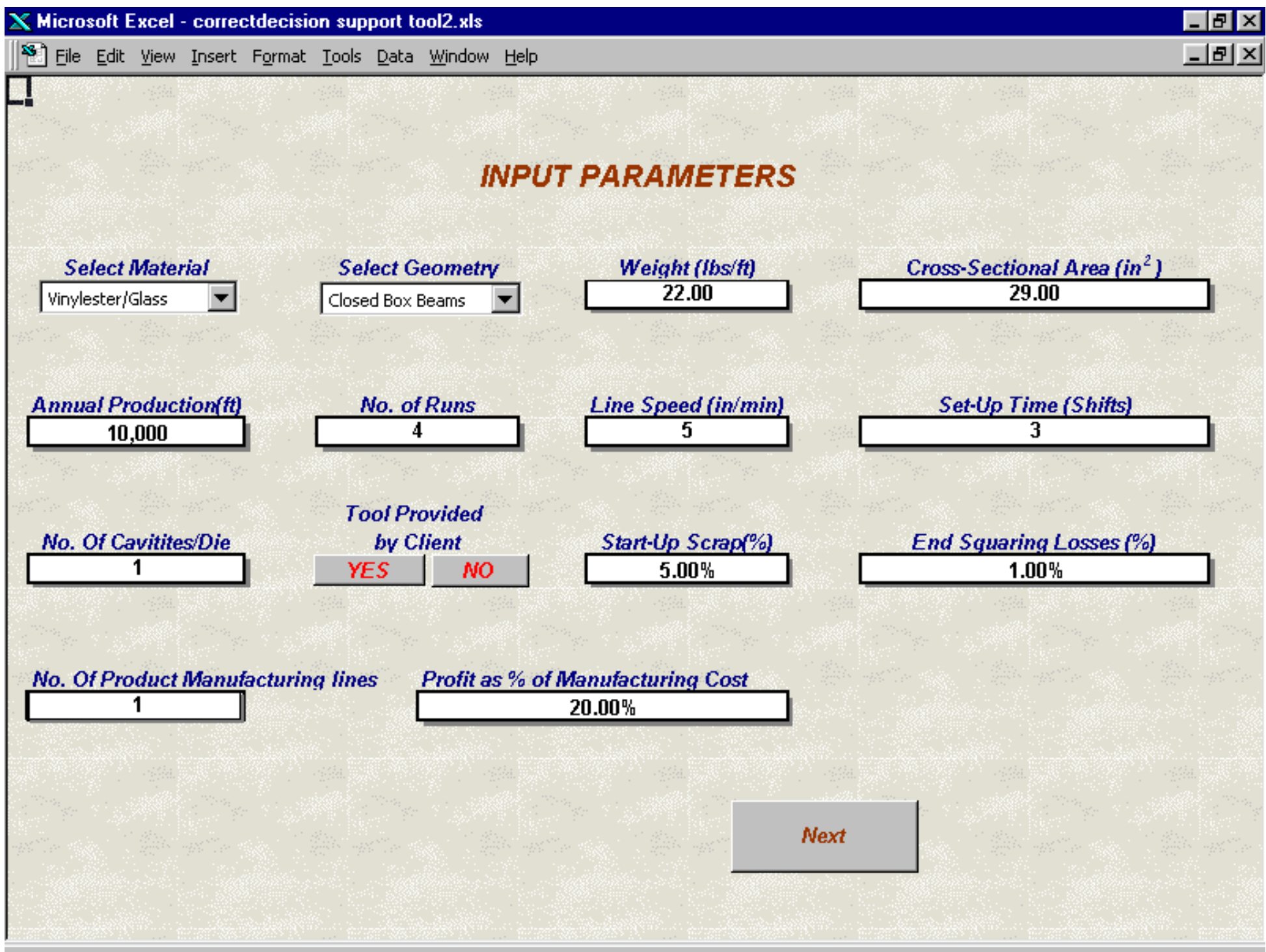

Figure 1. INPUT PARAMETERS USER SCREEN 


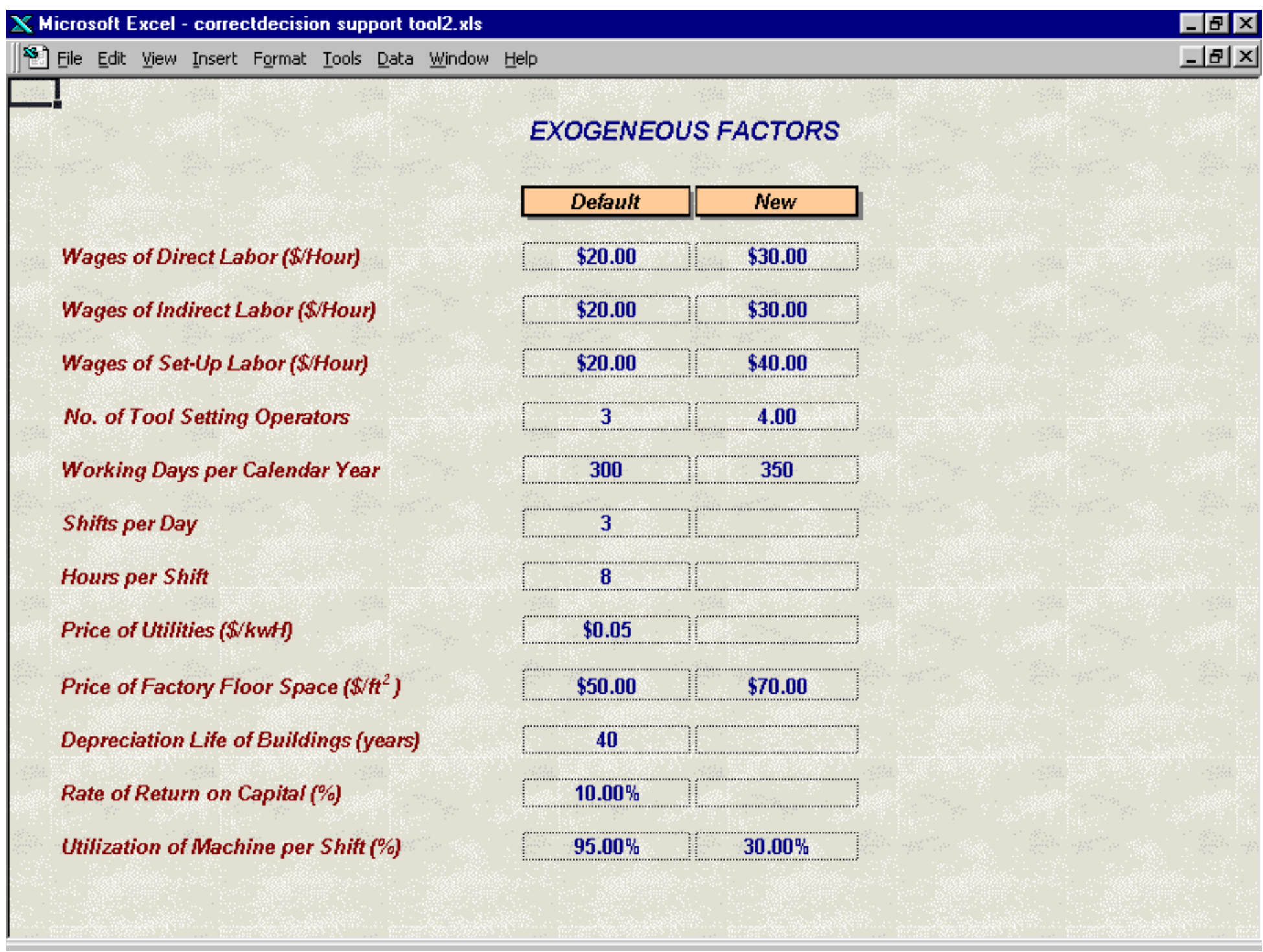

Figure 2. EXOGENEOUS FACTORS USER SCREEN 


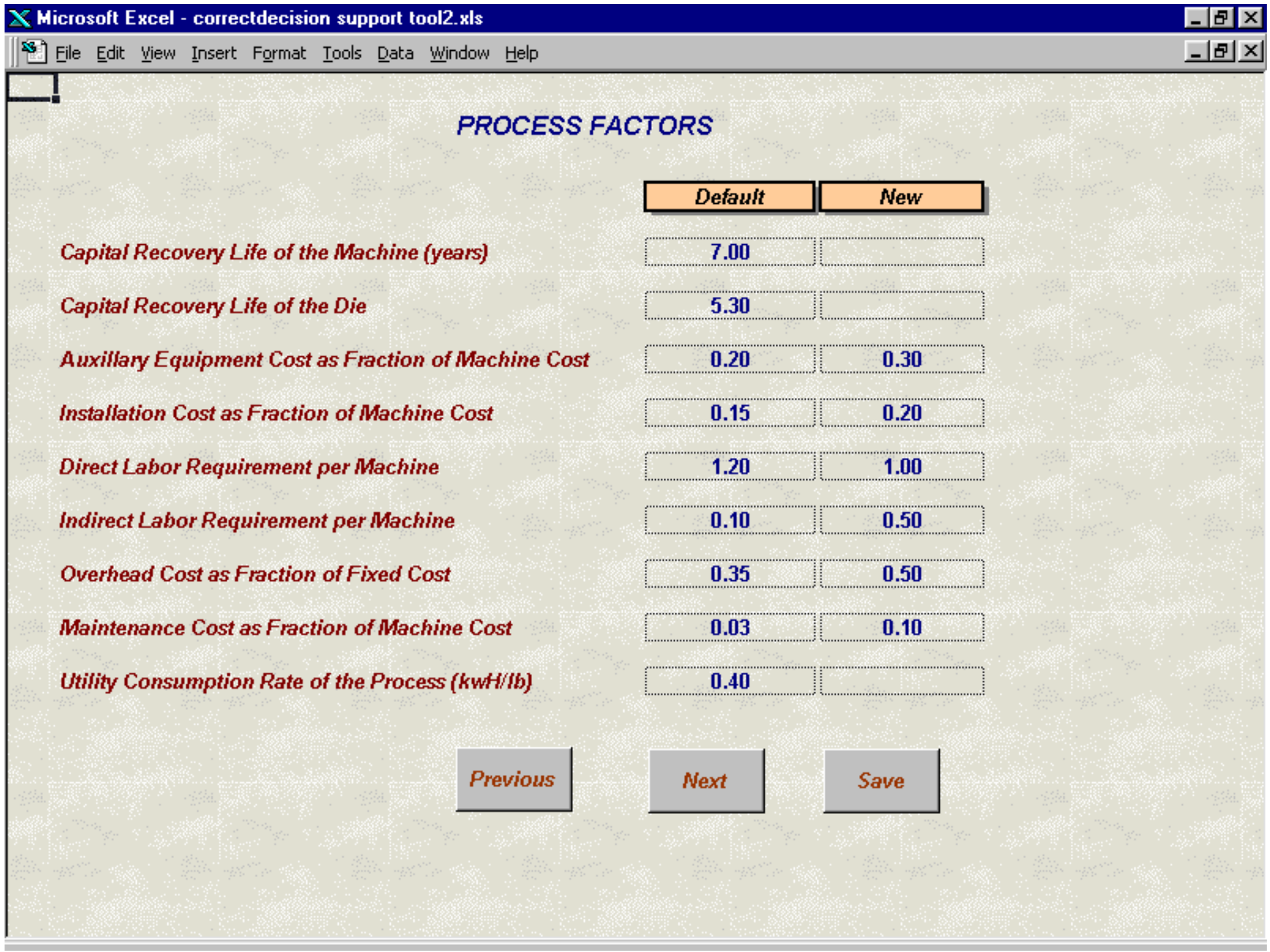

Figure 3. PROCESS FACTORS USER SCREEN 


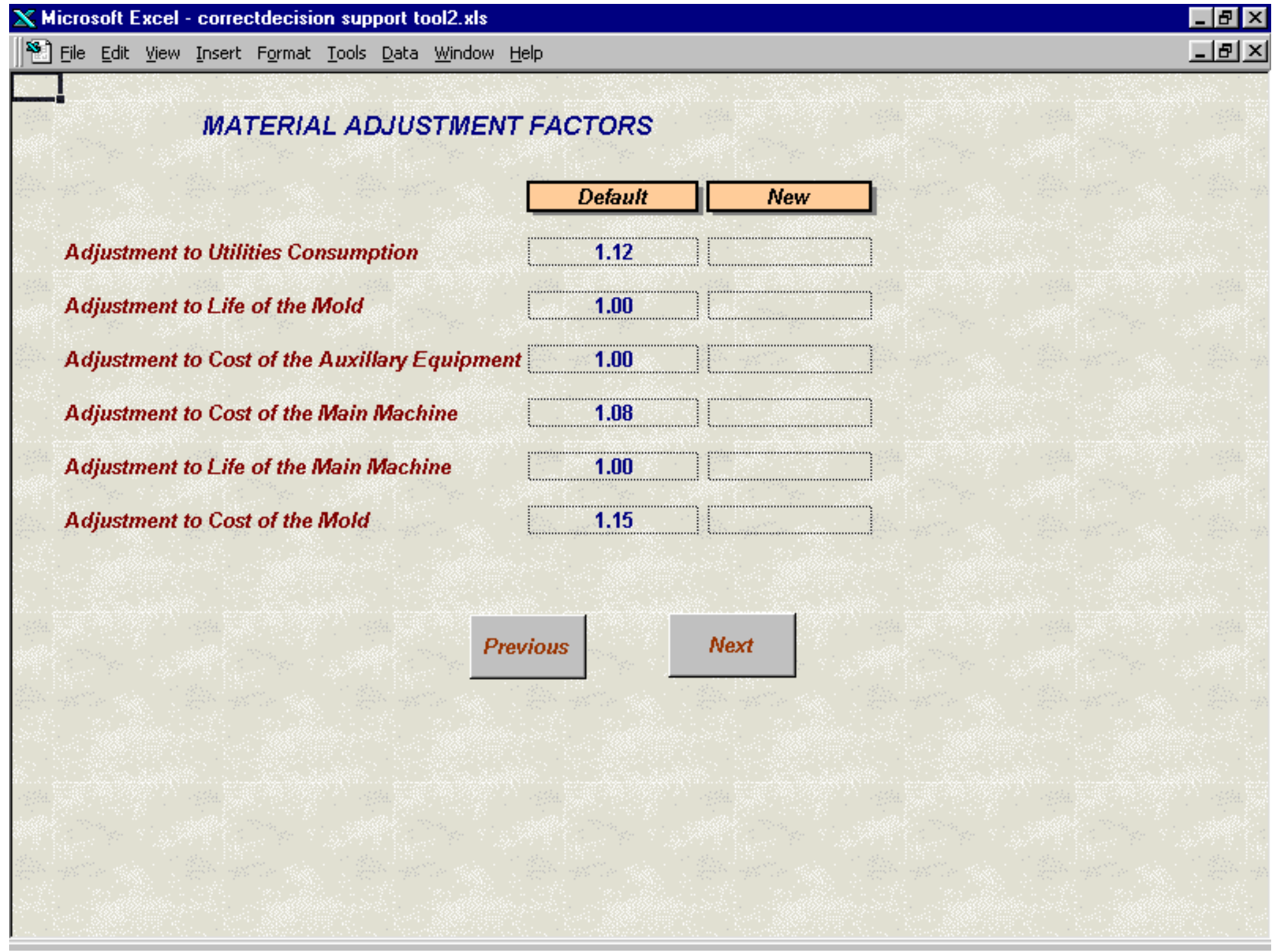

Figure 4. MATERIAL ADJUSTMENT FACTORS USER SCREEN 


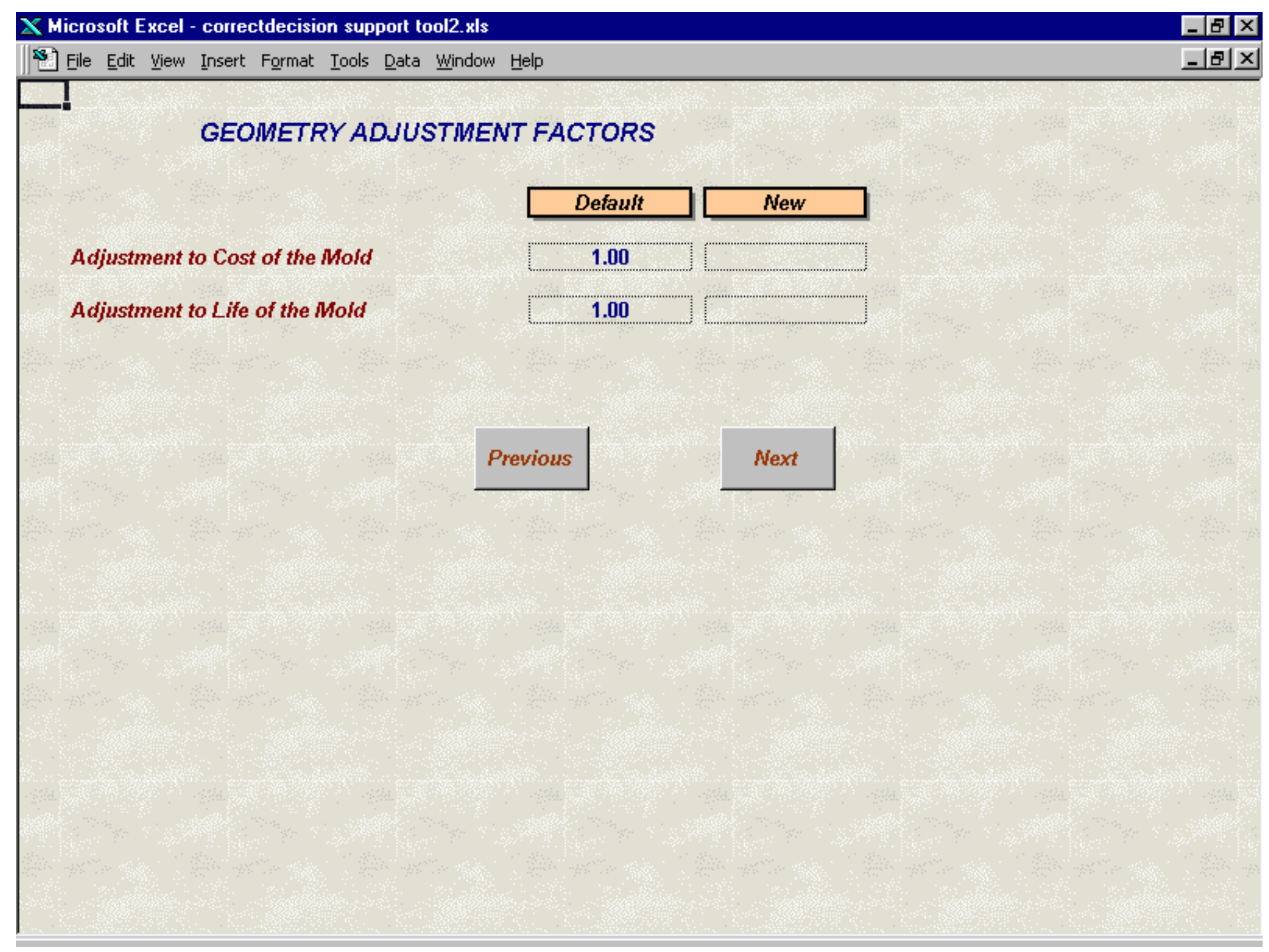

Figure 5. GEOMETRY ADJUSTMENT FACTORS USER SCREEN 


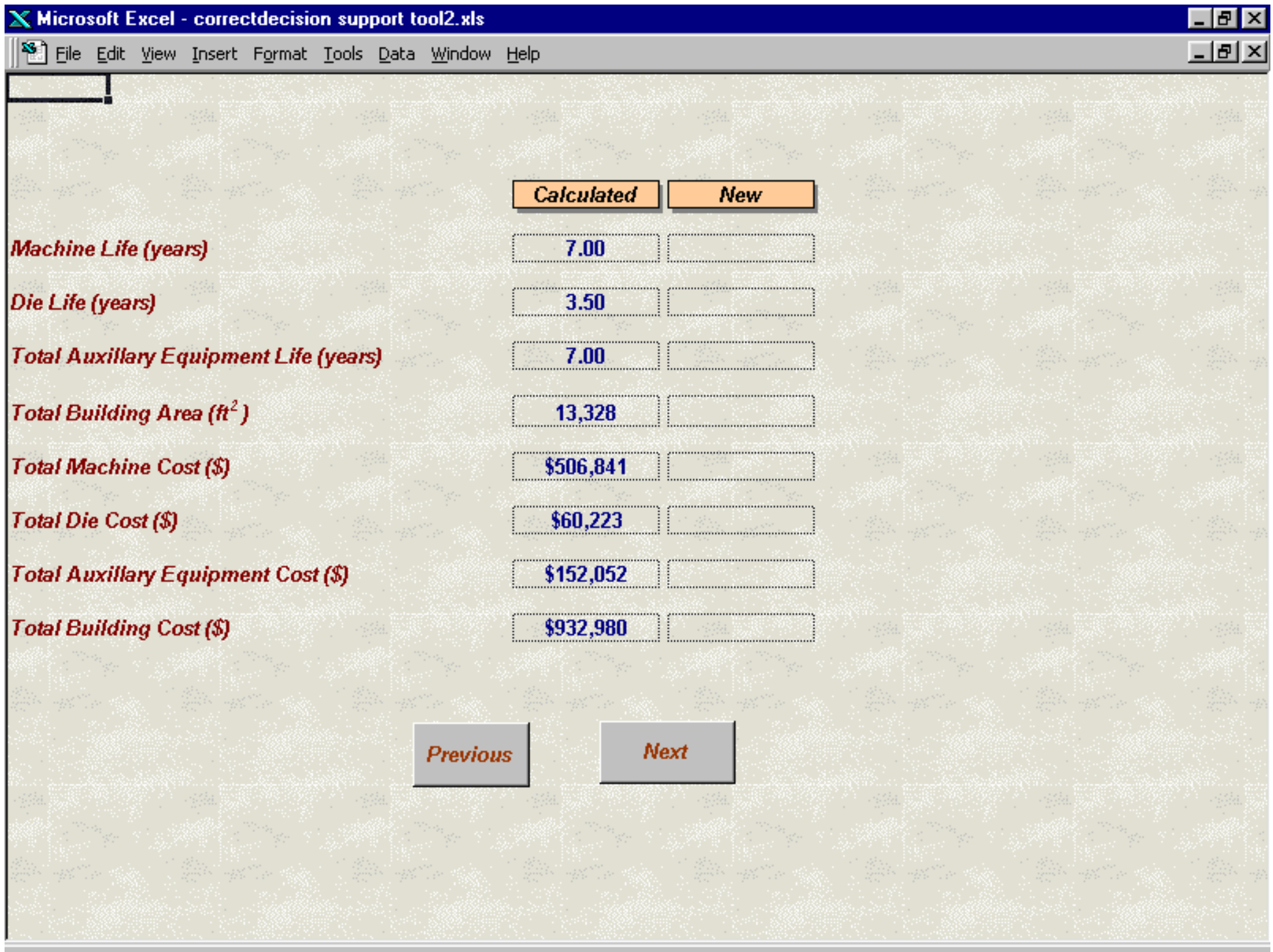

Figure 6. COST \& LIFE USER SCREEN 


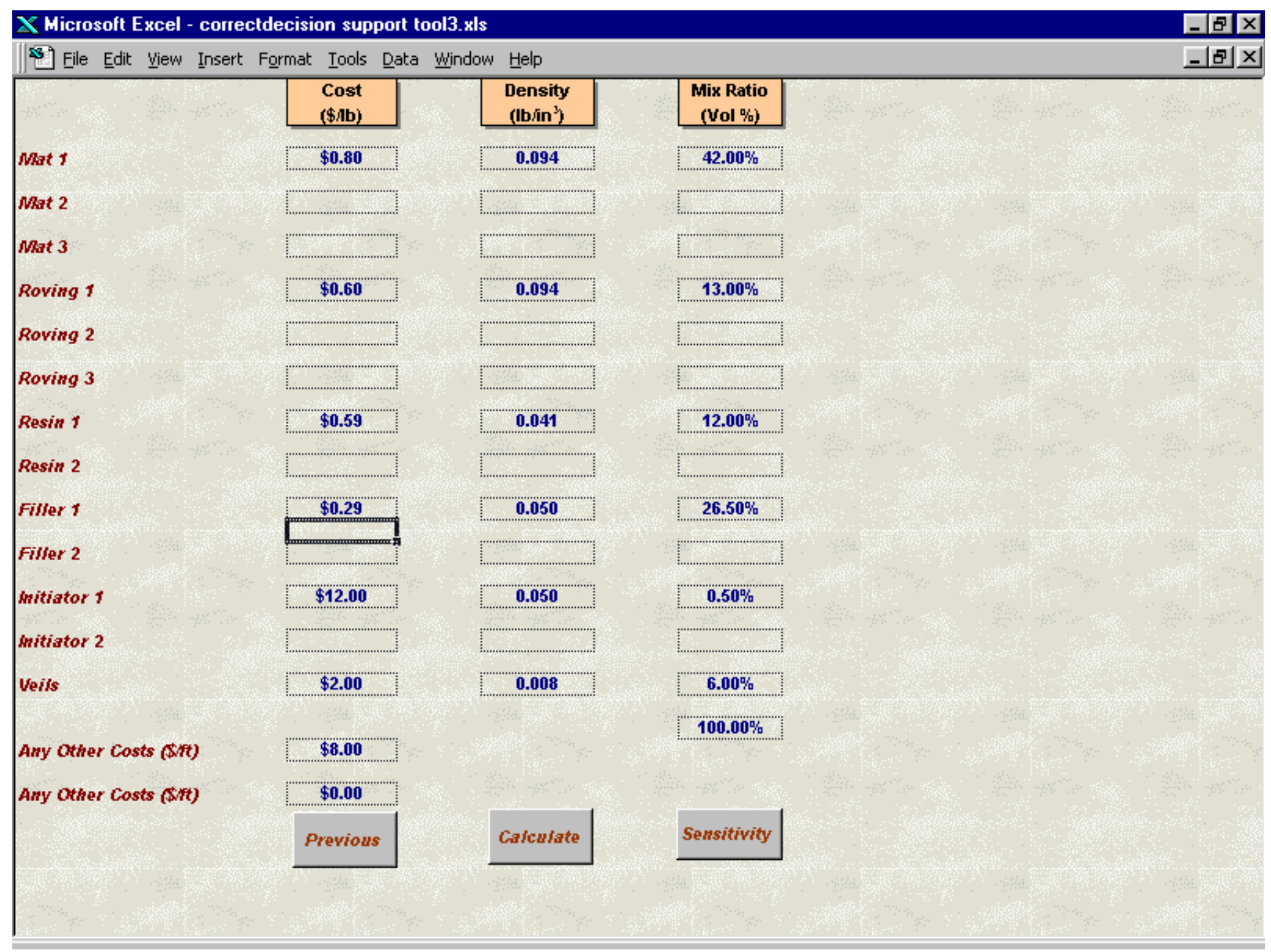

Figure 7. RAW MATERIAL COST INPUT USER SCREEN 


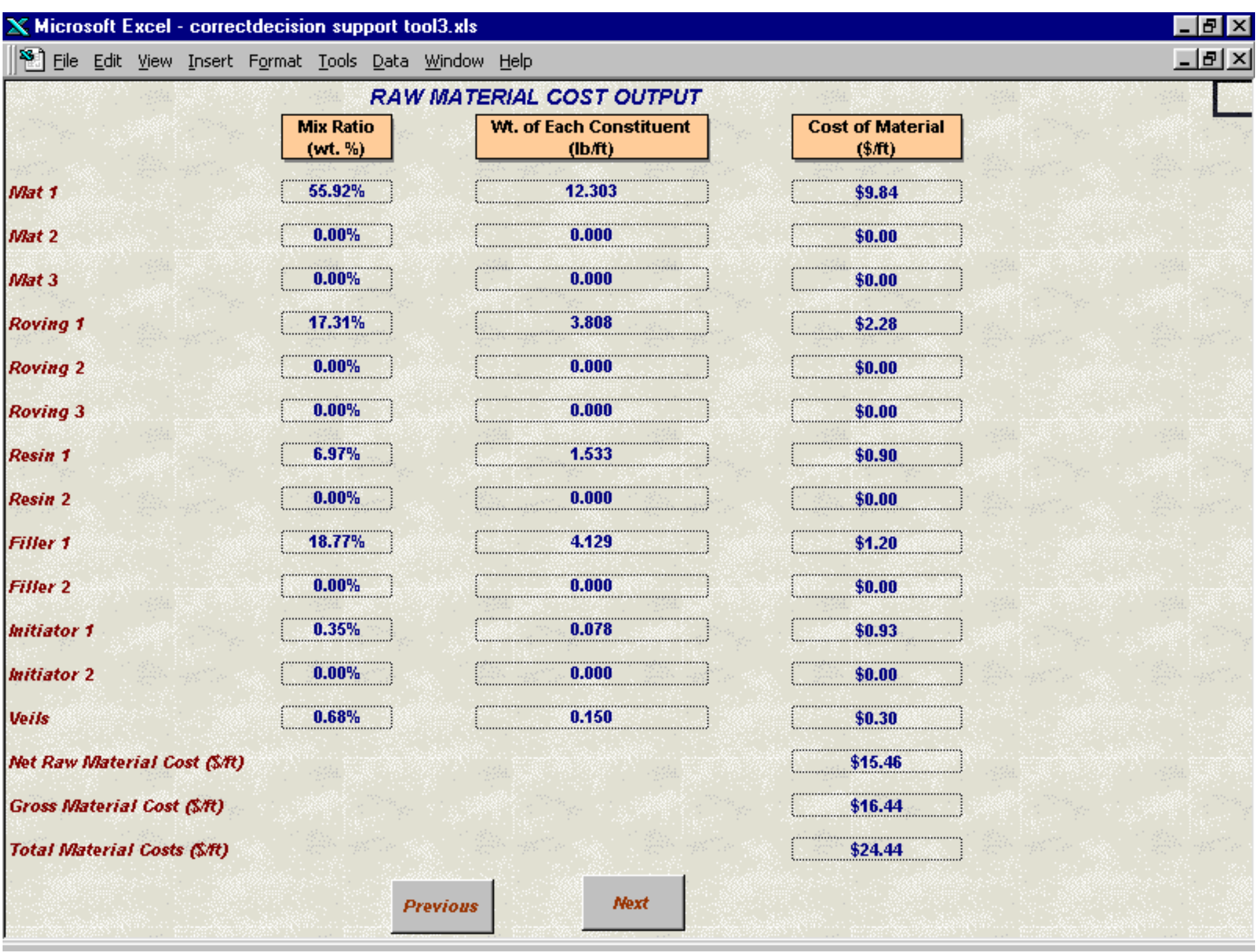

Figure 8. RAW MATERIAL COST OUTPUT USER SCREEN 


\begin{tabular}{|c|c|c|c|c|}
\hline \multicolumn{4}{|c|}{$\triangle$ Microsoft Excel - correctdecision support tool3.xls } & \multirow{2}{*}{ 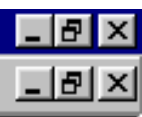 } \\
\hline 830 Eile Edit View Insert & Format Iools & Mindow $\underline{H}$ el & & \\
\hline \multicolumn{4}{|c|}{ COST OUTPUT SHEET } & \\
\hline & sift & \begin{tabular}{|l|} 
\$HHour \\
\end{tabular} & $\%$ of Total Cost & \\
\hline Toral Mfareyial Cast & $\$ 24.44$ & $\$ 468.86$ & $58.25 \%$ & \\
\hline Direertabar Cast & $\leqslant 1.28$ & $\leqslant 24.48$ & $3.04 \%$ & \\
\hline Iodirear Labor $C$ & $\$ 0.64$ & $\$ 12.24$ & $1.52 \%$ & \\
\hline Wility cast & $\$ 0.49$ & $\$ 9.45$ & $1.17 \%$ & \\
\hline \multirow[t]{2}{*}{ Total Variable cost } & $\$ 26.85$ & $\$ 515.03$ & $63.98 \%$ & \\
\hline & sift & SIHour & \% of Total Cost & \\
\hline Mfais Mactise Cast & $\$ 1.50$ & $\$ 28.73$ & $3.57 \%$ & \\
\hline Aurillary Equjpmens Cast & $\leqslant 0.45$ & $\$ 8.62$ & $1.07 \%$ & \\
\hline Toobing Cast & $\$ 1.72$ & $\$ 33.01$ & $4.10 \%$ & \\
\hline Taol Setring Qperatar Cast & $\$ 1.54$ & $\leqslant 29.46$ & $3.66 \%$ & \\
\hline Building Cast & $\leqslant 0.48$ & $\$ 9.26$ & $1.15 \%$ & \\
\hline mstallatian Cast & $\$ 0.30$ & $\$ 5.75$ & $0.71 \%$ & \\
\hline Mandenamee Cast & $\leqslant 0.15$ & $\$ 2.87$ & $0.36 \%$ & \\
\hline avertead Cast & $\$ 756$ & $\$ 144.98$ & $18.01 \%$ & \\
\hline Cast af Capsital & $\$ 1.42$ & $\$ 27.28$ & $3.39 \%$ & \\
\hline Total Fixed Cost & $\$ 15.12$ & $\$ 289.95$ & $36.02 \%$ & \\
\hline Total Cost & $\$ 41.96$ & $\$ 805.0$ & & \\
\hline Sales Price (\$) & $\$ 50.36$ & $\$ 966$ & & \\
\hline \multirow[t]{2}{*}{ Totai Annual Sales (\$) } & $\$ 503,569$ & $\$ 503,569$ & & \\
\hline & Preyiay & start & rsitivity & \\
\hline
\end{tabular}

Figure 9. COST OUTPUT USER SCREEN 


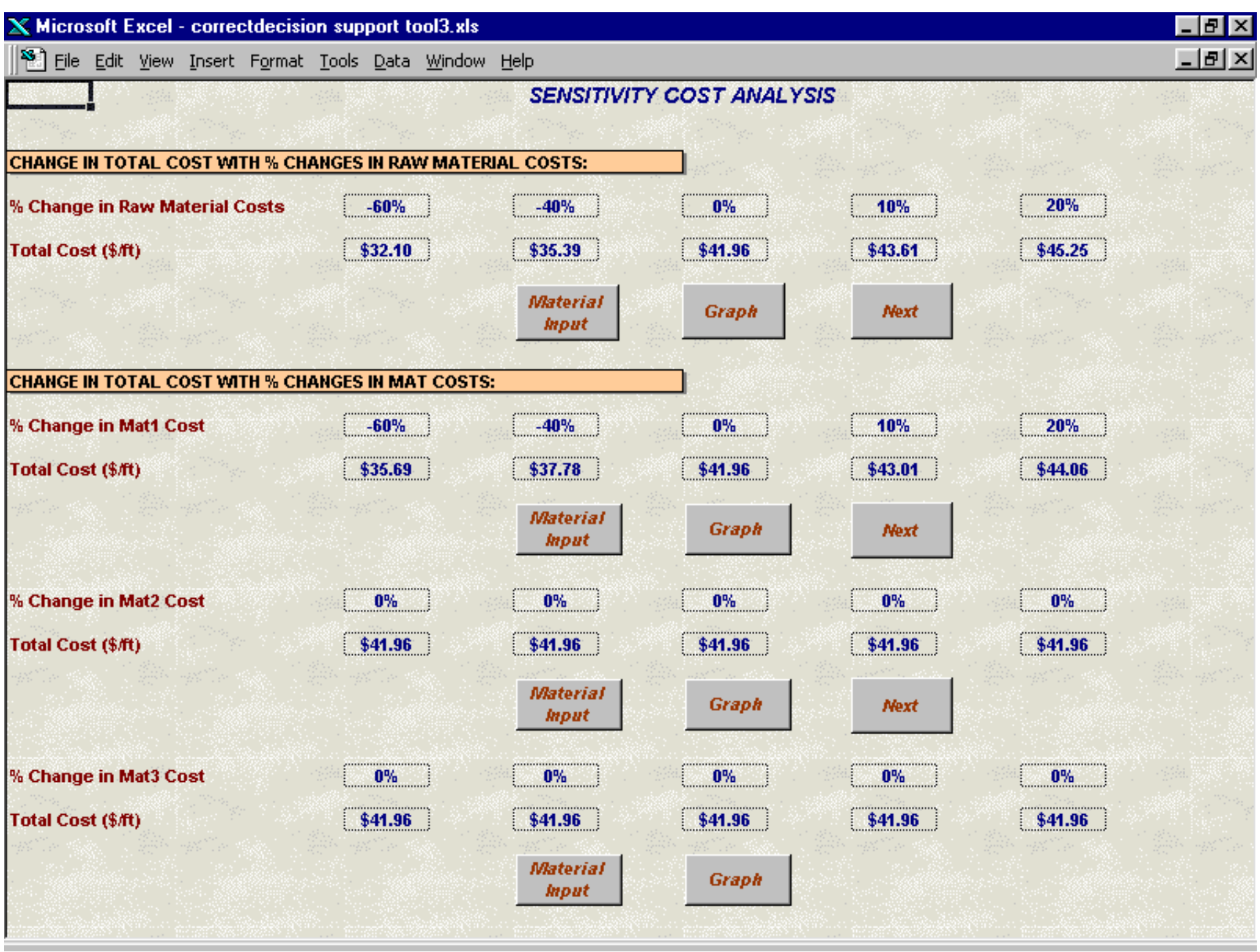

Figure 10. TOTAL RAW MATERIAL \& MAT COST SENSITIVITY ANALYSIS 


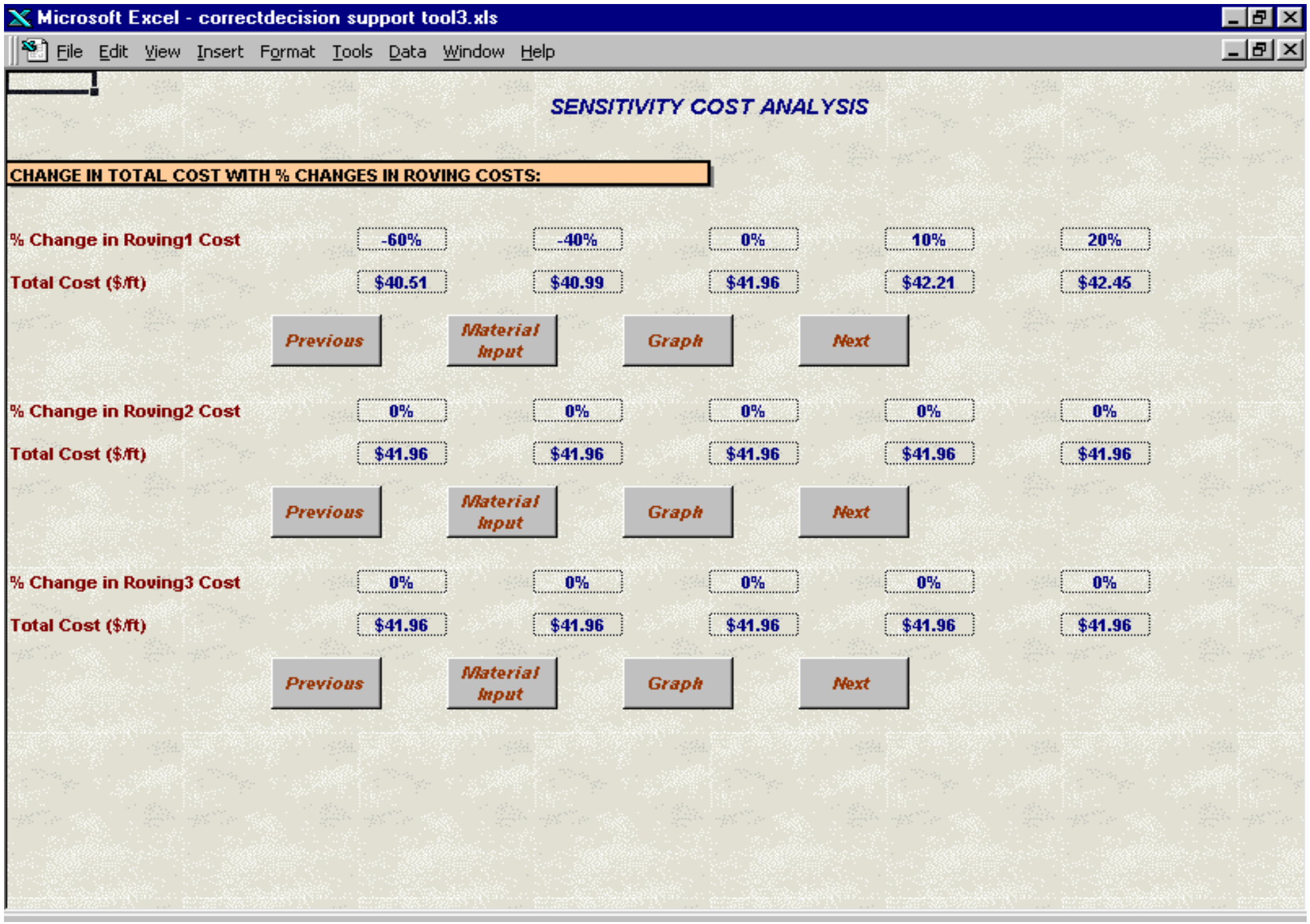

Figure 11. ROVING COST SENSITIVITY ANALYSIS 


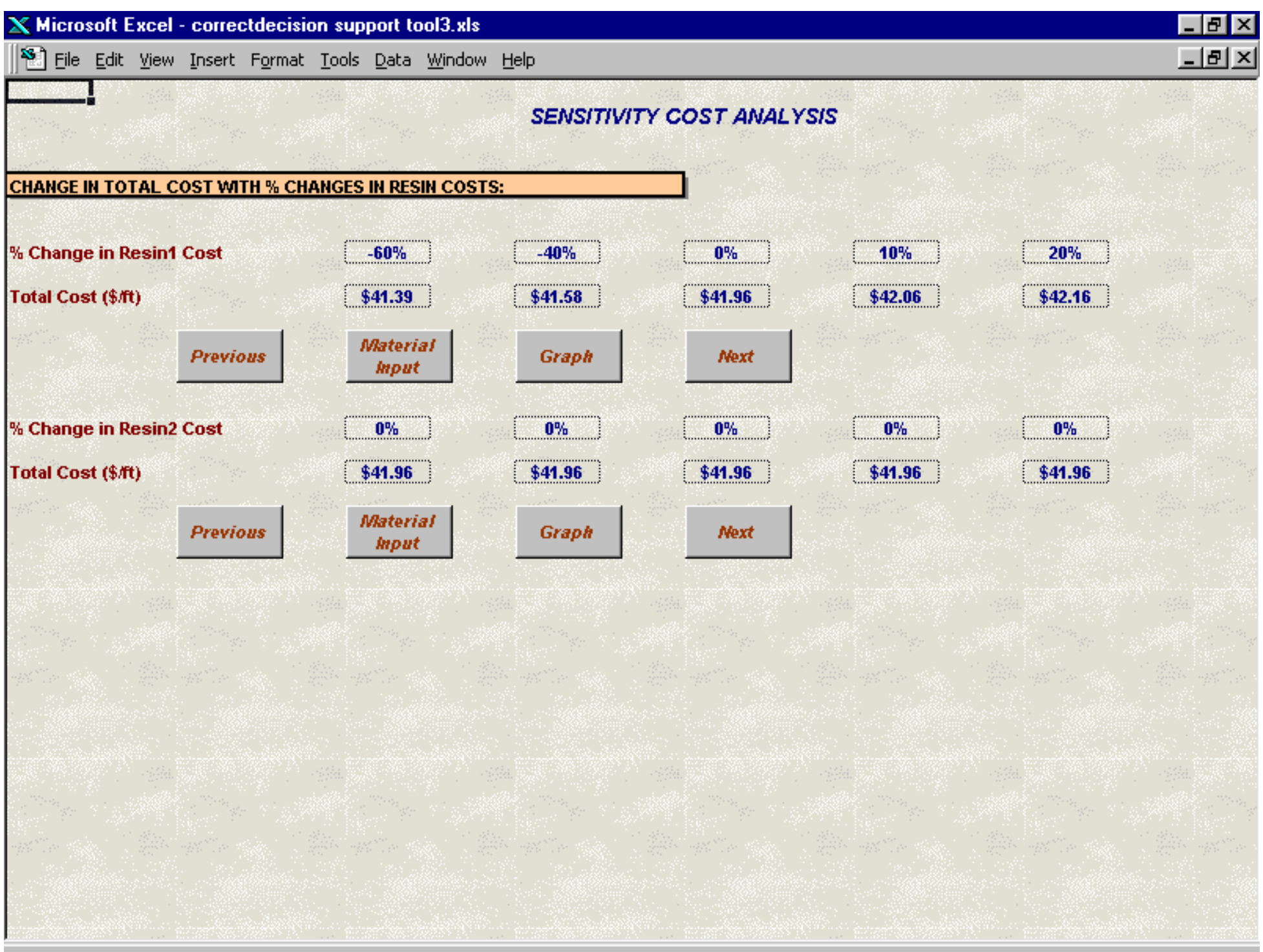

Figure 12. RESIN COST SENSITIVITY ANALYSIS 


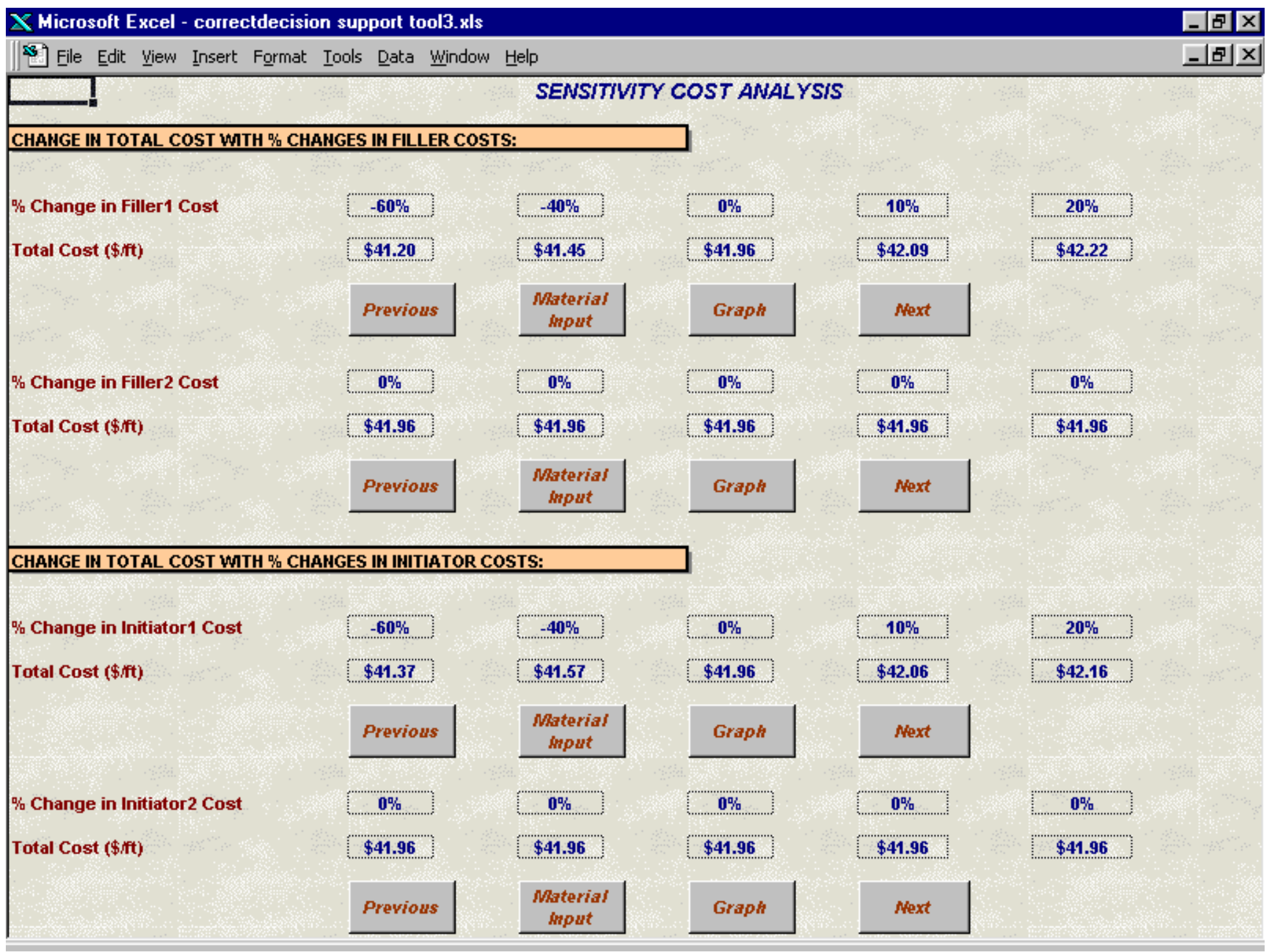

Figure 13. FILLER \& INITIATOR COST SENSITIVITY ANALYSIS 
X Microsoft Excel - correctdecision support tool3.xls

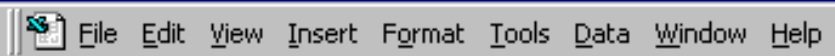

\section{SENSITIVITY COST ANALYSIS}

CHAHGE IN TOTAL COST WITH \% CHAHGES WW VEILS COSTS:

\begin{tabular}{|c|c|c|c|c|c|}
\hline$\%$ Change in Veils Cost & $-60 \%$ & $-40 \%$ & $0 \%$ & $10 \%$ & $20 \%$ \\
\hline Total Cost (\$Nit) & $\$ 41.77$ & $\$ 41.84$ & $\$ 41.96$ & $\$ 42.00$ & $\$ 42.03$ \\
\hline & Previous & $\begin{array}{c}\text { Material } \\
\text { mput }\end{array}$ & Graph & Next & \\
\hline
\end{tabular}

CHAHGE IN TOTAL COST WITH \% CHAHGES IW DIRECT LABOR COSTS:

\section{CHAHGE IHTOTAL COST UMTH\% CHAHGES IN DIRET LABOR COSTS:}

$\%$ Change in Direct Labor Cost
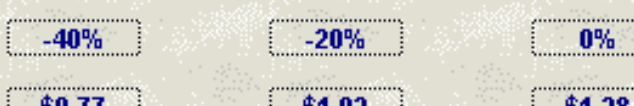

$20 \%$

$40 \%$

Direct Labor Cost (\$ift)

$\$ 0.77$

$\$ 1.02$

$\$ 1.28$

Total Cost (\$fit)

$\$ 41.45$

$\$ 41.71$

$\$ 41.96$

$\$ 42.22$

$\$ 42.47$

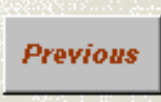

Graph

Mext

CHAHGE IH TOTAL COST MITH \% CHAHGES IN UTILITY COSTS:

\% CHANGES IHUTHLIY COSTS:

$\%$ Change in Utility cost

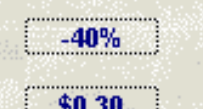

$-20 \%$

$0 \%$

$20 \%$

$40 \%$

Utility Cost (\$ift)

$\$ 0.30$

$\$ 0.39$

$\$ 0.49$

$\$ 0.59$

$\$ 0.69$

Total Cost (\$fif)

$\$ 41.77$

$\$ 41.87$

$\$ 41.96$

$\$ 42.06$

$\$ 42.16$

Figure 14. VEILS, DIRECT LABOR \& UTILITY COST SENSITIVITY ANALYSIS 


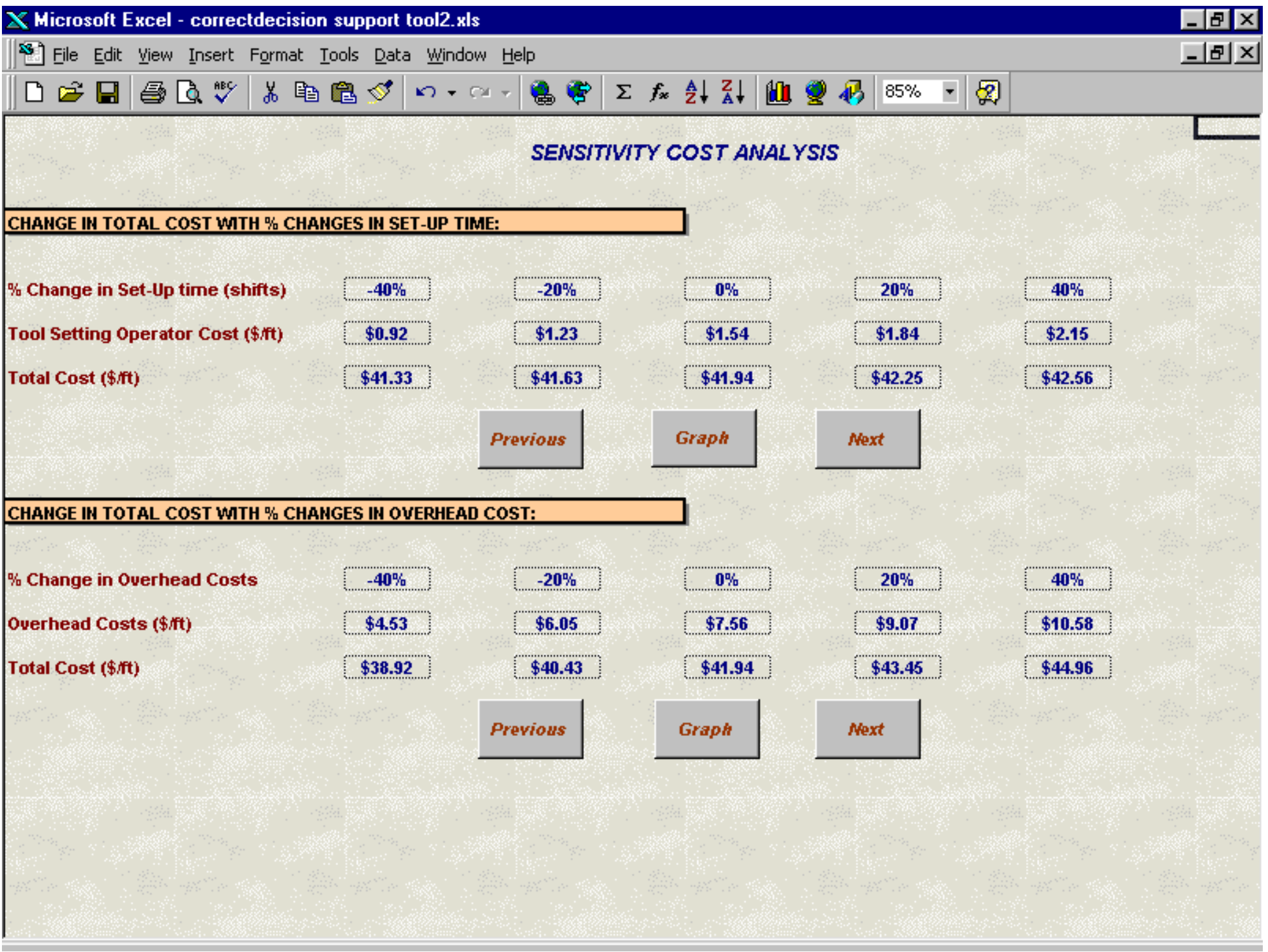

Figure 15. SET-UP TIME \& OVERHEAD COST SENSITIVITY ANALYSIS 


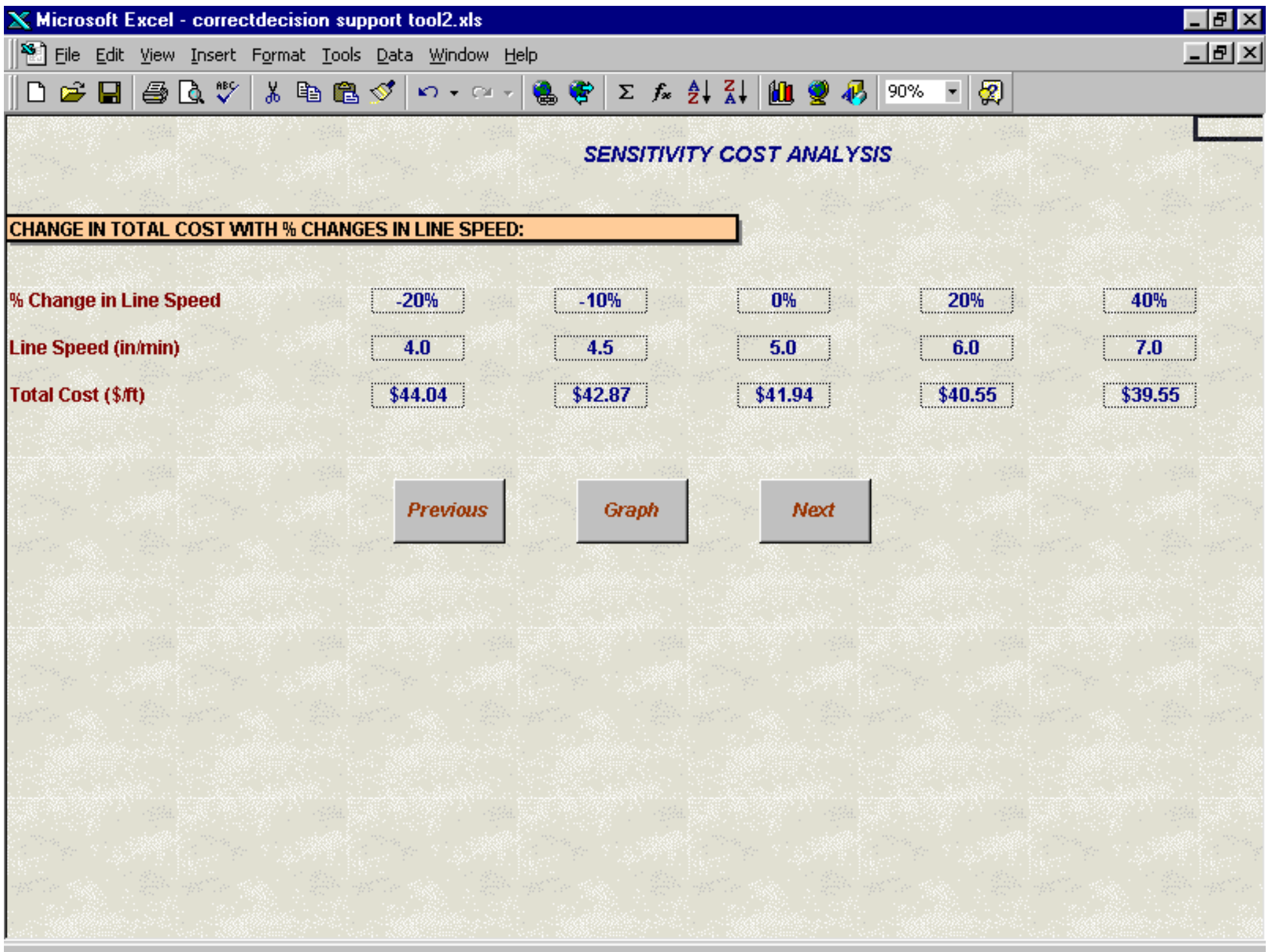

Figure 16. LINE SPEED SENSITIVITY ANALYSIS 


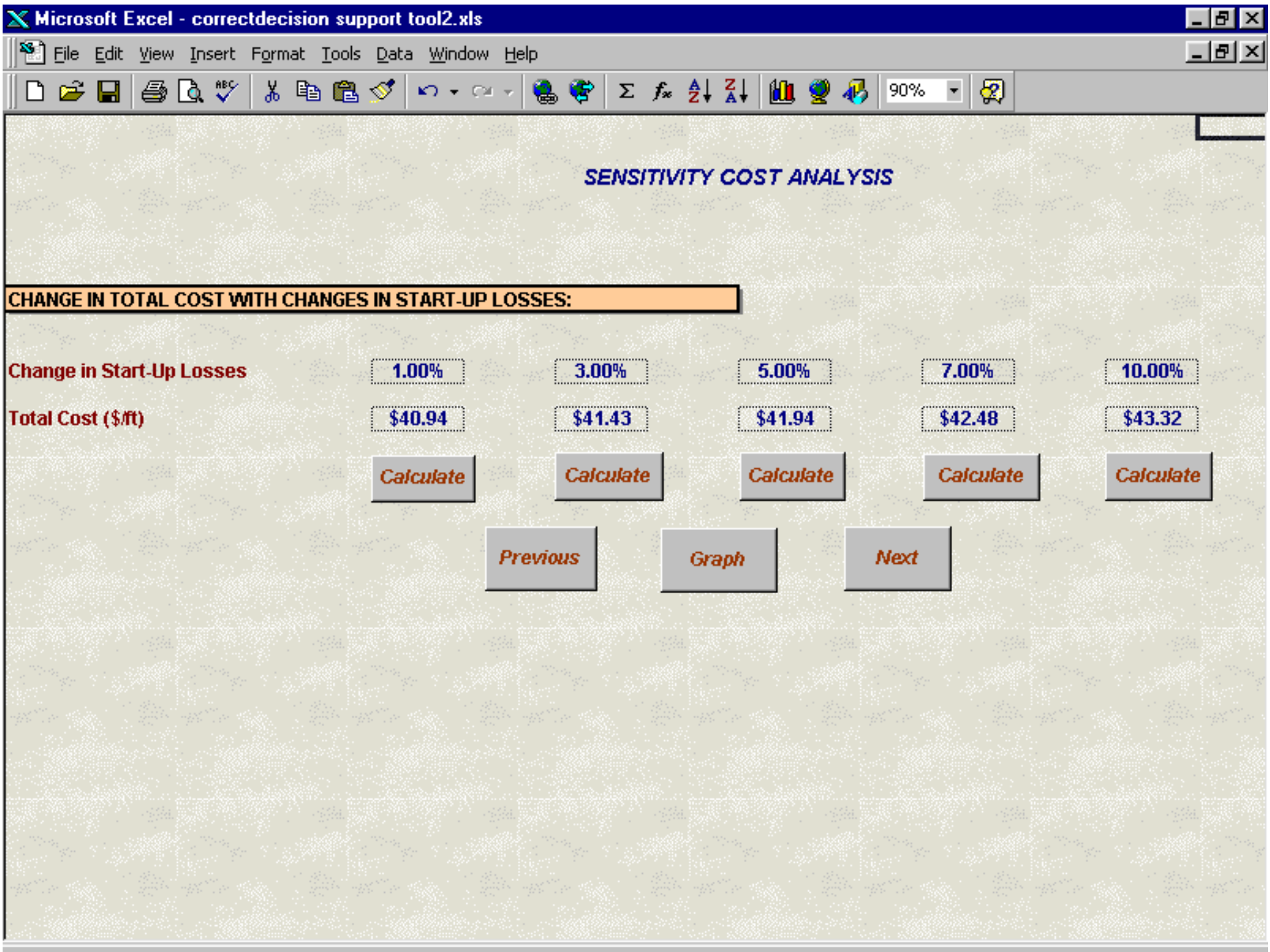

Figure 17. START-UP LOSSES SENSITIVITY ANALYSIS 


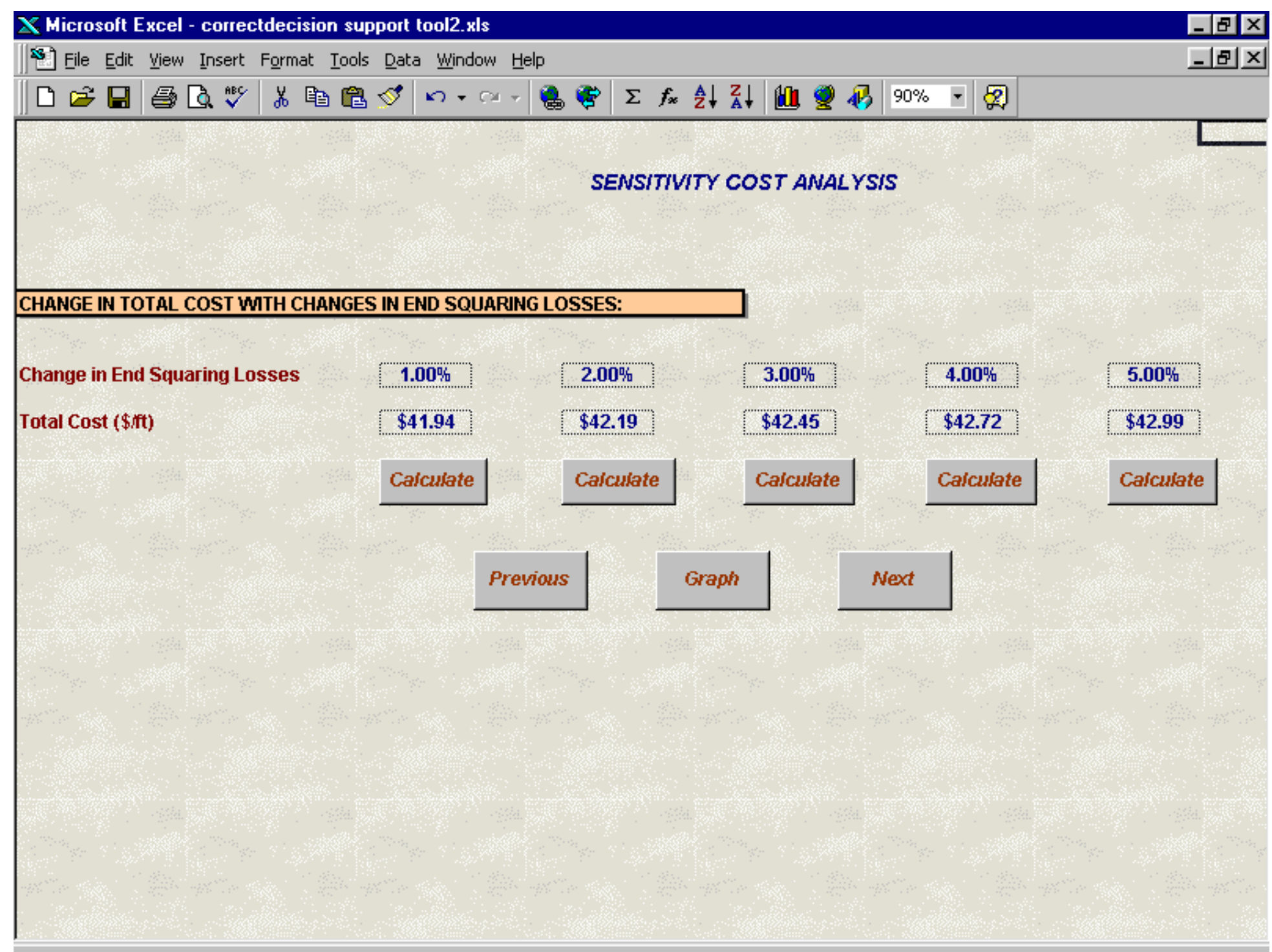

Figure 18. END-SQUARING LOSSES SENSITIVITY ANALYSIS 


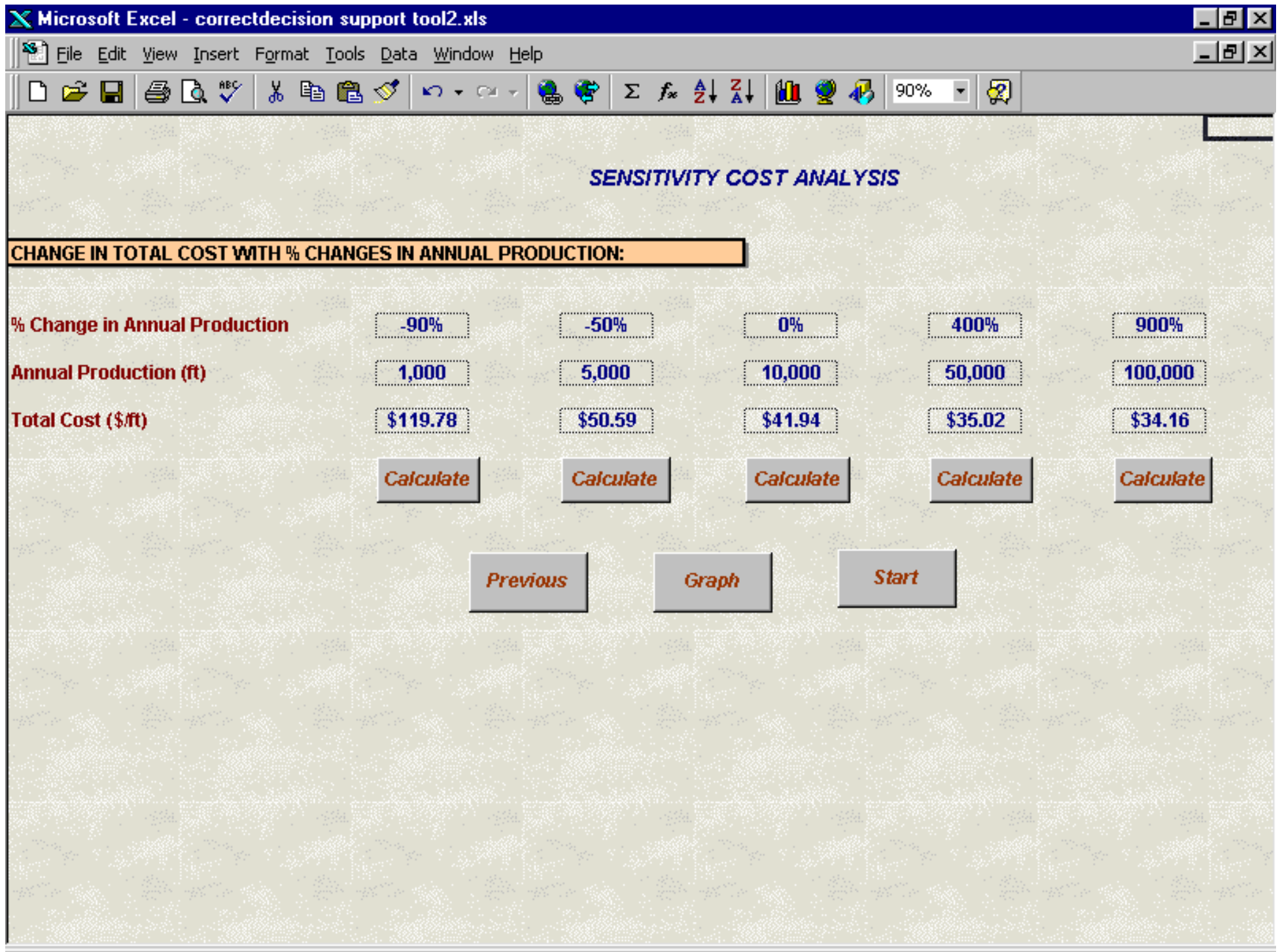

Figure 19. ANNUAL PRODUCTION SENSITIVITY ANALYSIS 


\section{VITA}

Taher B. Patrawala (Son of Mr. Badrudin Patrawala and Ms. Fatema Patrawala) was born in Bombay, Maharashtra, India on August 17, 1974. He received his primary and secondary education at Antonio De Souza High School at Bombay, during which he earned many merit certificates. Also, he was honored by Lions Club of Bombay for his outstanding performance in SSC (secondary school certificate). He completed his Diploma in Mechanical Engineering at M.H. Saboo Siddik Polytechnic from Bombay University in May 1993 and stood $27^{\text {th }}$ in the State of Maharashtra. He earned a Bachelor of Science in Production Engineering at M.H. Saboo Siddik College of Engineering from Bombay University in May 1996. He entered West Virginia University in Fall 1997 to earn Masters of Science in Industrial \& Management Systems Engineering in the Decision Science Program. 